Andrews University

Digital Commons @ Andrews University

\title{
Self-Efficacy and Self-Regulation as Predictors of Academic Motivation among Undergraduate Students in the United States
}

Fatimah Aljuaid

Andrews University

Follow this and additional works at: https://digitalcommons.andrews.edu/dissertations

Part of the Counselor Education Commons, and the Educational Psychology Commons

\section{Recommended Citation}

Aljuaid, Fatimah, "Self-Efficacy and Self-Regulation as Predictors of Academic Motivation among Undergraduate Students in the United States" (2021). Dissertations. 1744.

https://digitalcommons.andrews.edu/dissertations/1744

https://dx.doi.org/10.32597/dissertations/1744

This Dissertation is brought to you for free and open access by the Graduate Research at Digital Commons @ Andrews University. It has been accepted for inclusion in Dissertations by an authorized administrator of Digital Commons@ Andrews University. For more information, please contact repository@andrews.edu. 


\section{ABSTRACT}

\section{SELF-EFFICACY AND SELF-REGULATION AS PREDICTORS OF ACADEMIC MOTIVATION AMONG UNDERGRADUATE STUDENTS IN THE UNITED STATES}

Fatimah Aljuaid

Chair: Elvin Gabriel 


\title{
ABSTRACT OF GRADUATE STUDENT RESEARCH
}

\author{
Dissertation \\ Andrews University \\ College of Education \& International Services
}

Title: SELF-EFFICACY AND SELF-REGULATION AS PREDICTORS OF ACADEMIC
MOTIVATION AMONG UNDERGRADUATE STUDENTS IN THE UNITED STATES

Name of researcher: Fatimah Aljuaid

Name and degree of faculty chair: Elvin Gabriel, EdD

Date completed: March 2021

\section{Problem}

Some undergraduate students demonstrate lack of academic motivation which negatively affects engagement and perseverance in higher education (Busse \& Walter, 2017; Rizkallah \& Seitz, 2017; Dresel \& Grassinger, 2013). Amotivated students are more likely to drop out of school and disengage from learning activities or underachieve (Wang \& Pomerantz, 2009). Although the lack of academic motivation is correlated with deficiency in self-regulation and self-efficacy, relatively little studies have been conducted to examine the impact of these factors on academic motivation particularly in the U.S. This study constructed a hypothesized model to investigate the role of self-regulation and self-efficacy in academic motivation.

Method

The sample consisted of 349 undergraduate students enrolled in U.S. universities. Participants were recruited via the online-tool QuestionPro. The students completed the Academic Motivation Scale (AMS) and Motivated Strategies for Learning Questionnaire 
(MSLQ) online providing input about their academic motivation, self-regulation, and selfefficacy. Structural equation modeling was used to evaluate the impact of self-regulation and self-efficacy on academic motivation.

\section{Results}

Analysis of the data indicated that the initial model did not fit the data. The Chi-square value was $271.569, d f=40, p=.000$, and poor fit indices were found $(\mathrm{GFI}=.875, \mathrm{NFI}=.874$, $\mathrm{CFI}=.889, \mathrm{RMSEA}=.129 . \mathrm{SRMR}=.090)$. Therefore, an exploratory analysis was conducted, and modifications made based on modification indices and theory in order to improve the fit indices. The adjusted model showed acceptable fit between the theoretical covariance matrix and the empirical covariance matrix $(\mathrm{GFI}=.918, \mathrm{NFI}=.913, \mathrm{CFI}=.928, \mathrm{RMSEA}=.108$, and SRMR $=.072$ ) indicating that the data fit the hypothesized model. The overall adjusted model explained $41 \%$ of the variance of academic motivation, in which self-efficacy $(\beta=.45 ; p<.01)$ was a better predictor of academic motivation than self-regulation $(\beta=.24 ; p<.01)$. There was significant correlation between self-regulation and self-efficacy $(r=.69, p<.01)$

\section{Conclusion}

Self-regulation and self-efficacy can predict students' academic motivation. Self-efficacy was the best predictor of academic motivation. Students who reported high beliefs in their capabilities and control over their effort showed high levels of intrinsic motivation. In addition, advanced levels of metacognitive strategies, time and study environment, and effort regulation predict high levels of academic motivation. Further research should be conducted to determine other factors that may contribute to students' academic motivation. This study offers recommendations for future research and professional practice. 
Andrews University

School of Education

\title{
SELF-EFFICACY AND SELF-REGULATION AS PREDICTORS OF ACADEMIC MOTIVATION AMONG UNDERGRADUATE STUDENTS IN THE UNITED STATES
}

\author{
A Dissertation \\ Presented in Partial Fulfillment \\ of the Requirements for the Degree \\ Doctor of Philosophy
}

by

Fatimah Aljuaid

March 2021 
(C) Copyright by Fatimah Aljuaid 2021

All Rights Reserved 


\title{
SELF-EFFICACY AND SELF-REGULATION AS PREDICTORS OF ACADEMIC MOTIVATION AMONG UNDERGRADUATE STUDENTS IN THE UNITED STATES
}

\author{
A dissertation \\ presented in partial fulfillment \\ of the requirements for the degree \\ Doctor of Philosophy
}

by

Fatimah Aljuaid

APPROVAL BY THE COMMITTEE:

Chair: Elvin Gabriel, EdD

Dean, College of Education and International Services

Alayne Thorpe

Member: Nadia Nosworthy, PhD

Member: Tevni Grajales, PhD

External: Lionel Matthews, PhD Date approved 


\section{TABLE OF CONTENTS}

LIST OF FIGURES ….............................................................................. vi

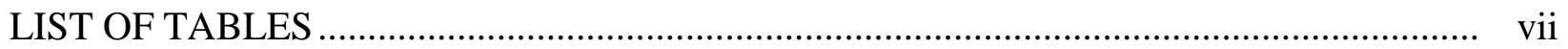

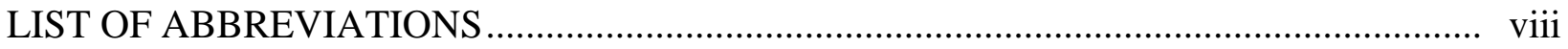

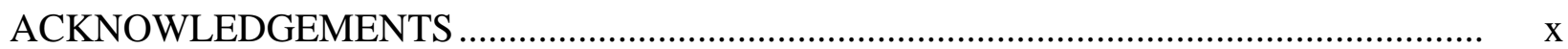

Chapter

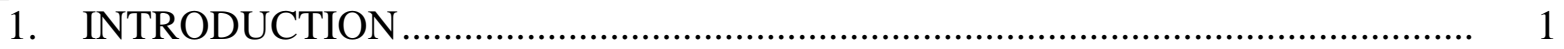

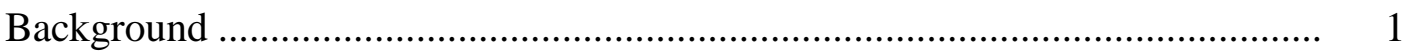

Rationale for the Study ..................................................................... 2

Statement of the Problem .......................................................................... 3

Purpose of the Study ................................................................................. 4

Conceptual Framework ............................................................................. 4

Social Cognitive Theory ...................................................................... 4

Self-Determination Theory (SDT) ................................................... 9

Research Question .............................................................................. 15

Research Hypotheses.............................................................................. 15

Significance of the Study ....................................................................... 16

Definitions of Terms ............................................................................ 18

Limitations of the Study ........................................................................ 20

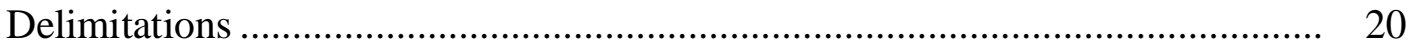

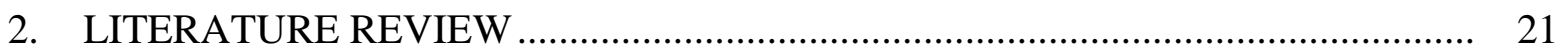

Organization of the Literature Review ..................................................... 21

Literature Search Strategies...................................................................... 21

Motivation: A Brief Historical Overview ............................................... 21

Behaviorism .................................................................................. 22

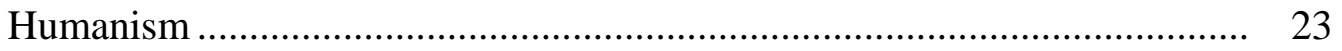

Cognitive Psychology ..................................................................... 23

Academic Motivation: A Conceptual Overview ........................................... 24

Self-Regulation: A Historical/Theoretical Overview ..................................... 26

Precursory $1891-1950$................................................................... 26

Emergent 1950-1970 ........................................................................ 27

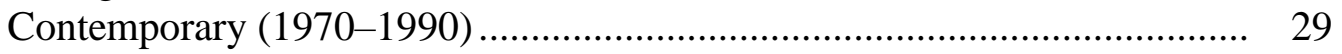

Expansionism (1990-2006) ................................................................ 29

Self-Efficacy: A Historical/Theoretical Overview ........................................ 31

The Relationship Between Self-Regulation and Academic Motivation ............ 32 
The Relationship between Self-Efficacy and Academic Motivation ....

The Relationships among Self-Efficacy, Self-Regulation, and Academic Motivation ............................................................................ 38

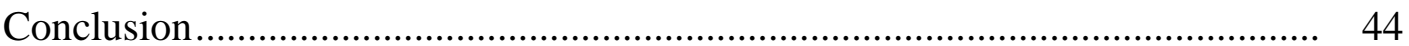

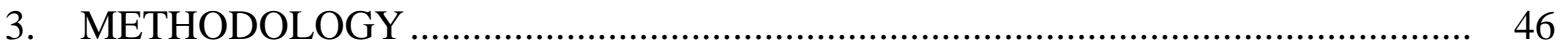

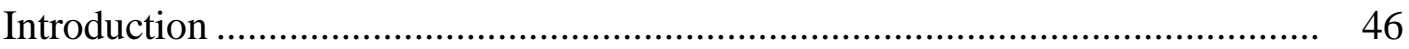

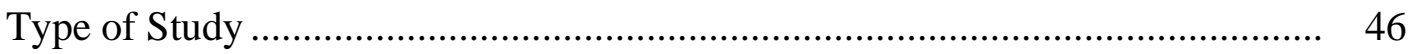

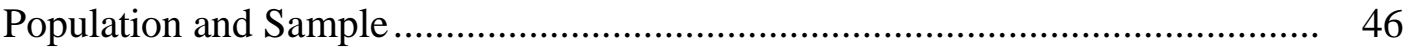

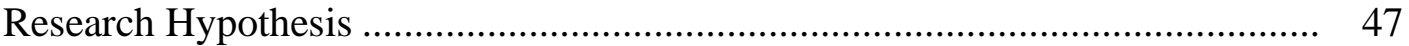

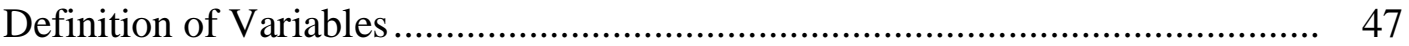

Academic Motivation .......................................................................... 47

Self-regulation ............................................................................... 50

Self-efficacy ............................................................................. 52

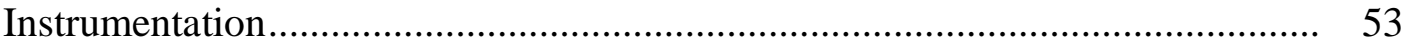

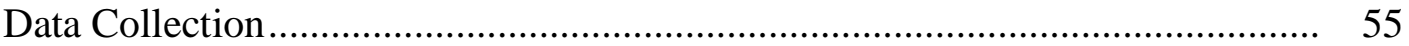

Analysis of the Data .............................................................................. 56

The Advantages of Using SEM ........................................................... 56

Creating a Data File ..................................................................... 56

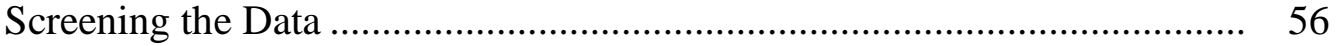

Developing the Model Specification ....................................................... 56

Assessing Model Fit ............................................................................. 57

Model Modification ........................................................................... 57

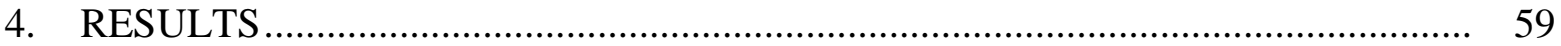

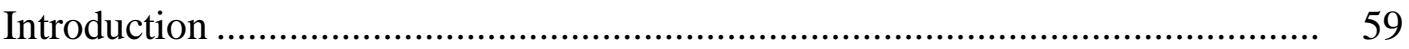

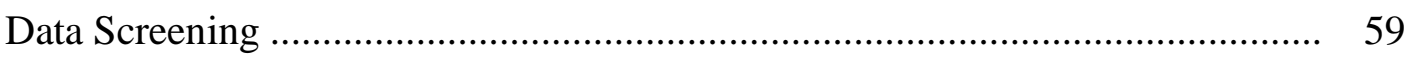

Demographic Characteristics .................................................................. 59

Observed Variables Description................................................................. 61

Zero-Order Correlations ............................................................................. 61

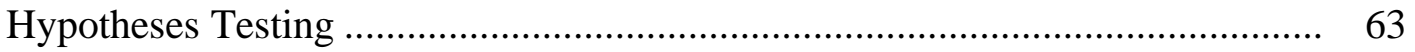

The Adjusted Model ................................................................................ 64

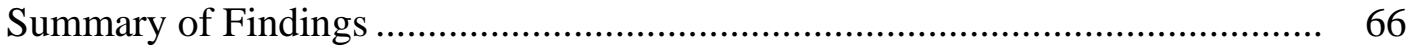

5. SUMMARY, FINDINGS, DISCUSSION, CONCLUSIONS AND

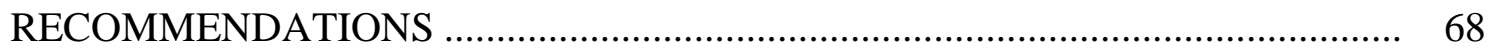

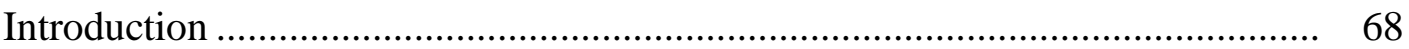

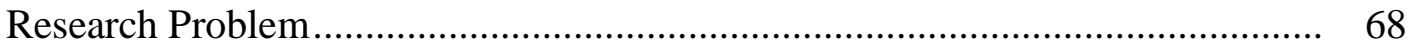

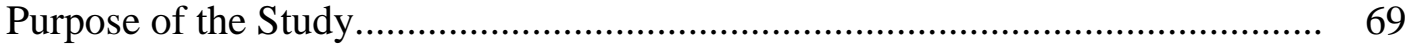

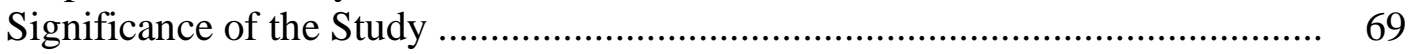

Research Hypotheses.............................................................................. 70

Summary of the Literature ................................................................. 70

The Relationship Between Self-Regulation and Academic Motivation ..... 70

The Relationship Between Self-Efficacy and Academic Motivation .......... 71

The Relationship Between Self-Efficacy, Self-Regulation and 
Academic Motivation ............................................................. 72

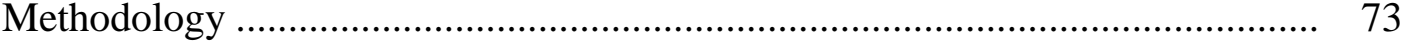

Summary of Demographics ............................................................... 73

Summary of Findings .................................................................... 73

Correlational Path from Self-regulation and Self-efficacy ....................... 74

Predictive Direct Effect from Self-regulation to Students'

Academic Motivation ........................................................................... 76

Predictive Direct Effect From Self-efficacy to Academic Motivation ........ 79

Direct Path from Self-regulation to Amotivation...................................... 80

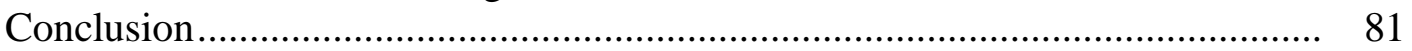

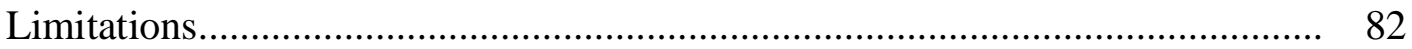

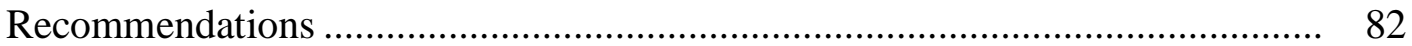

Recommendations for Future Research ............................................. 82

Recommendation for Educational Practice ............................................. 83

APPENDIX A: IRB APPROVAL .................................................................... 86

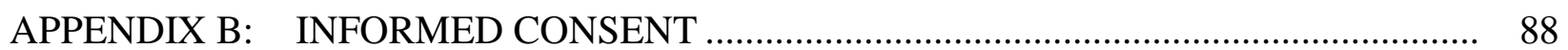

APPENDIX C: $\quad$ DEMOGRAPHIC QUESTIONNAIRE \& MSQL \& AMC ........................ 91

APPENDIX D: $\quad$ STRUCTURAL EQUATION MODELING ANALYSIS TABLES........... 98

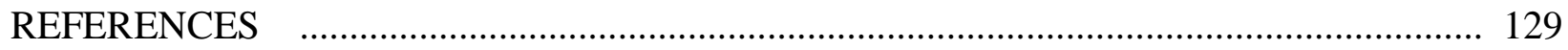




\section{LIST OF FIGURES}

Figure 1: A Cyclical Phase Model of Self-regulation that Integrates Metacognitive

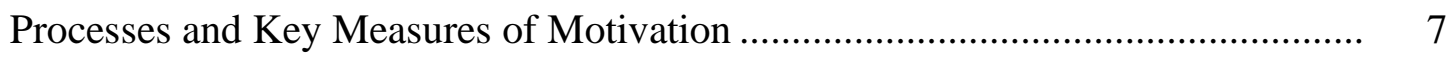

Figure 2: Self-efficacy and Self-regulation Predict Academic Motivation ......................... 16

Figure 3: The Hypothesized Model .......................................................................

Figure 4: The Modified Model .................................................................................. 


\section{LIST OF TABLES}

Table 1: Demographic Characteristics of Participants in the Data ................................. 60

Table 2: $\quad$ Measured Variables Correlation and Descriptive Statistics............................... 63 


\section{LIST OF ABBREVIATIONS}

AM Academic Motivation

AMOS Analysis of a Moment Structures

AMOT Amotivation

CFI Comparative Fit Index

GFI Goodness of Fit Index

InMC Intrinsic Motivation to Accomplishment

InMD Intrinsic Motivation-Identified Regulation

InME Intrinsic Motivation-External Regulation

InMK Intrinsic Motivation to Know

InMN Intrinsic Motivation-Introjected Regulation

InMS Intrinsic Motivation to Experience Stimulation

NFI Normed Fit Index

RMSEA Root Mean Squared Error of Approximation

SCT Social Cognitive Theory

SDT Self-determination theory

SE Self-efficacy

SEC Control of Learning Beliefs

SELP Self-efficacy of Learning and Performance

SEM Structural Equation Modeling

SMR Metacognitive Self-regulation

SPSS Statistical Package for the Social Sciences 


$\begin{array}{ll}\text { SR } & \text { Self-regulation } \\ \text { SREF } & \text { Self-regulation_-Effort Regulation } \\ \text { SRMR } & \text { Standardized Root Mean Residual } \\ \text { SRTE } & \text { Self-regulation — Time and Study Environment Management }\end{array}$




\section{ACKNOWLEDGEMENTS}

Allhamdulillah, I praise and thank Allah SWT for His greatness and for giving me the strength and courage to complete this dissertation.

First and foremost, I offer my sincere gratitude to my husband who provided me with love, encouragement and all the needed support. He was my shoulder to lean on and my best friend. I am thankful to my daughters for their patience and for making my doctoral journey joyful.

I am deeply grateful to my mother and all my family members for their prayers and their many sacrifices.

I am thankful to my committee members: Dr. Gabriel, Dr. Grajales, and Dr. Nosworthy; without their guidance, understanding, and patience, this would not have been possible. 


\section{CHAPTER 1}

\section{INTRODUCTION}

\section{Background}

Motivation is a significant psychological concept and plays a crucial role in education. Psychologists illustrate motivation through various perspectives-humanistic (Maslow, 1943), behaviorist (Skinner, 1953), and social-cognitive (Bandura, 1991). Generally, motivation implies that an individual's drive, desire, and willingness play a significant role in functions. Social involvement and personal responsibility are promoted by motivation (Tabernero \& Hernandez, 2011). A high level of motivation increases the likelihood of an individual behaving and responding to fulfill particular standards (Bandura, 1991). Motivation is one of the significant influences on educational outcomes. Motivated students are more likely to value learning activities and produce positive performance (Zimmerman, 2008; 2000b). Motivation leads individuals to choose a systematic and deep approach to learning (Prat-Sala \& Redford, 2010).

Self-efficacy is at the core of motivation. It refers to people's belief that they can achieve and master tasks (Bandura, 1991; Schunk \& Pajares, 2002). It affects their drive to set goals, develop plans, and control environmental factors to accomplish tasks. Self-efficacy enhances students' academic performance (Komarraju \& Nadler, 2013) and increases the likelihood of engagement in the self-regulation process (Zimmerman, 2000a).

There are significant correlations between self-efficacy and self-regulation (Ghonsooly \& Ghanizadeh, 2011; Uzuntiryaki-Kondakci \& Capa-Aydin, 2013). Self-regulation is defined as an individuals' ability to control emotional, behavioral, and cognitive functions (Zimmerman, 1998). Those who can self-regulate are more capable of controlling behaviors, inhibiting impulsivity, being flexible to change, and regulating emotional responses (1998). Self-regulation 
is an essential cognitive ability that enhances social interactions, psychological health, and academic performance. Klapp (2016) emphasizes the crucial role of self-regulation in reducing negative emotions. Self-regulation has a strong impact on enhancing intrinsic and extrinsic motivation. Pintrich and Schunk (1996) indicated that goal orientation, as a process of selfregulation, improves intrinsic motivation more than outcome rewards.

Self-regulation, self-efficacy, and academic motivation have reciprocal correlations in which the constructs influence each other. For example, utilizing self-regulatory strategies enhance students' academic motivation and self-efficacy. Kormos and Csizer (2014) developed a model that suggests motivational factors - the purpose of learning, orienting effort to achieve a goal, and personal belief —are effective in promoting self-regulation. Similarly, Yusuf (2011) explained the mediational role of self-efficacy on achievement motivation, learning strategies and academic achievement. However, relatively little research has been done to analyze the complex relationships between the three variables — self-regulation, self-efficacy, and academic motivation. This study investigated a hypothesized model that describes the complex relationships between these variables within the framework of SCT. The hypothesized model suggested that self-efficacy and self-regulation predict academic motivation.

\section{Rationale for the Study}

Enrollment in higher education is viewed as a transition point when students experience difficulty in adapting to a new system of education in addition to dealing with other occupational and social responsibilities (Busse \& Walter, 2017; Wang \& Pomerantz, 2009). Students experience massive maladaptive changes in their motivation to learn which in turn affect their academic success, retention, effective engagement in learning, and occupational training activities (Dresel \& Grassinger, 2013). 
Several factors impact academic motivation among university students. They are related to faculty assessments and feedback, campus activities, and educational environment (Rowell \& Hong, 2013); as well as to self-esteem, self-confidence, expectancy, emotional regulation, and goal commitment (Zimmerman, 1998). Self-efficacy and self-regulation contribute to academic motivation (Bandura,1991; Deci \& Ryan 2008). Few studies have been conducted to determine the impacts of self-efficacy and self-regulation on academic motivation among university students, particularly in the United States. The majority of studies reviewed were conducted in cultures such as Iran, Africa, and Hong Kong (Alafgani \& Purwandari, 2019; Lavasani et al., 2011; Ning \& Downing, 2010).

\section{Statement of the Problem}

There is evidence that students' motivation to learn and level of self-efficacy decreases over their academic years (Busse \& Walter, 2017; Dresel \& Grassinger, 2013; Rizkallah \& Seitz, 2017). Lack of motivation negatively impacts students' academic performance and tend to lead students to disengage from learning activities, underachieve, or drop out of school (Wang \& Pomerantz, 2009). During the first year of university students show a significant decrease in academic motivation, self-concept, mastery-approach goals, and the subjective value of their course of studies. This decline in academic motivation is associated with a negative impact on self-regulatory strategies (Dresel \& Grassinger, 2013; Wang \& Pomerantz, 2009).

Ben-Eliyahu (2011) argues that the absence of motivation inhibits the construction of self-regulatory strategies such as setting goals, planning, and monitoring behaviors. Lack of motivation also affects students' performance and enthusiasm, and students lose their productivity and creativity. Thus, motivation and self-regulation cooperate in improving learning operations. Impairment of self-regulation has a negative effect on academic achievement, 
motivation, and mental health. Thirteen percent of graduate students suffer from depression and $2 \%$ of them engage in suicide attempts or have mental health problems (Eisenberg et al., 2007). Failure in self-regulation leads an individual to commit crimes or to alcohol addiction and drug use (Baron, 2003). It contributes to problems such as financial issues, obesity, performance impairment, crime, and drug and alcohol addiction (Kruglanski \& Higgins, 2007). Low selfefficacy also impacts motivation because it correlates strongly with high levels of worry, anxiety, and depression (Tahmassian \& Moghadam, 2011). When students are depressed and anxious, they lack the ability to regulate negative emotions.

\section{Purpose of the Study}

The purpose of the study was to test a theoretical model of the influence of selfregulation and self-efficacy on academic motivation. In particular, a hypothesized model of the relationship between these variables was created and data measuring the self-regulation, selfefficacy, and academic motivation of undergraduate students was collected and analyzed through Structural Equation Modeling (SEM).

\section{Conceptual Framework}

The conceptual framework for this study is based on Bandura's SCT (1986) and the SelfDetermination Theory (SDT) proposed by Deci and Ryan (1985).

\section{Social Cognitive Theory}

According to SCT, humans learn within a social context. Social interactions influence the initiating and attainment of behaviors. The triadic reciprocal determinism of SCT assumes that behavior, internal factors, and the environment interact during the process of learning. Therefore, self-efficacy and self-regulatory abilities affect academic motivation. Individuals observe a model that scaffolds a particular behavior, then form a belief to perform this behavior 
successfully. Hence, they tend to set goals and plan and they become motivated to engage in task performance. However, observation alone is not enough to perform effectively. Bandura emphasizes the role of experience which involves monitoring one's performance and cognitive functions. Mastering a wide range of experiences increases individuals' belief in their abilities, which in turn improves their self-regulation and motivation (Bandura, 1991).

\section{SCT and Self-Efficacy}

Self-efficacy influences individuals' thoughts, affects, motivation, and actions, which impact directed and organized purposeful behaviors. The system of beliefs, including selfefficacy of competence and beliefs of the changeability or controllability of the environment, improves people's motivation to achieve goals. Hence, people with high levels of self-efficacy and beliefs in their abilities to control environmental factors are more likely to use their personal competencies and abilities to adapt to environments to produce successful performance (Zimmerman, 2000b). Therefore, they enhance their self-efficacy and motivation to set challenging goals. Individuals' engagement in self-reflective processes leads to perceived capabilities to perform a particular task; and such beliefs enhance the processes of internal motivation (Bandura, 1994). According to SCT, humans build self-efficacy beliefs through four major resources: mastery experience, vicarious experience, social persuasion, and emotional and physical reaction (1994). The integral impact of personal factors and environmental influences was clear among students who believe themselves competent in mathematics (Schunk \& Usher, 2019). Those students tend to engage in class activities, make an effort to learn, and persevere. When teachers recognize their performance and environmental influence, the students' selfefficacy improves and encourages motivation (2019). Environmental influences and personal factors are incorporated in the formation of self-efficacy beliefs. Self-efficacy can be developed 
by observing a successful model (Bandura, 1994). Also, productive feedback and persuasive comments from significant models increases the sense of efficacy (Bandura, 1997; Schunk \& Usher, 2019). Social and cognitive influences are significant predictors of self-efficacy. They include model observation, self-monitoring, goal settings, self-evaluation, and comparison with social standards (Schunk \& Usher, 2019).

One of the most important personal influences for developing self-efficacy is achieving goals. Success then develops beliefs in one's capabilities. Emotional arousal that individuals experience while engaged in behavior also affects self-efficacy. Low-level anxiety increases selfefficacy whereas high-level anxiety decreases self-efficacy (Bandura, 1994; Schunk \& Usher, 2019). In terms of behavioral influences, individuals who believe that they are efficacious in performing a task, usually get involved in activities, persist in difficulties, and perform well (Schunk \& Usher, 2019; Zimmerman \& Moylan, 2009).

\section{SCT and Self-Regulation}

Bandura (1994) defines self-regulation as the human tendency to achieve a sense of agency in which individuals believe in their capacity to control their actions and environment. The sense of agency can be achieved by directing thoughts and actions (Usher \& Schunk, 2018). Human actions are not only a consequence of environmental factors; indeed, individuals intentionally choose their environment in a way that contributes to achieving their learning objectives. This demonstrates the reciprocal aspects of this theory (Bandura, 1997).

Self-regulation processes are highly dependent on self-monitoring, self-evaluation, and effective self-reaction (Zimmerman \& Moylan, 2009). The cyclical model of self-regulation (Figure 1) comprises three main phases—forethought, performance, and self-reflection. The forethought phase assists individuals in motivating themselves and organizing their performance. 


\section{Figure 1}

A Cyclical Phase Model of Self-regulation that Integrates Metacognitive Processes and Key

\section{Measures of Motivation}

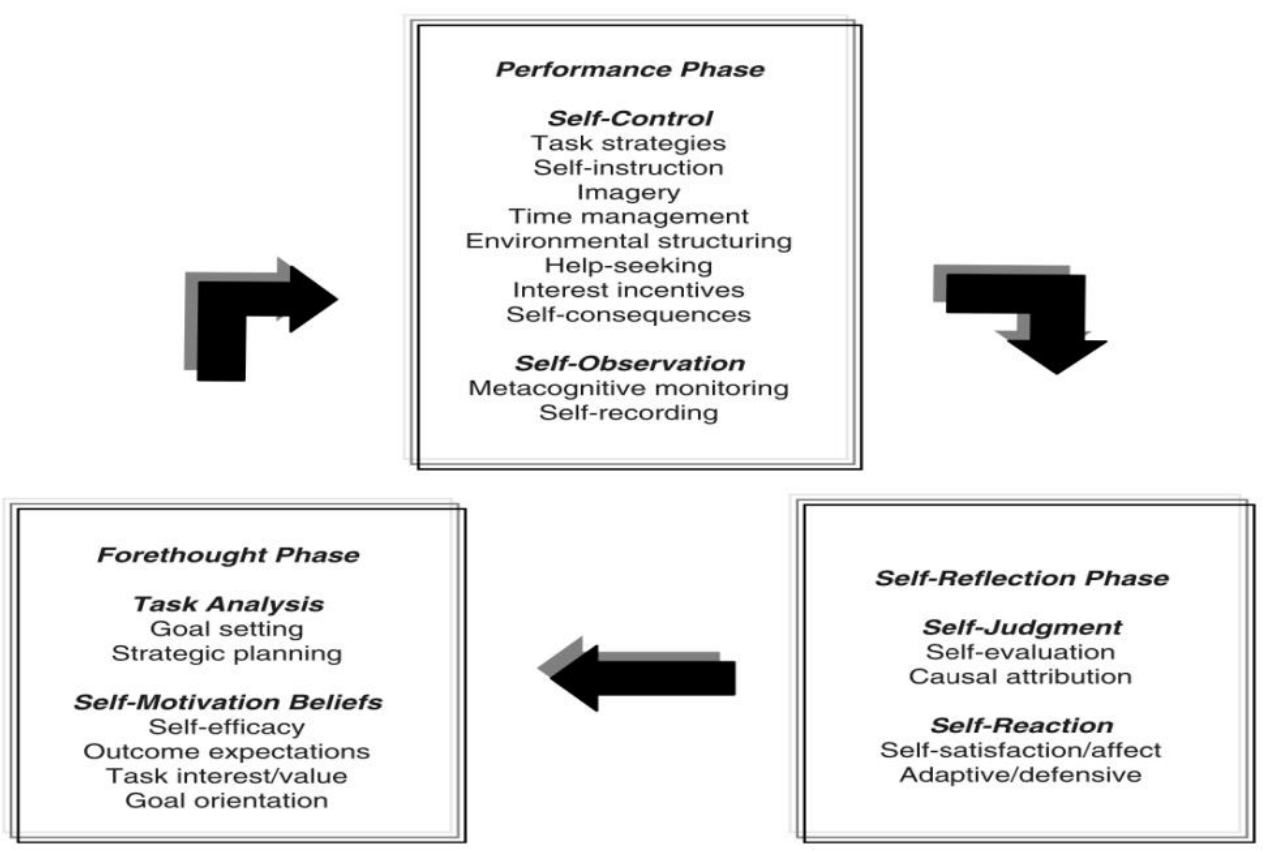

People select strategies, plan, and build motivation. In the performance phase individuals implement the selected strategies and monitor the progress of their actions. The self-reflective phase consists of evaluating outcomes and making attribution of such outcomes. When desired outcomes are achieved satisfaction occurs; however, if outcomes did not meet specified standards, modification is made (Zimmerman \& Moylan, 2009).

This cyclical model of self-regulation represents the reciprocal interactions between personal, behavioral, and environmental influence (Usher \& Schunk, 2018). After the selfreflective phase, if learners discover that the applied strategies were effective, they go back to the performance phase. However, if their strategies need modifications, they return to the forethought phase to adopt new strategies. During these processes, personal influence (cognition) 
interacts with behavioral and environmental influence and vice versa (Schunk \& DiBenedetto, 2020; Zimmerman \& Moylan, 2009).

Deliberate thinking guides the self-regulatory process by considering emotional, motivational, and actual performance. Attention is important to the success of self-regulation (Zimmerman \& Moylan, 2009). Bandura (1991) emphasizes the role of knowledge about one's performance because cognitive regulation of motivation is based on an anticipatory, proactive system that includes effective self-monitoring, self-evaluation, self-incentive, and self-reaction.

\section{SCT and Academic Motivation}

According to SCT, the ability to regulate motivation, affect, and action is significant in developing motivation. Therefore, setting goals and planning is not enough to perform effectively (Bandura, 1991). However, the engagement in self-evaluative processes where one compares outcomes of actions to personal standards will produce self-reactive influences (Bandura \& Cervone, 1986). Self-reactive influences consist of self-satisfaction, perceived selfefficacy, self-set goals. The effective use of self-reactive influence motivates a person positively, whereas using self-incentive because of self-reactive influence enhances one's motivation to accomplish the desired behavior. Zimmerman (1998) demonstrated that people who tend to reward themselves after attainment differ in their ability to regulate their motivation and action from those who did not use self-incentive. Self-evaluation and self-incentive lead to selfsatisfaction which in enhances motivation to pursue performance. For instance, when individuals evaluate their performance based on specific standards and reward themselves when they are satisfied with the outcome, their motivation to accomplish more increases. Bandura (1991) indicated that self-evaluation, whether based on personal standards or social comparison, improves self-satisfaction when goals are met, which enhances academic motivation. SCT posits 
behavioral and environmental influences impact motivation and they in turn are affected by motivation (1991). For instance, observing a successful model who has relatively similar characteristics and abilities improves motivation (Bandura, 1986).

Academic motivation is affected by factors such as internal beliefs, cognitions, and social interactions. Outcome expectancies and value affect motivation to act; and expecting positive results develop the desire to engage in productive behaviors (Schunk \& DiBenedetto, 2020) Students who acknowledge the significance of learning tasks and value learning outcomes, are more likely to be motivated and to engage in learning activities. Individuals' beliefs in their abilities significantly affect motivation (Schunk \& DiBenedetto, 2020). Social interactions, where positive comments and feedback from significant others imply the effective abilities to perform well, improve a sense of efficacy and increases one's motivation for further functions. In addition, social comparison as a personal influence has a significant effect on motivation in which comparing oneself with an observed model facilitates building motivation to perform a task (Bandura, 1986; Schunk \& Usher, 2019). Motivation is affected by behavioral influences such as choosing to engage in activities, making an effort, persisting when difficulties occur, and regulating the environment (Schunk \& DiBenedetto, 2020).

\section{Self-Determination Theory}

SDT, developed by Deci and Ryan (1985), demonstrates human motivation. Their theory suggests that humans develop and change by satisfying three main psychological needscompetency, relatedness, and autonomy. Competency is knowing how to obtain external and internal outcomes and the ability to perform effectively. Relatedness is connecting thoughts and behaviors with social norms and acting accordingly. Autonomy refers to the ability to initiate and regulate one's performance (Deci et al., 1991; Ryan \& Deci, 2020). 
SDT suggests three types of motivation that energize and direct human behaviors and activities. (1) Intrinsic motivation - which leads to volitionally engaging in a behavior because of a sense of satisfaction and pleasure without any interest in external contingencies. (2) Extrinsic motivation — which refers to integrating the behavior's value into the sense of self. (3) Controlled motivation — which comprises external regulation (explains the external reinforcements such as rewards or punishments that direct people to engage in a behavior or activity) and introjected regulation (individuals behave to avoid the feeling of shame, to develop self-esteem, or for the sake of ego-involvement) (Deci \& Ryan, 2008; Ryan \& Deci, 2020). The theory also distinguishes between autonomous motivation (individuals become self-determined; it consists of both intrinsic motivation and extrinsic motivation specifically the identified regulation) and controlled motivation (Ryan \& Deci, 2020).

An autonomy continuum explains the processes of internalization where humans integrate the external contingencies into internal processes (Deci et al., 1991). To achieve positive outcomes, it is imperative to enhance autonomous regulation through internalized and integrated extrinsically motivated behaviors. The internalization processes emphasize the role of fulfilling the needs of relatedness, competence, and autonomy. Even though personal experiences and outcomes are important in the process of internalization, social factors have significant impacts in which the engagement of extrinsically motivated behavior can be attributed to fulfilling the sense of belonging because such behavior is valued by significant others. Promoting competence assists internalization; hence enhancing self-efficacy is a key to people tending to engage in a valuable performance through relevant social groups only when they believe it is efficacious. Also, the experience of autonomy is essential to facilitate internalization (Deci et al., 1991; Ryan \& Deci, 2000). 


\section{SDT and Self-regulation}

SDT posits an autonomy continuum that distinguishes between self-regulation (autonomy) and external regulation (heteronomy) (Deci et al., 1991, Ryan \& Deci, 2000). The autonomy continuum explains the degree of self-determined behavior where individuals develop autonomous motivation rather than controlled motivation. Autonomously oriented people engage in performance because they have an interest in and value the outcomes of the activities. In contrast, people who are control-oriented act for the sake of external forces such as rewards or punishment avoidance.

Autonomy can be developed through considering students' feelings and allowing them to have choices and to make decisions (Ryan \& Deci, 2002). Identified regulation, when behavior is relatively internal, correlates with students' tendency to adopt regulatory strategies such as coping mechanisms and planning for effort. In contrast, students with external regulation of motivation were less interested in learning processes, avoided effort, and blamed others when a failure occurred (Ryan \& Deci, 2000).

Perceiving learning activities as personally important indicates advanced levels of selfdetermination among students. Self-determined students perform learning activities out of pleasure, interest, and value; they persist and produce a high level of academic achievement (Ryan \& Deci, 2006). In contrast, students who perceive learning as pressured or engage in learning processes because of external demands are more likely to quit when facing obstacles and to produce low levels of achievement (Niemiec \& Ryan, 2009). An autonomous-supportive environment is significant in fostering self-regulation. Students who perceive autonomy support show high levels of autonomous self-regulation (Deci \& Ryan, 2008; Ryan \& Deci, 2020).

Creating an environment that satisfies autonomy, competence, and relatedness needs with 
autonomy support from parents, teachers, or instructors can promote competence and autonomous self-regulation (Deci \& Ryan, 2008). In contrast, students who experience thwarting of their psychological needs (autonomy, competence, and relatedness) report controlled selfregulation. Autonomous motivation such as intrinsic motivation and identified regulation are associated with autonomous self-regulation, perceived competence, and perceived high academic performance. In contrast, introjected regulation and external regulation leads to controlled selfregulation and incompetence (Jeno \& Diseth, 2014).

\section{SDT and Self-efficacy}

SDT emphasizes the satisfaction of psychological needs (autonomy, relatedness, and competence) to enhance human behaviors. Competence as a psychological need is related to selfefficacy. Competence is a broader concept that illustrates how much people believe they have an effective role in their society. Self-efficacy within SDT is called perceived competence which is a significant factor for motivation (Ryan \& Deci, 2006). SDT is about the level of beliefs and the quantity of one's motivation and why one holds such a belief. SDT also explains how such a distinction of motivation affects the consequences of behavior. This concept facilitates the differentiation between autonomous and controlled actions.

Students who have an internal locus of causality (or control) believe that they have control over their learning processes and thus engage in self-determined behavior. Students who have an external locus of control believe they have little control over their learning outcomes and are more likely to perform controlled behavior (Deci et al., 1991). Perceived competence mediates the relationship between positive feedback and intrinsic motivation. The integration of feeling competent and autonomy, particularly the locus of control, significantly affects intrinsic motivation (Ryan \& Deci, 2000). 
There is evidence that fulfilling the needs of competence will foster a sense of selfefficacy (Ryan \& Deci, 2020). There are four sources of self-efficacy: mastery experience, vicarious experience, social persuasion, and physiological and emotional states (Bandura, 1997). Therefore, feedback from teachers and parents plays a significant role in constructing students' beliefs in their capabilities and control over their actions. Negative feedback undermines students' sense of competence while positive feedback promotes perceived competence which in turn influences intrinsic motivation (Deci et al., 1991).

Perceived autonomy is associated with self-efficacy (Ryan \& Deci, 2020). An educational environment that supports autonomy and treats students as active learners is imperative to encourage competency. When students have opportunities to be responsible for their learning processes and the freedom to make decisions and have unique perspectives, they then will be motivated to regulate their learning, utilize effective strategies, and evaluate their progress. As a result, successful outcomes will increase belief in one's capabilities to perform well. Satisfying the needs for autonomy promotes self-determined behavior which then constructs self-efficacy (Ryan \& Deci, 2020).

Girelli et al. (2018) constructed a model that predicts undergraduate students' intention to drop out by examining their perceived autonomy support from teachers and parents; and how this autonomy support influences their motivation and self-efficacy. Students who perceive autonomy support from teachers and parents develop greater levels of autonomous motivation and self-efficacy. In addition, students who attend university because of intrinsic motivation and beliefs in their capabilities were less likely to want to drop out of school and more likely to experience academic adjustment (Girelli et al., 2018) 


\section{SDT and Academic Motivation}

The theory identifies several types of motivation: intrinsic motivation, identified regulation, introjected regulation, and external regulation. The basic motivation is intrinsic motivation which promotes self-determined functions. Self-determined students tend to engage in learning activities and produce positive academic performance compared to students who are less self-determined (Vallerand et al., 1992). Students who report high levels of intrinsic motivation show advanced academic progress. Those who learn to attain knowledge and implement information were compared to those who learn materials to do well on a test. The findings demonstrated that students with intrinsic motivation and autonomous regulation show greater conceptual learning than extrinsically motivated students (Deci et al., 1991). Students with intrinsic motivation demonstrated high levels of enjoyment in academic settings, positive emotions, and satisfaction with academic activities (Deci et al., 1991; Vallerand et al., 1992) An autonomous-supportive approach enhances academic motivation. This approach helps students in the process of internalization which in turn facilitates the integration of external regulation to become part of intrinsic motivation (Deci \& Ryan, 2008; Ryan \& Deci, 2020). Graduate students involved in practical learning activities show greater levels of intrinsic motivation compared to undergraduate students where the focus was on attaining theoretical knowledge (Koludrović \& Ercegovac, 2015). A study was conducted to investigate the role of psychological needs fulfillment—autonomy, relatedness, and competence. The researchers suggested a motivational model for examining what factors may predict academic motivation. The path analysis results indicated significant correlations between autonomy and academic motivation as well as competence and academic motivation. Competence was a better predictor of intrinsic academic motivation than autonomy which was mediated by identity development. 
Relatedness was not a significant predictor of academic motivation (Faye \& Sharpe, 2008).

In terms of improving academic motivation through satisfying competence and relatedness needs, positive feedback and interpersonal involvement of teachers and parents were effective in enhancing intrinsic motivation. An autonomy-supportive environment facilitates the internalization process of external regulation (Deci et al., 1991). Autonomy-supportive teachers consider students' perspectives and provide them with a rationale to implement activities, as well as the opportunity to choose learning activities and to take initiative for their academic work. Supporting autonomy leads to supporting relatedness needs and competence, specifically when teachers provide constructive feedback (Ryan \& Deci, 2020).

\section{Research Questions}

This exploratory study examined a hypothesized model of the influence of selfregulation and self-efficacy on academic motivation, among undergraduate students in the United States. The primary research question was, "Are the theoretical covariance matrix and the empirical or observable covariance matrix equal?" This main question addressed the following research question, was the hypothesized theoretical model a good fit to the sample? The subresearch questions were:

1. Was there a significant correlation between self-regulation and self-efficacy?

2. Did self-regulation affect academic motivation?

3. Did self-efficacy affect academic motivation?

\section{Research Hypotheses}

The main hypothesis of this study was that the reproduced covariance matrix proposed in the theoretical model and the observed sample covariance matrices were equal. In simple terms, this meant that the structural model would be a good fit with the observed data. Using the 
conceptualized model depicted in Figure 2, this study hypothesized (1) There was a significant correlation between the two exogenous variables, self-regulation and self-efficacy, (2) Selfregulation had a significant, direct effect on the endogenous variable academic motivation, (3) Self-efficacy had a significant, direct effect on the endogenous variable academic motivation.

\section{Figure 2}

Self-efficacy and Self-regulation Predict Academic Motivation

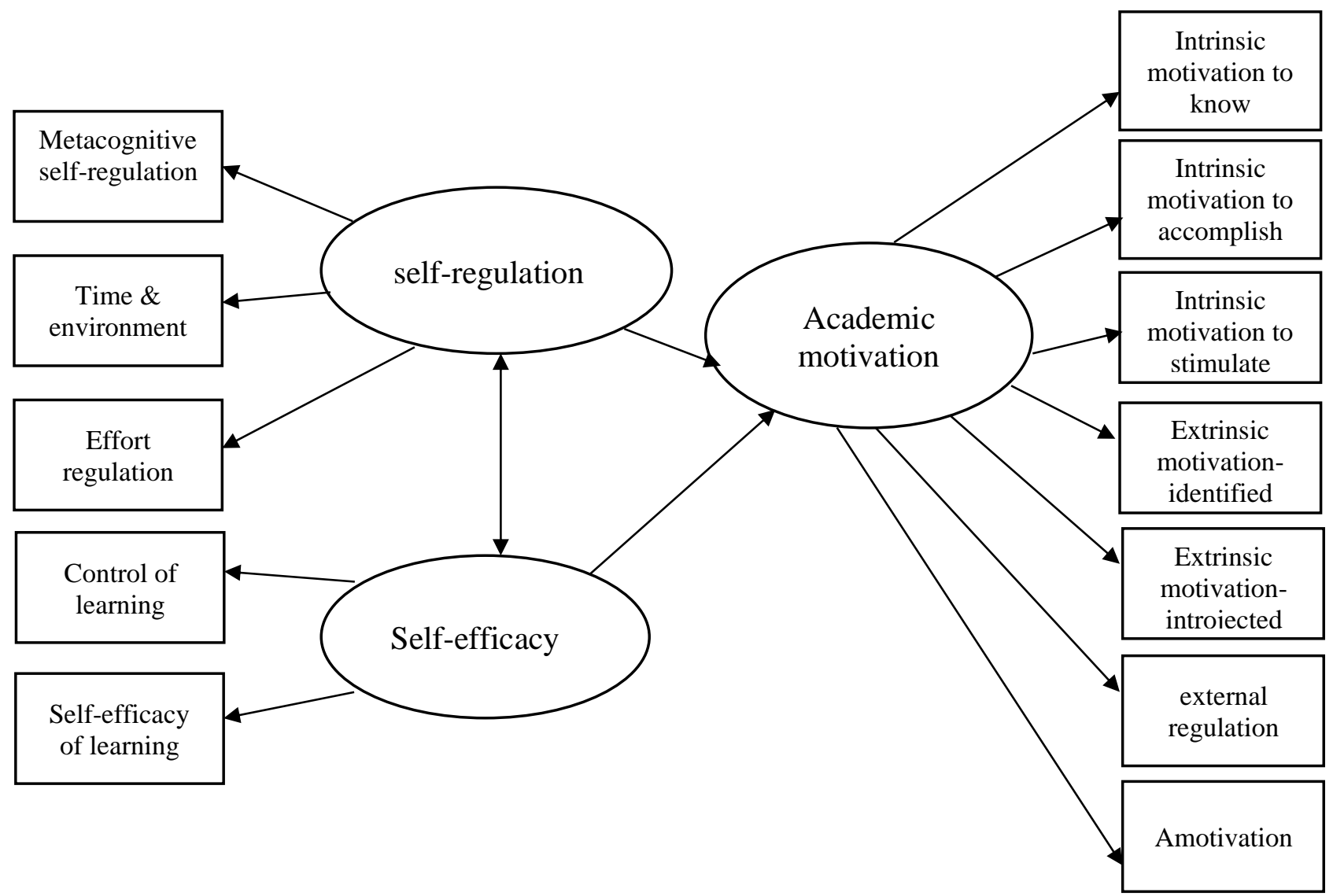

Significance of the Study

The significance of this study is girded by the fact that the demand for higher education has grown in different societies. Higher education aims not only to provide knowledge but also to offer vocational training to prepare qualified members of society. However, current statistics indicate that the number of enrolled students in higher education has declined. Researchers found 
that university students tend to underachieve or drop out of school as a result of an inability to adapt easily during the transition period from secondary education to higher education (Wang \& Pomerantz, 2009). One reason underlying this phenomenon is students' lack of motivation to learn, self-efficacy, and a self-regulatory mechanism (Busse \& Walter, 2017; Dresel \& Grassinger, 2013; Rizkallah \& Seitz, 2017). Hopefully, my findings can benefit society and governments by offering information regarding critical variables that influence the motivation of students in higher education. This information may enhance knowledge of academic motivation, which will lead to a decrease in the number of students who drop out of school and an increase in the number of graduate students who will serve in different fields to improve society.

The outcome of the current study can help policymakers and personnel of higher education to improve students' academic motivation by emphasizing the role of enhancing students' beliefs in their capabilities and integrating effective self-regulatory processes in higher education learning and curriculum. The findings of the study can contribute to increasing the understanding of critical factors that impact students' motivation to learn. Such significant knowledge is going to provide faculty and students with important strategies and techniques related to developing motivation to learn. For instance, instructors can focus on planning lectures to incorporate self-efficacy and self-regulatory strategies. Students who enroll in higher education can also concentrate on developing their beliefs in self and practicing self-regulatory strategies whenever their motivation to learn abates. Even though many studies have investigated academic motivation, very few were conducted with the higher education population.

Although previous studies have investigated the correlation between self-efficacy and academic motivation (Bandura, 1991; Cerino 2014) and self-regulation and academic motivation (Cetin, 2015; Ning \& Downing 2010), there is a lack of studies that focus on predicting the role 
of self-efficacy and self-regulation on academic motivation. This justified the existence of this study. This study can serve as a guide for researchers to investigate the combination of the study's variables among different populations and to detect other factors that may predict academic motivation among university students.

\section{Definition of Terms}

Academic motivation refers to the intrinsic or extrinsic orientation that drives one to set goals and prepare plans to perform in a particular way. Thus, motivation is the interest or the will that drive students to accomplish academic goals (Ryan \& Deci, 2000; Vallerand et al., 1992). Amotivation refers to the concept of describing individuals' tendency to disengage in activities or actions as a result of the absence of desire or to the lack of valuing an outcome (Vallerand et al., 1992).

Control of learning beliefs refers to students' beliefs in their ability to control their effort and a successful outcome will be attributed to the extent of effort rather than external factors such as luck or instructors (Pintrich et al., 1993).

Effort regulation refers to students' abilities to manage themselves during the process of learning despite the obstacles and difficulties that they may encounter to achieve desired goals (Pintrich et al., 1993).

External regulation refers to factors that drive behavior to obtain rewards or avoid punishment (Vallerand et al., 1992).

Extrinsic motivation refers to factors that enhance students' desire to perform effectively to achieve academic success such as esteem or reward (Ryan \& Deci, 2000; Vallerand et al., 1992). 
Identified regulation indicates that the reason for the engagement is not fully external but the regulating behavior is relative to its value and personal reasons (Vallerand et al., 1992).

Intrinsic motivation refers to the internal desire students have to engage in academic activities such as satisfaction (Ryan \& Deci, 2000; Vallerand et al., 1992).

Intrinsic motivation to accomplishment refers to the pleasure and satisfaction individuals experience when accomplishing something (Vallerand et al., 1992).

Intrinsic motivation to know refers to the pleasure and satisfaction individuals experienced when they learn, understand, and explore new things (Vallerand et al., 1992).

Intrinsic motivation to experience stimulation is defined as engaging in activities due to the experience of excitement, enthusiasm, or aesthetics (Vallerand et al., 1992).

Introjected regulation refers to the tendency to engage in behavior to improve self-esteem or avoid anxiety and a sense of guilt (Vallerand et al., 1992).

Metacognitive self-regulation refers to individuals' ability to conduct effective strategies that assist in controlling and regulating performance such as setting goals, planning, monitoring, and modifying behaviors (Pintrich et al., 1993).

Self-efficacy refers to the belief in one's capabilities to conduct the well-organized behavior needed to accomplish a task (Schunk \& Pajares, 2002; Zimmerman, 2000a). It includes judgments about one's ability to accomplish a task as well as one's confidence in the skills to perform that task (Pintrich et al., 1993).

Self-efficacy for learning refers to both expectancy for success and confidence in one's ability to accomplish a task where expectancy for success is more related to the performance and expectations than the judgment of one's abilities and skills and how much confidence the students have in their capabilities (Pintrich et al., 1993). 
Self-regulation refers to the individuals' ability to control their emotional, cognitive, and behavioral responses and make changes and adjustments to adapt successfully (Bandura, 1991; Zimmerman, 2000a).

Time and study environment management: time management refers to the effective use of study time including daily, weekly, and monthly plans and schedules. Whereas study management refers to students' tendency to avoid distraction and prepare a quiet and organized study environment (Pintrich et al., 1993).

\section{Limitations of the Study}

The limitations of this study were as follows:

1. The self-report questionnaires used imply a response bias because participants may have faked their responses to look good or to respond according to their socially desirable norm.

2. The Likert scales may have been subject to participants misinterpreting the meaning of the scale points. Thus, some may have responded around the midpoint areas of the scale, whereas others may have responded on the extreme edge points of the scale.

3. The convenience sampling method used in this study may have limited the generalization of the findings to similar populations.

\section{Delimitations of the Study}

This study was limited to undergraduate students 18-22 years old. Although academic motivation is influenced by a variety of psychological and social factors, the primary focus of this study was on the effect of self-regulation and self-efficacy on academic motivation. A structural model was used to analyze and interpret the data, instead of a measurement model, because the researcher focused on the predictive roles of self-regulation and self-efficacy in academic motivation. 


\section{CHAPTER 2}

\section{LITERATURE REVIEW}

\section{Organization of the Literature Review}

This chapter is divided into five main sections: (1) literature search strategies; (2) historical and theoretical overviews of motivation generally as well as academic motivation, selfregulation, and self-efficacy; (3) the relationship between the variables self-regulation and academic motivation; (4) the relationship between self-efficacy and academic motivation; (4) the relationships between self-efficacy, self-regulation, and academic motivation; (5) an analysis and synthesis of the literature review.

\section{Literature Search Strategies}

The purpose of this literature review was to demonstrate how the primary resources contributed to understanding the research problem. It prevented unnecessary duplication of research while revealing any gaps which might require additional research. Synthesizing prior research helped determine my research.

I used two databases: James White Library and Google Scholar. In James White Library, I used Articles/Databases, Education, ERIC, PsycINFO, and Academic Search CompleteEBSCO. I used the following search terms - self-regulation and academic motivation, selfregulation and self-efficacy, self-efficacy and academic motivation, and self-regulation and selfefficacy with their correlation to academic motivation. I selected peer-reviewed literature published within the last ten years (2009-2020), focused primarily on studies conducted in academic settings with adult subjects. I used the same process to search Google Scholar.

\section{Motivation: A Brief Historical Overview}

The concept of motivation is rooted in Ancient Greek philosophers, primarily Plato and 
Aristotle (Gollwitzer \& Oettingen, 2001). Plato contemplated the idea of a hierarchy organized around emotional, rational, and dietary components. Aristotle believed that the components of the hierarchy could be used as motivators of human behaviors. He viewed the dietary and emotional components (pain or pleasure) as irrational motivators. The Ancient Greeks based motivational activities on three primary components - the body's desire, feeling pain or pleasure, and spiritual effort of will (Gollwitzer \& Oettingen, 2001).

Later, Descartes declared the will to be a more effective motivator than the physical body, therefore, articulating the first theory of motivation (Gollwitzer \& Oettingen, 2001). Descartes believed that the power of will is a strong motivator because the human mind has mental, moral, and intellectual mechanisms that induce will (Gollwitzer \& Oettingen, 2001), whereas the body's needs are just physical and biopsychological forces that interact naturally with environmental factors to fulfill satisfaction (Gollwitzer \& Oettingen, 2001).

In the early twentieth century, human behaviors were attributed to physiological needs. Sigmund Freud (1924) addressed the life instinct idea which suggests that human behavior is driven by instinct. He believed humans react to satisfy physiological needs which then reduces the levels of stress or anxiety because of deprivation. Some researchers (Lewin, 1936; Skinner, 1935) denied the idea of restricting motivational factors to instincts while ignoring other potential elements. Therefore, researchers such as Pavlov (1927) and Skinner (1935) conducted several studies and assessments to analyze human motivation from a variety of perspectives including behaviorism, humanism, and cognitive approaches.

\section{Behaviorism}

Behaviorists explained motivation based on the stimulus-response model and classical conditioning perspective (Rensh et al., 2020). Theorists such as Pavlov (1927), Thorndike 
(1989), Watson (1913), and Skinner (1935) believed that environmental factors guide human behavior, thus reinforcements are the main drivers of actions. Gestalt psychology (Lewin, 1936) contributed to the theoretical concept of motivation, hypothesizing goal formation as promoting achievement motivation.

\section{Humanism}

Humanism emphasizes the role of psychological needs regarding motivation and direction of behaviors. Maslow (1943) suggested that human needs motivate individual behavior and response. He postulated a hierarchy of needs through which humans progressed. He identified the needs, in order from lowest to highest as physiological, safety, love, self-esteem, and self-actualization. Hence, being motivated to satisfy deficiency needs is essential for reaching the level of growth and self-actualization.

McClelland (1987) attributed human behaviors to the acquired need for power, achievement, and affiliation. Herzberg (1959) based his motivation theory model of employee performance on two factors - motivator factors that have a positive impact on workers' function and the hygiene factor that negatively affects their performance. Alderfer (1969) developed the ERG theory which categorizes Maslow's hierarchy of needs into three phases: Existence, Relatedness, and Growth. Rogers (1951) attributed human behavior to the tendency to satisfy self-actualization. Allport (1961) emphasized the important role of conscious motivation in human behavior. The concept of autonomy of motives indicates that the recent motive is independent of its original condition (Rensh et al., 2020).

\section{Cognitive Psychology}

Cognitive psychology has contributed to the literature on motivation. Heckhausen and Heckhausen (2008) conceptualized motivation as a cognitive process. SCT by Bandura (1991) 
plays a crucial role in understanding the motivation of behaviors as a construct. To illustrate the characteristics of the motivation behind the social interaction processes, Rotter (1966) initiated the locus of control concept which is defined as the belief in one's control. Locus of control is internal-individuals attribute the outcome of performance to internal resources or externalrelated to external environmental factors. Nuttin (1964) theorized motivation as goals and the process of achieving them.

Several theories investigated motivation in terms of significant factors such as outcome expectancy and perceived equity. Vroom's (1964) expectancy theory suggested that motivation can be affected by expectation. Therefore, individuals perform a specific action because they believe it will lead to a desirable outcome which in turn enhances satisfaction. The equity theory of motivation by Adams (1965) assumes that fairness and social equity influence individuals' motivation. Lawler and Porter (1967) developed a model based on the expectancy theory and the equity theory. This model suggests that needs, expectancy, and rewards affect the levels of motivation (Rensh et al., 2020).

SDT focuses on the quality rather than the quantity aspects (Deci \& Ryan, 2008). The theory categorizes motivation into intrinsic motivation, extrinsic motivation, and amotivation.

\section{Academic Motivation: A Conceptual Overview}

It was clear from the historical overview that motivation is an interesting psychological phenomenon that has been studied for many years. Researchers tried to understand motivation in education to gain insight into why students who willingly engage in learning activities perform better in academic subjects (Deci \& Ryan, 2008). Accordingly, the academic motivation concept has developed through a variety of motivational dimensions including beliefs or perceptions, values, and goals (Rowell \& Hong, 2013). The concept also advanced as a result of 
psychological components in SCT (Bandura, 1991) and SDT (Deci \& Ryan, 2008; Ryan \& Deci, 2000).

The components of individuals' beliefs or perceptions of motivation are self-efficacy, autonomy, and attributional beliefs. Self-efficacy refers to individuals' beliefs in their ability to accomplish a task (Bandura, 1991). Students who possess high levels of self-efficacy are more likely to be motivated when they engage in learning activities, make the effort to succeed, and persevere when difficulties occur (Schunk \& Pajares, 2002). Students with low efficacy beliefs perform poorly, disengage in learning activities, and give up whenever they encounter difficulties (Wang \& Pomerantz, 2009). The sense of autonomy, students' belief that they have control over their goals and behavior formation, is imperative. Autonomous learners tend to be active during learning procedures, engage in classroom and task performance, regulate time and effort toward learning, and become self-determined learners (Ryan \& Deci, 2000). Attributional beliefs identify the way students attribute their learning outcomes which in turn affect their subsequent performance. There are three main components of attributional beliefs: locus of control, stability, and controllability (Rowell \& Hong, 2013). Students who attribute their academic achievement to effort tend to be academically motivated because such attribution is based on internal locus of control, unstable cause, and controllable factors.

Goals are fundamental components of academic motivation. They assist students in forming plans and procedures that affect their cognitive, emotional, behavioral responses. Goal orientation consists of mastery goal orientation and performance goal orientation. Mastery goaloriented students perform better than performance goal-oriented students because they believe abilities can be developed, and successful performance results from their effort. Hence, they utilize effective strategies and hold a positive attitude to their learning. Performance goal- 
oriented students tend to avoid challenging tasks and attribute their failure to the lack of abilities. Mastery goal orientation enhances students' sense of competency and their intrinsic motivation (Ames \& Archer, 1988). Bandura (1991) believes that setting goals and planning motivate individuals to achieve their goal by regulating required actions and effective strategies.

Value is an essential component of academic motivation. Students who value the task tend to engage in learning activities and perform well. However, students who perceive the course/task as valueless, become unmotivated to participate effectively in learning. The value of learning a task is derived from three elements of the course - intrinsic value (interesting), attainment value (important), and utility value (useful) (Eccles, 2005).

SDT differentiates between intrinsic motivation and extrinsic motivation. Intrinsically motivated students engage in learning activities because of experiencing pleasure and enjoyment. Conversely, extrinsically motivated students perform to obtain external rewards or grades and to avoid feelings of shame (Deci \& Ryan, 2008; Vallerand et al., 1992).

\section{Self-Regulation: A Historical/Theoretical Overview}

An interval analysis of self-regulation studies conducted by Post et al. (2006) analyzed studies that defined self-regulation and its developmental processes, defined factors that influence self-regulation, and studied with the general overview of self-regulation and its implication. As a result of the analysis, the researchers identified the theoretical perspective of self-regulation in chronological order, grouped in four categories: precursory, emergent, contemporary, and expansionism.

\section{Precursory 1891-1950}

During the precursory period, self-regulation was discussed based on the behaviorist's overview in which the external factors influence self-control. The emphasis was on the role of 
drives to fulfill the sense of joy and pleasure or avoid pain. In 1891, the definition of will or volition was attributed to disobedience response, while the child behavior was expressed within the unconscious response and automatic reactions (Post et al., 2006).

In the twentieth century, the self-regulation concept was discussed in many terms. Selfrealization implied the rejection and refusal of pain. Behavioral consequences are important in the formation of regulation (Thorndike, 1898). Evolution of consciousness theorized behavior as a result of cognition and systematic thought. Freud (1924) determined the self-regulatory processes according to the control of internal drives that may affect the adaptation of the behaviors. Pavlov (1927) demonstrated self-regulation based on external factors and correlated learning to an automatic response to a conditioned stimulus.

The 1930s saw the formation of the behaviorism perspective. In 1940, psychological research studied latent learning, reinforcement, persistence, discriminative conditioning, and repetition stimulating. Miller and Dollard (1941) integrated the behaviorism perspective with Freud's point of view. They theorized social learning which suggests a strategy of planning to obtain rewards in which actions are regulated by internal desire and external environmental factors. Thorne (1946) wrote the first article about the concept of self-regulation. He referred to self-regulation as intelligent adaptation.

\section{Emergent 1950-1970}

Miller and Dollard's (1941) social learning theory was the turning point of the emergent period. This period discussed self-regulation from cognitive perspectives with the denial of the behavioral approach in terms of controlling action by external factors. Research focused on reflection, reaction, and reevaluation. The factors that affect the self-regulatory processes include 
the limitation of fear and the levels of motivation toward reinforcements with emphasis on the impact of compliance in self-regulation.

The scholarship of cognitive scientists has affected the perspective of self-regulation. Piaget (1952) emphasized the role of mental structures on the processes of adaptation and regulation of external environmental factors. Individuals' schemes influence assimilation and accommodation processes to perceive stimuli. SCT emerged when Heider (1958) investigated how to predict future events. The cognitive structures, particularly social schemata, organized the information regarding social construct and persons. Vygotsky (1962) demonstrated how selfregulatory processes influence the social and cultural environment. He believed that social interaction, including scaffolding and language (cooperative dialogue and private speech), is essential for the development of self-regulation. Such interaction should occur within the child's Zone of Proximal Development, which represents the abilities of an individual and what one can learn or achieve with support. Thus, self-regulation develops as a result of personal factors and social interaction through the process of accommodation and adaptation.

Self-regulation as a construct was unknown during the 1970s and early 1980s. However, scholars such as Dale Schunk, Ann Brown, Michael Pressley, Joel Levin, and Donald Meichenbaum, conducted a variety of research studying aspects of the self-regulatory processes such as imagery, self-instruction, goal setting, and effective use of strategies. The turning point of the development of self-regulation was in 1986 during a symposium (Zimmerman, 2008) at the American Educational Research Association Annual Meeting. In this symposium, Zimmerman defined self-regulation as a metacognitive construct consisting of different processes. Since then, researchers such as Barbara McCombs, Lyn Corno, Mary McCaslin, Richard Newman, Dale Schunk, and Monique Boekaerts and others, have investigated self- 
regulation as an integrated system that includes self-control, self-monitoring, self-concept, and learning strategies (Zimmerman, 2008).

\section{Contemporary (1970-1990)}

Flavell, Friedrichs, and Hoyt (1970) distinguished between metacognitive strategies including monitoring and self-regulation and cognitive abilities. The contribution of SCT (Bandura, 1991) advanced the study of self-regulation where self-evaluation is imperative during learning from social observation. Subsequently, the information processing model illustrated how individuals organize information and can effectively engage in processing such information through short-term memory, working memory, and long-term memory. Self-control, thus, assists individuals in directing attention toward important information and shield or ignore distracting stimuli (Post et al., 2006). Winne (1995) developed a model to conceptualize self-regulation based on information processing theory. The model was updated in 1998 into The WinneHadwin Model of Self-regulated Learning to differentiate self-regulation profiles according to metacognitive aspects (Panadero, 2017).

\section{Expansionism (1990-2006)}

In education, the core aim was to develop students' abilities to regulate their thoughts, emotions, and behaviors. Therefore, most of the research incorporated the perspectives of behaviorism of Vygotsky (1962) and Bandura to demonstrate self-regulation. Other studies focused on examining self-regulation across varied cultures, different ages, and a variety of teaching approaches and special needs (Post et al., 2006).

The researchers developed several models to demonstrate the self-regulation construct within a framework of social and cognitive impact. To illustrate, Zimmerman (1989) developed the model A Triadic Analysis of Self-regulated Functioning. This model is congruent with 
Bandura's perspective and includes three factors - environmental, personal, and behavioral. Subsequently, Zimmerman developed two more models. (1) A Multilevel Model of Selfregulatory Training (2000) posits four stages (observation, emulation, self-control, and selfregulation) that enhance students' competency to develop self-regulation. (2) The Cyclical Phase of Self-regulation (2009) consisting of metacognitive and motivational processes (Zimmerman \& Moylan, 2009, 2013). Pintrich's Self-Regulated Learning SRL Model (2000) illustrated four phases of self-regulatory learning processes: forethought, monitoring, control, and reaction and reflection.

Panadero (2017) reviewed two other models. (1) Boekaerts's model (1996) explained six components of self-regulation which were revised later into the Adaptable Learning Model. Her latest version is the Dual Processing Self-regulation Model which was extended in 2011 to include volitional strategies and emotion regulation strategies. (2) Efklides (2011) developed the Metacognitive and Affective Model of Self-regulated Learning based on SCT. The model determines the interaction between metacognitive, motivation, and affect. It differentiates between two levels: the top-down level (person) which demonstrates the interaction of individuals' competencies in the task domain, and the bottom-up level (task x person) which illustrates the function of self-regulation where activities are considered data-driven and metacognitive abilities control actions and motivation (Panadero, 2017).

During the 1980s, researchers developed several assessment tools to measure the construct of self-regulation (Zimmerman, 2008). They included the Learning and Study Strategies Inventory (LASSI; Weinstein et al., 1987), the Self-Regulated Learning Interview Scale (SRLIS; Zimmerman \& Martinez-Pons, 1986, 1988), and the Motivated Strategies for Learning Questionnaire (MSLQ; Pintrich et al., 1993). 


\section{Self-Efficacy: A Brief Historical Overview}

The study of self is traced back to the Greek philosophers such as Plato, Aristotle, and Socrates who defined self as a soul and spiritual entity (Remes \& Sihvola, 2008). During the Middle Ages, Aquinas (1975) introduced the idea of mind and body duality in which soul and body are integrated to illustrate the concept of self. In 1659, Descartes (2008, trans.) established the philosophy of thinking. He believed that doubt proved one's existence because doubt is a form of thinking. Cartesian rationalism emphasized the inner process of self-awareness which is considered the foundation of metacognitive processes. However, belief during past eras was mostly attributed to religion (Descartes, 1659; trans. 2008).

In the twentieth century, the study of self and self-beliefs developed based on William James' (1890) publication, The Consciousness of Self, in which he distinguished between the self, $I$, and the self, me, as knower and known. This philosophy presented the concept of selfreflection which Bandura (1997) later explained. James was also the pioneer of the self-esteem concept.

In the 1900s Cooley (1902) explained the self through The Looking-Glass Self Theory. In 1923 Sigmund Freud advanced his Psychoanalytic Theory, which theorized that self comprises

three components—id, ego, and superego. While behaviorist psychologists focused on external stimuli, humanistic psychologists focused on the study of self. For instance, Maslow's (1943) hierarchy of needs described human motivation as fulfilling different needs to achieve selfesteem and self-actualization. Although, initially, Bandura based his worldview on behaviorists' perspective, he rejected the idea of limiting human functions only by biological and environmental factors. He believed humans play an active role through their thoughts. Therefore, Bandura was a pioneer in the concept of self-efficacy (Schunk \& Pajares, 2002). 
The self-efficacy foundational concept emerged before the development of SCT. In the 1970s, Bandura explained motivation in terms of outcome expectations. Later he conducted therapeutic techniques for people who have phobias. Even though the participants were motivated to apply the techniques regardless of their fear of outcome expectations, some could not implement the techniques in real-life situations. Bandura attributed these individual differences to self-efficacy. He believed that self-efficacy has a stronger effect on motivation than outcome expectations do (Zimmerman, 2000).

In 1986, Bandura proposed the SCT which emphasizes the role of self-efficacy in cognitions, behaviors, emotions, and motivations. In the period 1991-1997, he concluded that people perceive beliefs in self through interaction with the environment in which they create beliefs of their capabilities. He conducted several studies to determine the power of self-efficacy on regulating and motivating human actions (Bandura, 1991; 1997).

\section{The Relationship Between Self-Regulation and Academic Motivation}

According to the Cyclical Model of Self-regulated Learning Processes (Zimmerman \& Moylan, 2009), the self-regulation process consists of three phases-forethought, self-control or performance, and self-reflection. During the forethought phase, people engage in task analysis and self-motivation through observing a model. It was hypothesized that involvement in these phases is cyclical where self-regulation affects motivation and motivation also influences selfregulatory processes in another task (Bandura, 1991, Zimmerman, 2000a). Such a hypothesis

explains the controversy among researchers regarding whether self-regulation affects motivation or motivation influences self-regulation.

Ning and Downing (2010) found evidence for the assumption that motivation and selfregulation have a reciprocal relationship. Their longitudinal study examined the reverse 
relationship between motivation and self-regulation as well as how this relationship affects students' performance. The study found that undergraduate students demonstrate the reciprocal effect between motivation and self-regulation because students who tend to regulate their function become more motivated to accomplish more tasks. The opposite is also true. The students' academic performance was impacted by this relationship.

In contrast to these findings, Cetin (2015) investigated the impact of self-regulation and academic motivation on university students' academic achievement. The study identified a relationship between academic motivation and self-regulated learning. However, there was no significant evidence that these variables predict academic achievement, except goal setting which is one of the self-regulatory factors that was found to be a good predictor of students' achievement (Cetin, 2015).

Undoubtedly, test anxiety negatively impacts students' academic performance. A study of 208 university students aimed to determine the relationship between self-regulated learning and academic motivation (competence and autonomy) while excluding the effect of test anxiety. The findings revealed a statistically significant correlation between self-regulated learning and academic motivation. Test anxiety did not affect this relationship. The variation of motivational components also did not affect the correlation between self-regulated learning and academic motivation (Miller, 2010).

Valinasab and Zeinali (2018) sought to demonstrate the relationship between academic emotions, self-regulated learning, academic motivation, and academic achievement. The study indicated that self-regulated learning correlated with academic motivation, and positive academic emotions are positively and significantly related to self-regulated learning and academic motivation. However, negative emotions have a negative relationship with both self-regulated 
learning and academic motivation. This means that positive emotions- - hope, pride, and pleasure — enhance students' motivation to learn and their self-regulation skills. However, negative emotions - sadness, anxiety, and anger - reduce the desire and motivation to engage in learning activities and negatively affect self-regulation. Self-regulation had a significant, positive, direct effect on academic achievement. Academic motivation, however, did not affect academic achievement. The study demonstrated that self-regulated learning plays a moderating role between academic emotions and academic achievement.

To understand the role of self-regulation and academic motivation on academic performance, Ariani (2016) studied a group of undergraduate students $(n=326)$. They hypothesized the implementation of a flexible assessment system would improve students' motivation to learn because they become independent learners who can detect their strengths and weaknesses. The results of the study indicated that a flexible assessment system had a positive effect on academic motivation and self-regulation. Academic motivation had a significant positive impact on self-regulation and academic performance. The study also found that academic motivation had a moderating role on the influence of the flexible assessment system on academic performance and self-regulation. The mediated role was found through self-regulation on the effect of the flexible assessment system and academic motivation on performance. This meant that the impact of the flexible assessment system on academic performance was mediated by self-regulation and academic motivation.

Saki and Nadari (2018) investigated the variables that predict academic motivation. They found that students with high levels of self-concept and self-regulated learning have high levels of intrinsic and extrinsic motivation. In comparison, students with low levels of self-concept and self-regulated learning lacked academic motivation. In addition, the study proposed that 
academic motivation can be predicted by self-concept and self-regulated learning among high school students.

Previous research provided evidence for the correlation between self-regulation, selfefficacy, and academic motivation through well-developed and clear argumentative studies. Yet, contradictory results have been found with the ability of self-regulation to predict academic motivation among Iranian students (Saki \& Nadari, 2018). However, academic motivation predicted self-regulation among Indonesian students (Ariani, 2016). This supports the idea that different cultures have a variant perspective. Therefore, it is imperative to examine the role of self-regulation in predicting academic motivation among undergraduate students in the United States where diversity may contribute to research on academic motivation.

\section{The Relationship Between Self-Efficacy and Academic Motivation}

Bandura (1991) defined self-efficacy as an individual's belief in his/her ability to complete a task. He suggested four resources that affect the formation of self-efficacy. They are mastery experiences, vicarious experience (which refers to observing a model), social persuasion, and physiological response awareness. Self-efficacy enhances an individual's performance and creativity as well as the ability to deal with difficulties and obstacles (Zimmerman, 2000b). According to SCT, self-efficacy is a key to learning and gaining knowledge because people who believe in their capabilities tend to have high levels of motivation and the ability to regulate themselves (Bandura, 1991). Regarding the correlation between self-efficacy and academic motivation, Ball and Edelman (2018) found that, for English students who believe that they had poor English literacy skills, their motivation to learn and use self-efficacy were moderate or below moderate even if they perceived English as very important. 
By the same token, learning motivation significantly correlated with self-efficacy among a group of medical science students (Hassankhani et al., 2015)

To examine a theoretical model that indicates a correlation between learning-oriented motivation, lifelong learning tendencies, and students' self-efficacy, Akyol (2016) studied a sample of 382 university students who were education majors in five different departments. Of the 382 students, $29.06 \%$ were studying information technology, $26.70 \%$ were studying the English language, $13.61 \%$ were studying history, and $8.38 \%$ were studying music. Also, $22.25 \%$ of the candidate teachers were involved in classroom teaching. Most of the participants (60.07\%) were females and the rest (39.53\%) were males. The analysis indicated that (1) students have high levels of learning-oriented motivation, a lifelong tendency to learning, and self-efficacy perception; and (2) the three variables are significantly correlated. SEM demonstrated that the relationship between learning-oriented motivation and self-efficacy perception was mediated by lifelong learning tendencies.

Further investigation of self-efficacy and academic motivation and its effect on learning activities have been conducted regarding students' tendency to procrastinate. For instance, Cerino (2014) examined self-efficacy and academic motivation as an explanation of procrastination and found that self-efficacy, academic motivation, and procrastination were correlated among university students. Academic motivation was a strong predictor of procrastination while self-efficacy had no impact when controlling for academic motivation. The findings of this study were consistent with Malkoç and Mutlu's (2018) research which aimed to determine whether academic self-efficacy or academic motivation predicts academic procrastination. The results indicated a negative relationship between academic self-efficacy and academic procrastination and between academic motivation and academic procrastination. The 
analysis demonstrated that academic self-efficacy and academic motivation predict academic procrastination. The researchers also conducted a partial correlation to identify whether the correlation between academic self-efficacy and academic procrastination would change after controlling for academic motivation. They found that motivation has a mediating role in the relationship between academic self-efficacy and academic procrastination.

To improve university students' self-efficacy and academic motivation, Mantasiah and Yusri (2018) conducted an experimental study using the Pay It Forward Learning Model. The model is based on the idea that each individual has an effective role in making changes in his or her learning environment. Such an idea was assumed to increase students' self-efficacy and their academic motivation. The researchers utilized the experimental method, specifically the preposttest, to investigate the effectiveness of the model. After applying the Pay It Forward Model in four meetings, the researchers ran a paired sample t-test to detect any improvement in selfefficacy and academic motivation compared to the pre-test results. They found a significant increase in both self-efficacy and academic motivation among the students. Students who have low self-efficacy beliefs and who lack academic motivation are more likely to procrastinate in learning (Cerino, 2014; Malkoç \& Mutlu, 2018).

SDT addresses the role of satisfying competence, relatedness, and autonomy needs to enhance academic motivation and efficacious beliefs (Deci \& Ryan, 2008). According to this perspective, students who enrolled in the Pay it Forward program developed high levels of selfefficacy and academic motivation because each student explained the materials to another group of two or three students. Thus, playing an active role in the class increases the sense of relatedness, competence, and autonomy (Mantasiah \& Yusri, 2018).

The literature review revealed only one study of whether self-efficacy played a 
significant role in predicting both academic motivation and self-control and self-management.

Other studies were well organized; they used a correlational method to investigate the relationship between self-efficacy and academic motivation among university students. Therefore, there is a lack of prediction methods for self-efficacy. The prediction method contributes to identifying the magnitude and direction of the relationship and it is currently recommended (Rensh et al., 2020) when investigating psychological phenomena.

\section{The Relationships between Self-Efficacy, Self-Regulation, and Academic Motivation}

Previous research suggested a dynamic correlation between self-efficacy, self-regulation, and academic motivation. To demonstrate that correlation, Yusuf (2011) employed a model that hypothesized a correlation between these variables. The model was tested on 300 undergraduate students. The analyzed data confirmed that self-efficacy, academic motivation, and self-regulated strategies were significantly correlated. Alafghani and Purwandari (2019) studied the relationship between self-efficacy, academic motivation, self-regulated learning, and academic achievement. The variables were significantly correlated. Students with high self-efficacy and academic motivation were more likely to engage in regulating their learning. Self-regulated learning moderated the relationship between academic motivation and academic achievement.

Consistent with the findings related to the impacts of students' motivation and selfefficacy on self-regulatory strategies, Prat-Sala and Redford (2010) examined the correlation between intrinsic and extrinsic motivation, self-efficacy, and studying approaches. They found that intrinsic and extrinsic motivation influenced the selectiveness of study approaches. A high level of motivation drives systematic approaches to studying. In addition, students' self-efficacy influenced their approach to study—low self-efficacy leads students to avoid deep approaches to studying. In contrast, Arik (2019) suggested that self-efficacy is a core predictor of university 
students' academic motivation, self-control, and self-management. However, academic motivation was not a determinant of self-control and self-management among university students.

Taking a different perspective, Saeid and Eslaminejad (2017) examined the role of selfdirected learning in predicting self-efficacy and academic motivation. Self-directed learning in the study comprised positive self-concept, independence in learning, informed acceptance, responsibility for learning, love of learning, creativity, positive view of the future, accepting learning, study and problem-solving skills (including some metacognitive, self-regulatory skills). They found that (1) self-directed learning was significantly correlated with both self-efficacy and academic motivation; (2) the independence in learning factor was the best predictor of a student's self-efficacy; and (3) skills such as studying and problem-solving were the best predictors of academic motivation.

The first procedure of the forethought phase within the self-regulatory process is goal settings. Goal setting plays a crucial role in academic motivation (Bandura, 1991; Zimmerman \& Moylan, 2009). Researchers examined a variety of goal orientations that influence academic motivation. AL-Baddareen et al. (2014) examined the effect of self-efficacy, goal achievement (mastery goals and performance goals), and metacognition on academic motivation among university students. The researchers hypothesized that the relationship between achievement goals and academic motivation is mediated by metacognition and self-efficacy. The analysis indicated that all independent variables and the dependent variable were significantly correlated. However, performance goals had no correlation with self-efficacy and a weak correlation with the other variables, even though it was significant. The combination of metacognition, mastery goals, performance goals, and self-efficacy significantly predicted academic motivation. Among 
these variables, mastery goals and metacognition were significant predictors of students' academic motivation, whereas self-efficacy and performance goals had no significant contribution in predicting academic motivation.

In contrast, self-efficacy was a significant predictor of academic motivation in a study by $\mathrm{Ng}$ (2012). The study investigated the role of self-efficacy, control beliefs, and four types of achievement goals (mastery development goals, extrinsic work goals, performance-approach goals, and social enhancement goals) on the learning performance of university students enrolled in a distance course. The study hypothesized that self-efficacy and control beliefs mediate the effect of achievement goals on learning strategies and students' attitude toward learning. Students' attitude referred to the sense of interest, enjoyment, and perceived value of doing a course. Findings indicated that self-efficacy and control beliefs significantly predict learning strategies, regulatory strategies, and attitudes toward learning. Therefore, self-efficacious students who believe they controlled the learning outcomes tended to utilize deep strategies, regulate their skills, manage their effort, and seek help when needed. Those students show a positive attitude toward learning through expressing their interests and enjoyment and valuing what they are learning.

To enhance self-efficacy and academic motivation, Yuka (2017) conducted an experimental study to identify the effect of goal setting (goal commitment, google difficulty, and goal specificity), intrinsic motivation, and self-efficacy in extensive reading among undergraduate students enrolled in the Business Administration and Economics departments. The study involved students in the extensive reading program (ER), which includes 170 books of both graded and leveled readers. The ER program consisted of 12 sessions each lasting twenty minutes during which students chose books independently. At the beginning of each session 
students filled in two sheets: ER record and self-evaluation. They wrote their goals, the number of words they expected to read, and commented on the content. On the self-evaluation sheet they wrote what they had accomplished compared to their goals and evaluated their progress, as well as what challenges or obstacles they encountered. The ER program included metacognitive selfregulation strategies such as goal setting, self-monitoring, and self-evaluation. The results revealed that goal difficulty and goal commitment have a direct effect on intrinsic motivation whereas goal specificity did not. The modified model demonstrated that goal specificity has no direct effect on both intrinsic motivation and self-efficacy. In addition, goal commitment was the only variable among goal setting variables that had a direct influence on self-efficacy. Thus, goal commitment can be considered an important factor or the best predictive factor of intrinsic motivation and self-efficacy.

The self-reflective phase is the process of self-evaluation and causal attribution that affect the adoption of new behavior (Zimmerman, 2009). Wang, Chen, et al. (2017) implemented selfreflection intervention to improve college students' positive thinking (self-confidence, selfsatisfaction, optimism, and appreciation), self-regulation, and academic motivation. The researchers measured self-confidence in terms of students' beliefs in their capabilities to master a task. The analysis of the study demonstrated that self-reflection intervention was effective in improving positive thinking, learning motivation, and self-regulation. Most importantly, these three variables were directly and significantly related to each other (Wang, Chen, et al., 2017). In addition, Lavasani et al. (2011) conducted an experimental study to predict self-efficacy, academic motivation, and academic achievement via self-regulation strategies. The selfregulation strategies program included instructing students how to set goals, monitor progress, assess behaviors, create a well-established environment, and make information meaningful. After 
the implementation, the researchers examined the effectiveness of the program on self-efficacy, academic motivation, and academic achievement. The results of the study indicated that students who received self-regulatory strategies training showed high levels of self-efficacy, academic motivation, and academic performance compared to a control group that did not receive training on the program (Lavasani et al., 2011).

In the realm of education, it is recommended that educators adopt an autonomoussupportive environment that facilitates the transition of extrinsic motivation into internalized motivational forces (Deci \& Ryan, 2008). Duchatelet and Donche (2019) conducted a study that suggests that the type of academic motivation, whether autonomous motivation or controlled motivation, should be accounted for in higher education when developing self-efficacy and selfregulation. Therefore, the study examined the correlation between academic motivation, selfefficacy, and self-regulation. It also investigated how students' perceived autonomy support influenced the relationship between self-efficacy, self-regulation, and academic motivation. The data were collected from 230 bachelor's degree students at a Dutch university. The SEM indicated that autonomous motivation was significantly correlated with self-efficacy and selfregulation. However, controlled motivation was not significantly correlated with self-efficacy and self-regulation. Amotivation was negatively correlated with self-efficacy. In addition, the assessment of the contribution of students' perceived autonomy support demonstrated that the behavior of autonomy-supportive teachers was positively correlated with autonomous motivation, but negatively correlated with amotivation. A perceived autonomy-supportive teacher was significantly related to self-efficacy, but not to self-regulation. The results, after eliminating non-significant baths, demonstrated that autonomous motivation has a direct relationship with self-efficacy and self-regulation. Most importantly perceived autonomy- 
supportive instruction mediated the relationship between academic motivation and self-efficacy, but it has no mediated role in the correlation between academic motivation and self-regulation. An active learning environment where students have freedom of choice, get quizzes, and participate in group discussions were recommended by previous research, but these findings determine the role of academic motivation in the way students perceived autonomy-supportive instruction. Amotivated students seem not applicable to such learning environments where only autonomous motivated students can benefit from autonomy-supportive environments to enhance their self-efficacy and self-regulation.

According to a study by Vallerand et al. (1992), amotivated students believe that they have no control over their actions, and thus attribute their performance outcome to something beyond their control. In addition, motivation has been found to be negatively associated with persistence. Hence, amotivated students have poor ability of effort regulation so they easily quit whenever difficulties and obstacles occur. These findings affirm the hypothesis that control beliefs/locus of control is imperative in forming motivational systems and self-regulatory mechanisms. Researchers found that internal locus of control predicts self-regulation among college students (Sidola et al., 2020). One study investigated the relationships between selfregulation and locus of control (individuals' belief that they have control over their actions and the consequences). The study also sought to identify the predicting role of self-regulation and the locus of control in willingness to communicate among 222 undergraduate English foreign language learners. The findings revealed a significant correlation between self-regulation, locus of control, and willingness to communicate. Students who use regulatory strategies take responsibility and believe that their internal factors control their performance. The locus of 
control played a significant role in predicting students' willingness to communicate rather than in self-regulation (Arkavazi \& Nosratinia, 2018).

Current thinking calls for the prediction method regarding the psychological processes of students' activities to better understand effective practices that will help in developing academic motivation and self-regulation (Rensh et al., 2020). However, not much research has been done in the predictive method (AL-Baddareen et al., 2014; Arik, 2019). Most research used correlation and experimental design (Lavasani et al., 2011; Wang, Chen, et al., 2017; Yuka, 2017). This study should fill in the research gap regarding the prediction of academic motivation, selfregulation, and self-efficacy in the United States because most research was conducted in other countries.

\section{Conclusion}

Academic motivation plays a crucial role in students' academic success. SDT researchers differentiate between intrinsic motivation and extrinsic motivation. Because intrinsic motivation enhances students' involvement in educational activities, researchers recommend an autonomous-supportive education system that helps students to internalize their extrinsic motivational factors (Ryan \& Deci, 2020). Promoting a sense of autonomy demands enhancing the abilities of students to regulate cognitive, emotional, and behavioral responses as well as their beliefs in their ability and controllability.

SCT suggests a reciprocal correlation between self-regulation, motivation, and selfefficacy (Bandura, 1991). Research supports the cyclical model of self-regulation. Ning and Dawning (2010) found such a correlation where both self-regulation and achievement affect are influenced by the other variable. There is evidence that academic motivation affects selfregulation (Alafghani \& Purwandari, 2019; Ariani, 2016); whereas other studies demonstrated 
that self-regulation predicts students' motivation (Mirhossini et al., 2018; Saki \& Nadari, 2018). Self-efficacy also predicts self-regulation and academic motivation (Alafghani \& Purwandari, 2019; AL-Baddareen et al., 2014, Arik, 2019).

The purpose of this research review was to help the reader understand the relationships between self-regulation, self-efficacy, and academic motivation. The connections between these variables supported the conceptual model hypothesized in the current study. Students' beliefs in their capabilities and their abilities to regulate learning processes influence academic motivation. This is significant because undergraduate students who lack motivation experience academic difficulties and may drop out of school. More research and testing are required to gain a better understanding of why undergraduate students' motivation declined and which psychological factors affect their academic motivation. Helping students to form efficacious beliefs and to regulate their emotions, behaviors, and cognitions is extremely important in Western society where the lack of studies in this field was noticeable. 


\section{CHAPTER 3}

\section{METHODOLOGY}

\section{Introduction}

This study utilized a model based on SCT. The model hypothesized that self-efficacy (control for learning beliefs, self-efficacy of learning) and self-regulation (metacognitive selfregulation, time and study environment management, and effort regulation) predict academic motivation (intrinsic motivation, extrinsic motivation, and amotivation).

\section{Type of Study}

I used a non-experimental quantitative methodology and deductively developed a theoretical model based on SCT and SDT and previous studies to determine the relationship between self-regulation, self-efficacy, and academic motivation (Figure 2, p. 28). The correlation design was adopted because the study aimed to look at the relationship between the variables through predictive correlation design to examine the variance of one variable based on the variance of other variables. Specifically, model-testing design was adopted because the study examined a theoretical model which proposed that self-regulation and self-efficacy predict students' academic motivation. To collect an adequate number of participants in a relatively short time, the survey method was chosen.

\section{Population and Sample}

For fall 201816.6 million students—56\% female, and 44\% male—enrolled in institutions of higher education in the United States (Hussar et al., 2020). The students were 8.7 million White (not of Hispanic origin), 3.4 million Hispanic, 2.1 million Black, 1.1 million Asian, 0.6 million non-residents, and .6 million two or more other races.

A non-probability sampling method was used because samples were selected according 
to the researcher's subjective judgment. The study is based on convenience or accidental sampling. Participants were selected based on availability. The surveys were hosted online through QuestionPro, hence the sample was limited to those who have access to and were willing to use the internet. The scales of the study are as follows: (1) self-reported demographic information questionnaire; (2) 24 items measuring self-regulation; (3) 14 items measuring selfefficacy; and (4) 28 items measuring academic motivation. I chose the sample size by adding the number of the items on the three surveys and multiplying that total by five (number of participants for each item). Research suggested a sample size between 5-10 for each item (Hair et al., 2010). Accordingly, the suitable size for this study was 330 participants - 349 students participated which was adequate for conducting SEM.

\section{Research Hypotheses}

The main hypothesis of this study was that the reproduced covariance matrix proposed in the theoretical model and the observed sample covariance matrices were equal. In simple terms, this means that the structural model would be a good fit with the observed data. Using the conceptualized model depicted in Figure 2 (p. 28), this study hypothesized (1) there is a significant correlation between the two exogenous variables, self-regulation, and self-efficacy; (2) self-regulation has a significant direct effect on the endogenous variable academic motivation; (3) self-efficacy has a significant direct effect on the endogenous variable academic motivation.

\section{Definition of Variables}

\section{Academic Motivation}

Academic motivation (AM) was conceptually defined as the intrinsic or extrinsic orientation (reasons) that drives one to engage in a behavior. It is the interest or the will that 
drives students to accomplish academic goals. This was a latent variable measured by external regulation, introjected regulation, identified regulation, intrinsic motivation-knowledge, intrinsic motivation-accomplishment, intrinsic motivation-stimulation subscale, and amotivation (Vallerand et al., 1992). The latent variable was measured by scores on 28 items taken from the AMS.

External regulation (ExME) was conceptually defined as factors that drive behavior to obtain rewards or avoid punishment (Vallerand et al., 1992). It was instrumentally defined by four items (Q18, Q31, Q33, Q45). The scale included items such as "In order to obtain a more prestigious job later on." For the operational definition, items 18, 31, 33, and 45 which measured external regulation were scored using a 7-point Likert scale. The values for scoring ranged from one (does not correspond at all) to seven (corresponds exactly). The score was obtained by summing up the responses to each item. The minimum score for the Scale was four and the maximum was 28 .

Introjected regulation (ExMN) was conceptually defined as the tendency to engage in a behavior to improve self-esteem or avoid anxiety and sense of guilt (Vallerand et al., 1992). It was instrumentally defined by four items (Q24, Q30, Q37, Q43). The scale included items such as "To prove to myself that I am capable of completing my college degree." For the operational definition, items 24, 30, 37, and 43 were scored using a 7-point Likert scale. The values for scoring ranged from one (does not correspond at all) to seven (corresponds exactly). The score for the scale was obtained by summing up the responses to each item. The minimum score for the Scale was four and the maximum 28.

Identified regulation (ExMD) was conceptually defined as the reason for the engagement was not fully external but regulating behavior becomes relatively due to its value and personal 
reasons (Vallerand et al., 1992). It was instrumentally defined by four items (Q20, Q44, Q26, Q39). The scale included items such as "Because I believe that a few additional years of education will improve my competence as a worker." For the operational definition, items 20, 44, 26, and 39 are scored using a 7-point Likert scale. The values for scoring range from one (does not correspond at all) to seven (corresponds exactly). The score for the scale is obtained by summing up the responses to each item.

Intrinsic motivation-knowledge (InMK) is conceptually defined as the pleasure and satisfaction individuals experience when they learn, understand, and explore new things (Vallerand et al., 1992). It was instrumentally defined by four items (Q19, Q25, Q32, Q38). The scale included items such as "For the pleasure I experience when I discover new things never seen before." For the operational definition, items 19, 25, 32, and 38 were scored using a 7-point Likert scale. The values for scoring ranged from one (does not correspond at all) to seven (corresponds exactly). The score for the scale was obtained by summing up the responses to each item.

Intrinsic motivation-accomplishment (InMC) was conceptually defined as the pleasure and satisfaction individuals experience when accomplishing something (Vallerand et al., 1992). It was instrumentally defined as four items (Q23, Q29, Q36, Q42). The scale included items such as "For the satisfaction I feel when I am in the process of accomplishing difficult academic activities." For the operational definition, items 23, 29, 36, and 42 were scored using a 7-point Likert scale. The values for scoring ranged from one (does not correspond at all) to seven (corresponds exactly). The score for the scale was obtained by summing up the responses to each item. 
Intrinsic motivation-stimulation (InMS) was conceptually defined as engaging in activities because of the experience of excitement, enthusiasm, or aesthetic experience (Vallerand et al., 1992). It was instrumentally defined as four items (Q21, Q27, Q34, Q40). The scale included items such as "For the intense feelings I experience when I am communicating my own ideas to others." For the operational definition, items 21, 27, 34, and 40 were scored using a 7-point Likert scale. The values for scoring ranged from one (does not correspond at all) to seven (corresponds exactly). The score for the scale was obtained by summing up the responses to each item.

Amotivation (AMOT) was conceptually defined as individuals' tendency to disengage in activities or actions as a result of the absence of desire or the lack of valuing an outcome (Ryan \& Deci, 2000). It was instrumentally defined as four items (Q22, Q28, Q35, Q41). The scale included items like "I don't know; I can't understand what I am doing in school." For the operational definition, items $22,28,35$, and 41 were scored using a 7 -point Likert scale. The values for scoring ranged from one (does not correspond at all) to seven (corresponds exactly). The score for the scale was obtained by summing up the responses to each item.

\section{Self-regulation (SR)}

SR was defined as the metacognitive strategies by which students control and regulate their cognition, effort, time, and environment resources (Garcia \& McKeachie, 2005). This was a latent variable measured by metacognitive self-regulation, time and study environment management, and effort regulation (Pintrich et al., 1993). The latent variable SR was measured by scores on 24 items from MSLQ scales (Pintrich et al.,1993). Self-regulation included three subscales: metacognitive self-regulation, time and study environment management, and effort regulation. Responses to all items were summed to obtain the total score for the SR Scale. 
Metacognitive self-regulation (SMR) was conceptually defined as students' abilities to regulate and control their cognitive strategies including planning, monitoring, and regulating abilities (Pintrich et al., 1993). Metacognitive self-regulation was instrumentally defined as 12 items (MQ1-MQ12) that measured metacognitive self-regulation, where MQ1 and MQ8 were reversed items. The metacognitive self-regulation scale included items such as "If course materials are difficult to understand, I change the way I read the material" in a positive direction and others like "During class time I often miss important points because I'm thinking of other things" in a negative direction. For the operational definition, items MQ1-MQ12 measured metacognitive self-regulation were scored using a 7-point Likert scale. The values for scoring ranged from one (not at all true of me) to seven (very true of me). The score for the scale was obtained by summing up the responses to each item.

Time and study environment (SRTE) conceptually represented the effective use of study time and environment including daily, weekly, and monthly plans and schedules as well as the tendency to avoid distraction and prepare a quiet and organized study environment (Pintrich, et al.,1993). It was instrumentally defined as eight items TQ1-TQ8, where three items were reversed (TQ3, TQ7, TQ8). This scale included items such as "I usually study in a place where I can concentrate on my coursework" in a positive direction and others like "I find it hard to stick to a study schedule" in a negative direction. For the operational definition, items TQ1 through TQ8 were scored using a 7-point Likert scale. The score ranged from one (not at all true of me) to seven (very true of me). The score for the scale was obtained by summing up the responses to each item.

Effort regulation (SREF) was conceptually defined as students' abilities to manage themselves during learning despite the obstacles and difficulties that they may encounter to 
achieve desired goals (Pintrich, et al.,1993). It was instrumentally defined as four items (FQ1FQ4), where FQ1 and FQ3 were reversed items. This scale included items such as "I work hard to do well in the class even if I don't like what we are doing" in a positive direction and others like "When coursework is difficult, I give up or only study the easy parts" in a negative direction. For the operational definition, items QF1-QF4 were scored using a 7-point Likert scale. The values for scoring ranged from one (not at all true of me) to seven (very true of me). The score for the scale was obtained by summing up the responses to each item. The score ranged from four to 28 .

\section{Self-efficacy (SE)}

Self-efficacy (SE) referred to students' beliefs that their efforts to learn would result in positive outcomes. Self-efficacy included judgments about one's ability to accomplish a task and one's confidence in one's skills to perform that task (Pintrich et al., 1993). This was a latent variable measured by control of learning beliefs and self-efficacy for learning and performance (Pintrich et al., 1993). The latent variable SE was measured by scores on 12 items from the MSLQ scales. The scale included two subscales: control of learning beliefs and self-efficacy for learning and performance. Responses to all items were summed to obtain the total score for the SR Scale.

Control of learning beliefs (SEC) was conceptually defined as students' beliefs in the role of effort in which the reason for successful outcome will be attributed to the extent of effort rather than external factors such as luck or teachers (Pintrich et al.,1993). It was instrumentally defined as four items CQ1-CQ4 from the MSLQ (Pintrich et al., 1993). This scale included items such as "If I try hard enough, then I will understand the course material." For the operational definition, items CQ1-CQ4 were scored using a 7-point Likert scale. The values for 
scoring ranged from one (not at all true of me) to seven (very true of me). The score for the scale was obtained by summing up the responses to each item. The score ranged from four to 28 .

Self-efficacy for learning and performance (SELP) was conceptually defined as individuals' expectancy for success and confidence about personal capabilities to accomplish a task (Pintrich et al., 1993). It was instrumentally defined as 8 items (LQ1-LQ8). This scale included items like "I'm confident I can do an excellent job on the assignments and tests in the course." For the operational definition, items LQ1-LQ8 were scored using a 7-point Likert scale. The values for scoring ranged from one (not at all true of me) to seven (very true of me). The score for the scale was obtained by summing up the responses to each item. The minimum score for the scale was 8 and the maximum 56 .

\section{Instrumentation}

The instruments utilized by this study comprised four sections. Section one elicited selfreported demographic information including age, gender, ethnicity, and employment. The other three sections assessed academic motivation, self-efficacy, and self-regulation respectively. Academic motivation was measured by conducting the AMS college version (Vallerand et al., 1992). The scale was translated from a French measure of motivation which was developed based on SDT. It consisted of seven subscales (External regulation, Introjected regulation, Identified regulation, Intrinsic motivation-knowledge, Intrinsic motivation-accomplishment, Intrinsic motivation-stimulation, and Amotivation) each contained four items, totaling 28 . It is a self-report questionnaire on a 7-point Likert scale from one (Does not correspond at all) to seven (Corresponds exactly). Researchers conducted confirmatory factor analysis (CFA), internal consistency, and test-retest of the seven subscales to investigate the psychometric analyses (Vallerand et al., 1992). They conducted one study on 745 university students. The internal 
consistency of the subscales was high, ranging from .83 to .86 except for the identification subscale $(\alpha=.62)$. The researchers also conducted another study on 75 university students to assess temporal stability where test-retest results showed acceptable reliability in a period of one month. The score ranged from .72 to .78 . with a mean test-retest correlation of .79 . These results were identical to the original French-Canadian version.

Data were collected by utilizing the MSLQ (Pintrich et al., 1993). This self-report questionnaire was developed based on a cognitive-social perspective with a consideration of the dynamic correlation between motivation and the use of learning strategies. The questionnaire was designed to assess college students' motivation and learning strategies including cognitive and metacognitive strategies. During the process of developing the scales, between 1982-1986, the researchers developed 50-140 items that have been administered to more than 1,000 undergraduate students. The last version of the questionnaire consisted of a motivation section and a learning strategy section with a total of 15 subscales. The questionnaire consisted of 81 items ranging from one (not at all true of me) to seven (very true of me) and can be scored on a 7-point Likert scale. The motivation section was developed on three main constructsexpectancy, value, and affect. It contained six subscales. The learning strategy section is based on three main constructs—cognitive, metacognitive, and resource management. The MSLQ includes 15 scales, each of them measuring different aspects. According to Garcia and McKeachie (2005) the questionnaire is modular and can be conducted according to the instructors' or researchers' purpose:

The MSLQ is not a fixed entity being sold by a publisher; it is in the public domain, and we have always intended that the MSLQ be used in whatever ways will meet the needs of potential users. Accordingly, we encourage users to use the MSLQ in its entirety or to 
select whatever subscales are relevant for their purposes, in whatever format is most practical. (p.120)

The psychometric analyses showed the questionnaire has good reliability and validity. The researchers conducted CFA and they checked the predictive validity (Pintrich et al., 1993). The internal consistency for self-efficacy scales were robust, having scales of .93 on the coefficient alpha. Learning strategies scales demonstrated acceptable reliability where most of the coefficient alpha were above .70 . The researchers, through predictive analyses, found that the motivational scales, including self-efficacy scales, were correlated to students' performance and final grade - those who had high self-efficacy performed better on the final grade. The learning strategies construct scales were also found to have a significant correlation with academic performance and final grade. Students who tended to utilize deep cognitive processes were more likely to achieve higher than those who scored low on the learning strategies scales. The correlation between the self-efficacy subscales were good $(r=.44)$; so also, the correlation between the learning strategies scales which ranged between $(r=.58$ to $r=.70)$.

\section{Data Collection}

Before collecting the data, the researcher obtained approval from Andrews University's Institutional Review Board (Appendix A). QuestionPro hosted the surveys online. Participants were provided with an informed consent form (Appendix B) which (1) explained the purpose of the study and the significant role of their cooperation; (2) assured the participants of their right to withdraw without penalty; (3) demonstrated that their data and information would be secureonly the researcher and her committee members would have access to the data. The data were collected, they were transferred into Excel and SPSS. 


\section{Analysis of the Data}

SPSS and IBM SPSS Amos were used for statistical analysis. The research aimed to investigate if the hypothesized model, which suggested the role of self-regulation and selfefficacy in predicting academic motivation, fitted the data. Therefore, the null hypothesis stated that the structural covariance matrix was equivalent to the empirical covariance matrix. SEM was conducted, particularly the maximum likelihood estimation (MLE). SEM is a series of statistical methods that explains the relationship between multiple independent variables with multiple dependent variables. SEM is a confirmatory technique that contains a combination of factor analysis and multiple regression that will assess both measurement and structural relationships.

\section{The Advantages of Using SEM}

SEM was suitable because of its ability to determine complex theoretical structures with multiple dependent variables. The technique allows for identifying the correlation and also explaining if the variance is possible. A significant feature of SEM is that it accounts for measurement errors.

\section{Creating a Data File}

I created a data file in Excel and SPSS using the data from QuestionPro software.

\section{Screening the Data}

Before conducting SEM, SPSS was used to screen the data to check for and deal with outliers, missing data, missing values. Any case of missing value was deleted because the sample was large enough and the deletion did not affect the statistical power.

\section{Developing the Model Specification}

The data were cleaned, and the hypothesized model developed by IBM SPSS Amos (path diagram). Ovals or circles represent latent variables, while rectangles or squares represent 
measured variables. Residuals are always unobserved, so they are represented by ovals or circles. The correlations and covariances are represented by bidirectional arrows, which represent relationships without an explicitly defined causal direction.

\section{Assessing Model Fit}

First, the measurement model was tested using CFA which tests the relationships between factors and latent variables or between latent variables and other latent variables, but not does not identify direction. Once the measurement model indicates a good fit, the structural model can be tested. Second, path analysis was conducted to run the structural model; and Observed Variable Path Analysis (OVPA) tested the relationships among constructs represented by direct measures (observed variables), which were the items or subscale. Next, Latent Variable Path Analysis (LVPA) which simultaneously tested measurement and structural parameters CFA and OVPA was done. This analysis incorporated the relationship between observed and latent variables (measures and factors), relationships between latent variables, and errors and residuals that were left over from the prediction.

The null hypothesis was analyzed using the absolute fit indices and relative fit indices. The common absolute fit indices, Model x2, should be non-significant when $p>.05$ indicating a good fit. For Root Mean Squared Error of Approximation (RMSEA), an acceptable fit would be $<.10$; and a good fit <.05. For the Standardized Root Mean Squared Residual (SRMR) values below .08 suggest a good fit (Keith, 2019). A Goodness of Fit Index (GFI) > .90 is considered a good fit. Common relative fit indices including Normed Fit Index (NFI), Incremental Fit Index (IFI), and Comparative Fit Index (CFI) all range from 0-1; generally, values > .90 are considered good (Meyers et al., 2016). 


\section{Model Modification}

If the model does not indicate a good fit with the data, it can be improved to fit the data. The modification would be through checking the modification indices and connecting the suggested errors if they are logically correlated. 


\section{CHAPTER 4}

\section{RESULTS}

\section{Introduction}

The study hypothesized that self-regulation and self-efficacy predict academic motivation among university students. The hypothesized model suggested self-regulation and self-efficacy predict academic motivation. Self-regulation was measured by (a) metacognitive regulation (SRM), (b) time and study environment management (SRTE), and (c) effort regulation (SREF). Self-efficacy was indicated by (a) control of learning beliefs (SEC), and (b) selfefficacy of learning and performance (SELP). The outcome variable, academic motivation, was indicated by (a) Intrinsic motivation to know (InMK), (b) Intrinsic motivation to accomplishment (InMC), (c) Intrinsic motivation to experience stimulation (InMS), (d) External regulation (InME), (e) Introjected regulation (InMN), (f) Identified regulation (InMD), and (g) Amotivation (AMOT).

This chapter discusses the sample, demographic characteristics, descriptive statistics of the measurement variables, procedure of the analysis to test the hypothesis, and results of the original SEM as well as the adjusted model. The last section summarizes the chapter.

\section{Data Screening}

A total of 1,582 persons viewed the link to the survey. Viewers who were not undergraduate students aged 18-22 years old were excluded and 352 participants completed the survey. After screening the data, three cases were eliminated because of some missing data. The remaining 349 participants were included in the analysis.

\section{Demographic Characteristics}

The 349 participants were undergraduate students 18-22 years old. The participants were 
$80.2 \%$ female $(N=280)$ and $19.8 \%$ male $(N=69)$ (Table 1$)$. The majority of the students were Caucasian or White (62.2\%), 10.6\% Black or African American, 10.6\% Asian, 8.9\% Hispanic or Latino, 3.4\% Multiracial, and 1.4\% American Indian or Alaska Native (Table 1). Among the participants $73.3 \%$ were unemployed, $18.9 \%$ were employed part-time, and $7.7 \%$ were employed full-time (see Table 1).

Table 1

Demographic Characteristics of Participants in the Data

\begin{tabular}{llrr}
\hline Variable & & $\mathrm{N}$ & $\%$ \\
\hline Gender & & 69 & 19.8 \\
& Male & 280 & 80.2 \\
& Female & 349 & 100 \\
& Total & & \\
& & & \\
& & 27 & 7.7 \\
& Full-time employment & 66 & 18.9 \\
& Part-time employment & 7 & 2 \\
& Unemployed & & \\
& Student & 249 & 71.3
\end{tabular}

Ethnicity

Hispanic or Latino

$31 \quad 8.9$

American Indian or Alaska Native

$5 \quad 1.4$

Asian

Black or African American

10.6 


\begin{tabular}{|c|c|c|c|}
\hline \multicolumn{2}{|l|}{ Variable } & $\mathrm{N}$ & $\%$ \\
\hline & $\begin{array}{l}\text { Native Hawaiian or Other Pacific } \\
\text { Islander }\end{array}$ & 2 & 0.6 \\
\hline & Caucasian or White & 217 & 62.2 \\
\hline & Multiracial & 12 & 3.4 \\
\hline & Other & 1 & 0.3 \\
\hline & Prefer not to say & 7 & 2 \\
\hline & Total & 349 & 100 \\
\hline
\end{tabular}

\section{Observed Variables Description}

Table 2 presents the descriptive statistics of the observed variables including means and standards deviations. Metacognitive self-regulation $(M=4.25, S D=0.86)$, time and study environment management $(M=4.48, S D=0.74)$, effort regulation $(M=4.15, S D=0.79)$, control of learning beliefs ( $M=4.24, S D=1.04)$, self-efficacy of learning and performance ( $M=$ 5.03, $S D=1.07)$, extrinsic motivation external regulation $(M=5.31, S D=1.19)$, extrinsic motivation identified $(M=5.53, S D=1.12)$, extrinsic motivation integrated $(M=5.17, S D=$ 1.33), intrinsic motivation to know $(M=5.01, S D=1.24)$, intrinsic motivation to experience stimulation $(M=3.95, S D=1.39)$, intrinsic motivation to accomplish $(M=4.59, S D=1.32)$, and amotivation $(M=2.77, S D=1.67)$.

\section{Zero-Order Correlations}

Table 2 indicates that some variables have statistically significant correlations where $p$ values were less than .05 . The majority of the correlations between the observed variables were weak or moderate. Other correlations were not statistically significant: (1) between extrinsic motivation external regulation (ExME) $(r=-.01, p=.85)$ and intrinsic motivation to experience stimulation (InMS); (2) between control of learning beliefs (SEC) and effort regulation (SREF) 


\section{Table 2}

Measured Variables Correlation and Descriptive Statistics

\begin{tabular}{|c|c|c|c|c|c|c|c|c|c|c|c|c|}
\hline & ExME & ExMN & ExMD & InMK & InMC & InMS & AMOT & SMR & SRTE & SREF & SEC & SELP \\
\hline ExME & & $.473 * *$ & $.580 * *$ & $.332 * *$ & $.246 * *$ & -0.01 & $-.287 * *$ & $.120^{*}$ & $.296 * *$ & $.185^{* *}$ & $.162 * *$ & $.344 * *$ \\
\hline ExMN & & & $.523 * *$ & $.546^{* *}$ & $.635 * *$ & $.335^{* *}$ & $-.230 * *$ & $.285^{* *}$ & $.256^{* *}$ & $.263 * *$ & $.156^{* *}$ & $.420 * *$ \\
\hline ExMD & & & & $.579 * *$ & $.486^{* *}$ & $.201 * *$ & $-.521 * *$ & $.298 * *$ & $.458 * *$ & $.323 * *$ & $.133^{*}$ & $.515^{* *}$ \\
\hline InMK & & & & & $.733 * *$ & $.534 * *$ & $-.354 * *$ & $.462 * *$ & $.389 * *$ & $.341 * *$ & $.135^{*}$ & $.542 * *$ \\
\hline InMC & & & & & & $.617 * *$ & $-.224 * *$ & $.485^{* *}$ & $.275^{* *}$ & $.281 * *$ & $.266 * *$ & $.490 * *$ \\
\hline InMS & & & & & & & $.111^{*}$ & $.418 * *$ & 0.096 & 0.092 & $.188 * *$ & $.262 * *$ \\
\hline AMOT & & & & & & & & $-.134^{*}$ & $-.472 * *$ & $-.490 * *$ & $.191 * *$ & $-.346 * *$ \\
\hline SMR & & & & & & & & & $.491 * *$ & $.424 * *$ & $.253 * *$ & $.547 * *$ \\
\hline SRTE & & & & & & & & & & $.678 * *$ & 0.023 & $.543 * *$ \\
\hline SREF & & & & & & & & & & & -0.036 & $.537 * *$ \\
\hline SEC & & & & & & & & & & & & $.359 * *$ \\
\hline Mean & 5.31 & 5.17 & 5.53 & 5.01 & 4.59 & 3.95 & 2.77 & 4.25 & 4.48 & 4.15 & 4.24 & 5.03 \\
\hline SD & 1.18 & 1.32 & 1.11 & 1.24 & 1.32 & 1.38 & 1.67 & 0.86 & 0.73 & 0.79 & 1.03 & 1.07 \\
\hline Skewness & -0.58 & -0.56 & -0.69 & -0.19 & -0.24 & -0.01 & 0.52 & -0.16 & -0.39 & 0.3 & -0.25 & -0.31 \\
\hline
\end{tabular}

$(r=-.03, p=.51)$; and between time and study environment management $(\mathrm{SRTE})(r=.02, p=$ .67). In addition, amotivation (AMOT) had no statistically significant correlation with effort regulation $(\mathrm{SREF})(r=.09, p=.08)$ and time and study environment management $(\mathrm{SRTE})(r=$ 
$.09, p=.07)$. Even though the correlations were found between some variables, they were not high which helped to avoid the problem of collinearity.

\section{Hypotheses Testing}

To examine the null hypotheses, which indicates that the structural covariance matrix is equivalent to the empirical covariance matrix, SEM with Maximum Likelihood estimation (MLE) method was conducted. The SEM that was configured for the present study, based on the data from 349 undergraduate student participants, is shown in Figure 3. It was conducted to investigate the hypothesis that self-regulation and self-efficacy predict academic motivation. All these variables were latent variables in this model. The model specified two direct paths from self-regulation to academic motivation and from self-efficacy to academic motivation. The latent variable of academic motivation, used as the outcome variable in the model, was indicated by seven of the subscales of AMS - intrinsic motivation to know, intrinsic motivation to accomplish, intrinsic motivation to stimulate, extrinsic motivation integrated, extrinsic motivation identified, extrinsic motivation, external regulation, and amotivation. The first exogenous (predictor) latent variable represented self-regulation which was indicated by three indicators - metacognitive self-regulation, time and study environment management, and effort-regulation (Pintrich et al., 1993). The second exogenous, latent variable represented selfefficacy which was indicated by two subscales - control of learning beliefs and self-efficacy of learning and performance.

Fit indices demonstrated a statistically significant Chi-square with a value of $271.569, d f$ $=40, p=.000$, indicating that this hypothesized model did not fit our data because the Chisquare value is very large. $\mathrm{In}$ addition, $\mathrm{GFI}=.875, \mathrm{NFI}=.874$ and $\mathrm{CFI}=.889$, indicated a poor fit because all values were less than 0.9. Most importantly, RMSEA (.129) and SRMR (.090) 


\section{Figure 3}

The Hypothesized Model

Self-Regulation and Self Efficacy as Predictors of Academic Motivation

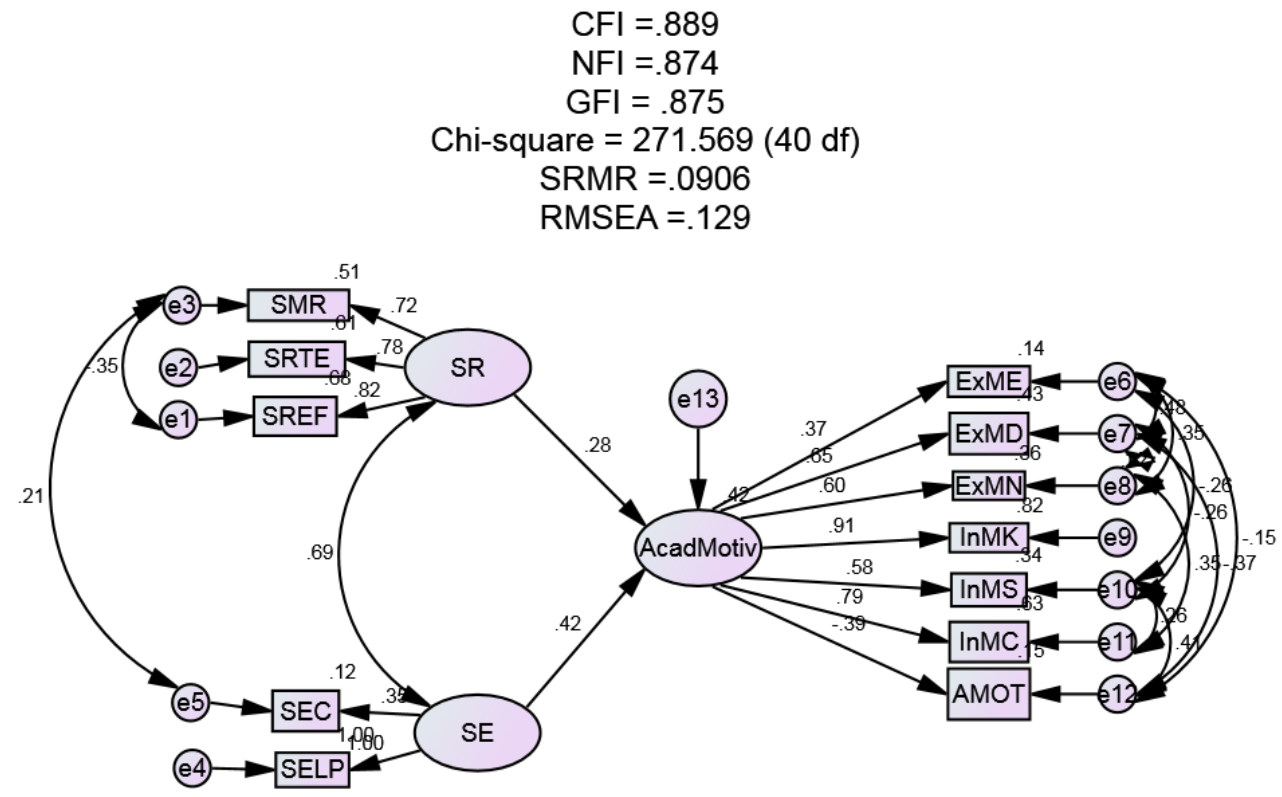

were greater than the optimal fit of .08 or less. Therefore, the data set did not confirm my

hypothesized model. I then adjusted the previous model after an examination of the modification indexes, estimated parameters, regression weight, and standardized regression weight.

\section{The Adjusted Model}

I considered modification indexes and theory before developing an adjusted model. Error term correlation was observed between same scale items, a significant factor loading of SEC and AMOT on SR. Heywood case was observed in SELP and the variance error was fixed to 0.

Finally, a significant error term correlation between SEC and AMOT was included assuming that shared variance between these items was not explained by the model. An adjusted SEM that fit the data much better emerged (see Figure 4). A Chi-square with a value of 187.547, $d f=37, p=$ 
.000 was obtained. However, because of the sensitivity of Chi-square to the sample size and the complexity of the model other fit indices were considered (Schermelleh-Engel et al., 2003, Vandenberg, 2006).

\section{Figure 4}

The Modified Model
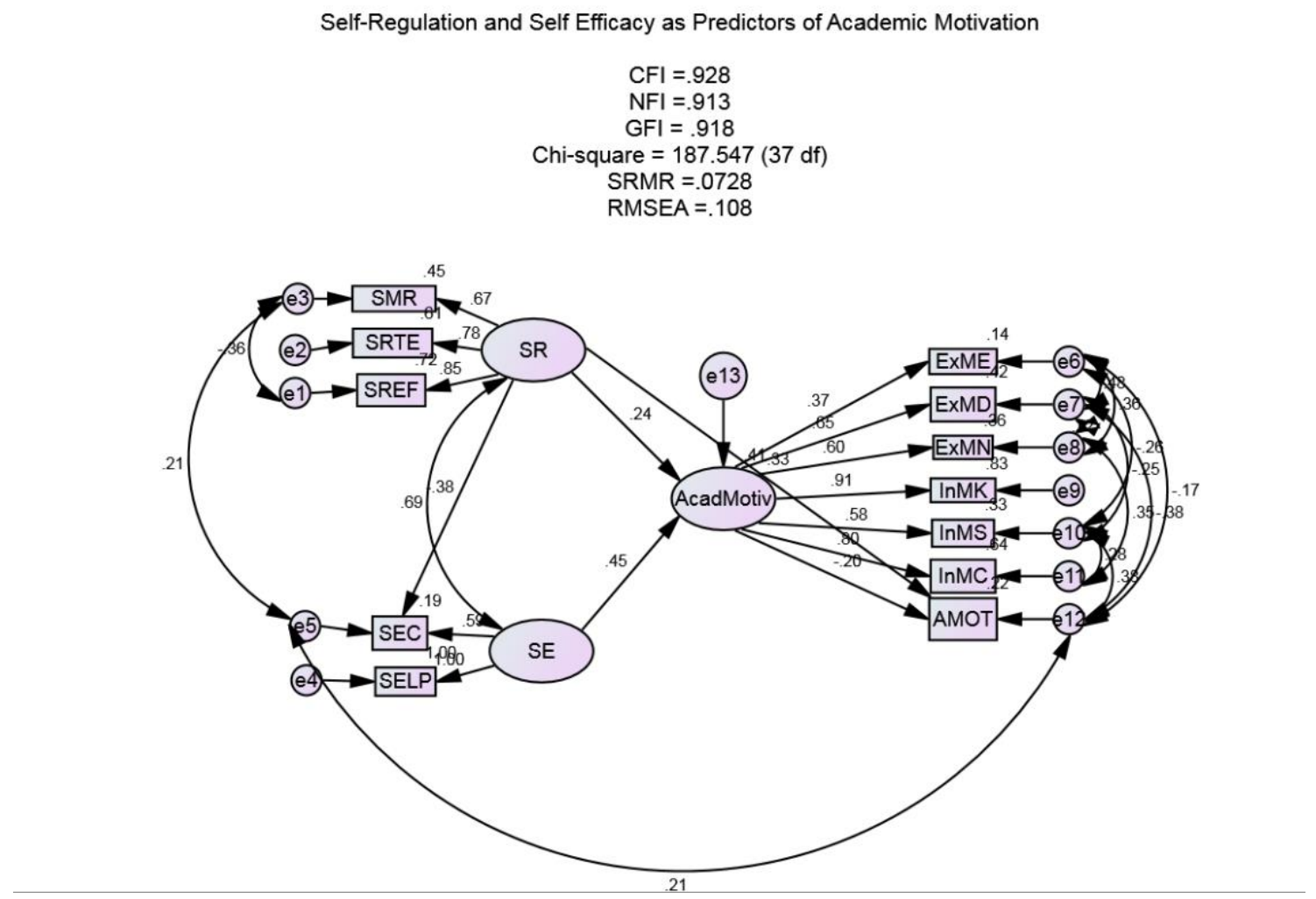

Other fit indices that were significantly better than those in the original model were considered. The GFI improved to .918 , the NFI improved to .913 and the CFI improved to .928 . The RMSEA and SRMR dropped to .108 and .072, respectively, both values were well within an acceptable range. Therefore, this last model adequately fitted the data and was much better than the original SEM. The model configuration accounted for approximately $41 \%(\mathrm{R} 2=.407)$ of the variance of academic motivation. 
In terms of the measurement model, all the pattern coefficients linking the measured variables to their latent variables were statistically significant. In the adjusted model, there were two significant paths between self-regulation (SR) and amotivation (AMOT); and between selfregulation (SR) and control of learning beliefs (SEC). This result was based on the psychometric characteristics of the items used, so self-regulation (SR) was not only the explanation for some proportion of the variance in metacognitive self-regulation (SMR), time and study environment management (SRTE), and effort-regulation (SREF), but also in control of learning beliefs (SEC) and amotivation (AMOT).

The construct model indicated that the exogenous variables were significantly correlated $(r=.69, p<.01)$ as expected. This indicated that self-regulation and self-efficacy have a statistically significant correlation. In addition, the direct path from self-regulation to academic motivation was statistically significant $($ standardized coefficient $=.236$ unstandardized coefficient $=.106$ with a standard error of $.036, p=.003$ ), indicating that self-regulation predicts $(\beta=.24 ; p<.01)$ academic motivation. The direct path from self-efficacy to academic motivation was statistically significant $($ standardized coefficient $=.452$ unstandardized coefficient $=.184$ with a standard error of $.038, p=.00)$. Therefore, self-efficacy $(\beta=.45 ; p<$ $.01)$ was the best predictor of academic motivation. Self-regulation $(\beta=.24 ; p<.01)$ was the lowest predictor of academic motivation. There was a correlation between error five and error 12 indicating that there was some variance between control of learning beliefs and amotivation that could be explained by this model.

\section{Summary of Findings}

The SEM techniques were conducted to determine if the theoretical covariance matrix and the imperial covariance matrix were equal. The hypothesized model for this study did not 
statistically fit the collected data. As a result, some modifications were made to improve the model. The modified model statistically fitted the data $(\mathrm{GFI}=.918, \mathrm{NFI}=.913, \mathrm{CFI}=.928$, RMSEA $=.108$ SRMR $=.072$ ). Self-regulation and self-efficacy have a statistically significant correlation $(\mathrm{r}=.69, p<.01)$. Self-efficacy $(\beta=.45 ; p<.01)$ is the better predictor of academic motivation compared to self-regulation $(\beta=.24 ; p<.01)$.

The results of the study were presented in this chapter. First, the demographic characteristics of the sample, in addition to data screening, were illustrated. Second, the observed variables, including means and standard deviation, were described. Third, the analysis of SEM was demonstrated for both the hypothesized model and the modified model. 


\section{CHAPTER 5}

\section{SUMMARY, FINDINGS, DISCUSSION, CONCLUSIONS, AND RECOMMENDATIONS Introduction}

This chapter summarizes the current study and presents an overview of the purpose of the study, research problem, summary of literature, significance of the study, hypothesis, and methodology. The chapter also provides the findings of the study and discusses the results with reference to the literature review. The last section identifies the limitations which impacted the results, discusses the results of the study, and provides suggestions and recommendations for future research and practice.

\section{Research Problem}

Despite the significant role of academic motivation in students' learning outcomes (Zimmerman, 2008; 2000b) students' motivation decreases over their school years. There is evidence that undergraduate students show low levels of academic motivation and low value of academic materials, self-concept, and formation of mastery-oriented behaviors (Dresel \& Grassinger, 2013; Wang \& Pomerantz, 2009). Amotivated students tend to drop out of school, perform poorly, and disengage from learning activities (Wang \& Pomerantz, 2009). Also,

amotivated students cannot regulate their learning processes (Dresel \& Grassinger, 2013). Deficiency in self-regulation is associated with depression (Eisenberg et al., 2007) and addiction (Kruglanski \& Higgins, 2007). Lack of self-efficacy is correlated with anxiety and depression (Tahmassion \& Moghadam, 2011). It is noteworthy that students with low levels of academic motivation, self-efficacy, and self-regulation produce low levels of academic achievement. Therefore, it is imperative to understand students' academic motivation and the psychological factors that may contribute to developing academic motivation among students. 


\section{Purpose of the Study}

The purpose of the study was to test a theoretical model of the influence of selfregulation and self-efficacy on academic motivation. In particular, a hypothesized model of the relationship between these variables was created and data measuring the self-regulation, selfefficacy, and academic motivation of undergraduate students were collected and analyzed through SEM.

\section{Significance of the Study}

The current study investigated whether self-regulation and self-efficacy predict academic motivation among undergraduate students. Previous studies reported a decline in students' academic motivation over their school years, particularly the first year of university study (Busse \& Walter, 2017; Dresel \& Grassinger, 2013; Rizkallah \& Seitz, 2017). This decline in motivation influenced students' academic achievement or led to dropping out (Wang \& Pomerantz, 2009). The finding of this study will help to explain factors that influence academic motivation. The examination of variables within various domains - cognition, motivation/affect, behavior, and context — enriches the understanding of academic motivation. Variables under investigation in this study contain a variety of components (metacognition, time and study environment management, effort-regulation, self-efficacy beliefs, and motivational factors) that will provide significant information regarding the predicting of academic motivation.

The findings will guide policy makers, curriculum committees, higher education personnel, and faculty to apply strategies that promote students' self-efficacy and self-regulation. The literature suggested predictive correlational research contributes to understanding psychological components such as academic motivation among students (Rensh et al., 2020). The review of previous studies also indicated that most studies of motivation were conducted in 
non-American cultures. Therefore, the current study filled in these gaps by conducting predictive correlation methods to investigate academic motivation among students in the United States.

\section{Research Hypotheses}

The main hypothesis of this study was that the reproduced covariance matrix proposed in the theoretical model and the observed sample covariance matrices were equal. In simple terms, this means that the structural model would be a good fit with the observed data. Using the conceptualized model depicted in Figure 2 (p. 28), this study hypothesized (1) There is a significant correlation between the two exogenous variables, self-regulation and self-efficacy; (2) Self-regulation has a significant direct effect on the endogenous variable academic motivation; (3) Self-efficacy has a significant direct effect on the endogenous variable academic motivation.

\section{Summary of the Literature}

This section provides a brief historical synopsis of the primary variables of this study and concludes with the research outcomes which address the interrelationships among them.

\section{The Relationship Between Self-Regulation and Academic Motivation}

Academic motivation refers to the interest or the will that drive students to accomplish academic goals. Intrinsic motivation refers to the internal desire students have to engage in academic activities, e.g., satisfaction; whereas extrinsic motivation refers to factors such as esteem or reward that enhance students' desires to perform effectively to achieve academic success (Ryan \& Deci, 2000; Vallerand et al., 1992). According to the SDT, motivation is influenced by three main psychological needs-competence, relatedness, and autonomy. An autonomy continuum was established to illustrate the types of motivation and how individuals engage in self-determined behavior instead of controlled behaviors (Deci \& Ryan, 2008). The theorists suggest that academic motivation can be enhanced through the process of 
internalization in which students integrate extrinsically- and intrinsically-motivated behaviors (Deci \& Ryan, 2008; Ryan \& Deci, 2020).

Self-determined students can initiate proper actions and pursue desired outcomes (Deci \& Ryan, 2008; Ryan \& Deci, 2020). Therefore, the ability to regulate one's behaviors, emotions, and cognitive functions are essential to satisfying the sense of autonomy. There was evidence that self-regulated students present high levels of academic motivation (Ariani, 2016; Ning \& Downing, 2010; Valinasab \& Zeinali, 2018). Moreover, self-regulation strategies and academic motivation were positively related to academic achievement (Ariani, 2016; Ning \& Downing, 2010). Students who are highly motivated in academic settings and capable of regulating their learning processes show positive emotions (Valinasab \& Zeinali, 2018), and prefer flexible assessment systems (Ariani, 2016).

\section{The Relationship Between Self-Efficacy and Academic Motivation}

The belief system significantly impacts one's sense of competence (Ryan \& Deci, 2000; Zimmerman, 2000b). SCT emphasizes the dynamic interaction between personal, behavioral, and environmental factors where self-efficacy is a fundamental motive to behave (Bandura, 1991).

Previous studies investigated the relationship between self-efficacy and academic motivation. Results findings found that students who believe in their competence and academic abilities show high levels of academic motivation (Hassankhani et al., 2015). However, students who reported low self-efficacy beliefs are less likely to engage in learning activities and their academic motivation was low (Ball \& Edelman, 2018).

Other studies focus on the impact of self-efficacy and academic motivation on procrastination (Cerino, 2014; Malkoç \& Mutlu, 2018). According to these studies, students who 
procrastinate have low motivation to engage in learning activities and low beliefs in their academic potential.

Engaging in an active learning environment influences students' self-efficacy and academic motivation (Mantasiah \& Yusri, 2018). After implementing Pay It Forward Learning, students developed self-efficacy and academic motivation because they had an active role in the learning processes and connecting with peers during the lessons.

\section{The Relationship Between Self-Efficacy, Self-Regulation, and Academic Motivation}

According to the literature review academic motivation, self-regulation, and self-efficacy are correlated among undergraduate students (Alafghani \& Purwandari, 2019; Yusuf, 2011). Academically motivated students who believe in their abilities tend to regulate their learning process (Alafghani \& Purwandari, 2019); intrinsically motivated students have a deeper approach to learning than extrinsically motivated students (Prat-Sala \& Redford, 2010). Students with mastery-oriented goals and the ability to conduct metacognitive strategies have increased levels of academic motivation (AL-Baddareen et al., 2014). Two experimental studies that aimed to develop self-efficacy and academic motivation through self-regulatory strategies (Lavasani et al., 2011) and goal commitment (Yuka, 2017), provided evidence of the effectiveness of these interventions. Students' positive thinking, self-regulation, and academic motivation were effectively improved via self-reflection intervention (Wang, Chen et al., 2017).

Amotivated students report a lack of control beliefs and persistence (Vallerand et al., 1992). However, students with an internal locus of control perceive themselves as active learners: able to regulate themselves (Arkavazi \& Nosratinia, 2018; Sidola et al., 2020), seek help, manage their effort, show interest and enjoyment, and value the learning tasks ( $\mathrm{Ng}, 2012)$. 


\section{Methodology}

This study adopted a quantitative, non-experimental, model-testing design. The sampling method was convenient because participants were recruited online through QuestionPro. All participants were undergraduate students ages 18 to 22 enrolled in a university in the United States. They responded to self-report surveys including a demographic questionnaire, MSLQ (Pintrich et al., 1993) to measure self-regulation and self-efficacy, and AMS (Vallerand et al., 1992) to assess academic motivation.

After screening and cleaning the data, 349 undergraduate students participated. The data were analyzed by SPSS and AMOS. To examine the prediction role of self-regulation and selfefficacy in academic motivation SEM, maximum likelihood of estimation (MLE) was conducted.

\section{Summary of Demographics}

A total of 349 undergraduate students completed the surveys. Most of the participants were female $(80.2 \%, n=280)$, Caucasian or white $(62.2 \%, n=217)$, and unemployed $(73.3 \%, n$ = 256). The number of Asian students $(10.6 \%, n=37)$ and Black or African American $(10.6 \%, n$ $=37)$ students were equal. They were followed by the White Hispanic or Latino $(8.9 \%, n=31)$

and Multiracial $(3.4 \%, n=2)$. The lowest ethnic groups were American Indian or Alaska Native $(1.4 \%, n=5)$ and Native Hawaiian or other Pacific Islander $(0.6 \%, n=2)$. The remaining participants did not specify their ethnic identity $(2.3 \%, n=8)$.

\section{Summary of Findings}

The current study hypothesized that self-regulation and self-efficacy predict students' academic motivation. SEM technique was conducted to examine whether the theoretical covariance matrix is equivalent to the empirical covariance matrix. Analysis of the data indicated that the initial model (Figure 3,76) did not fit the data, where Chi-square value was 271.569, $d f$ 
$=40, p=.000$, and poor fit indices were found $(\mathrm{GFI}=.875, \mathrm{NFI}=.874, \mathrm{CFI}=.889, \mathrm{RMSEA}=$

$.129 . \mathrm{SRMR}=.090)$. Therefore, an exploratory analysis was conducted, and some modifications were made based on modification indices and theory to improve the fit indices.

\section{Adjusted Model}

The modifications made included correlating error terms between same scale items, identifying the significant factor loading of SEC and AMOT on SR. Also, in Heywood case that was observed in SELP, the variance error was fixed to 0. Last, correlating error term between SEC and AMOT was made. As a result, the adjusted model (Figure 4, p. 77) showed an acceptable fit between the theoretical covariance matrix and the empirical covariance matrix $(\mathrm{GFI}=.918, \mathrm{NFI}=.913, \mathrm{CFI}=.928, \mathrm{RMSEA}=.108$, and $\mathrm{SRMR}=.072)$, indicating that the data fitted the hypothesized model. Overall, the adjusted model explained $41 \%$ of the variance of academic motivation, in which self-efficacy $(\beta=.45 ; p<.01)$ was the better predictor of academic motivation compared to self-regulation $(\beta=.24 ; p<.01)$. In addition, there was a significant correlation between self-regulation and self-efficacy $(r=.69, p<.01)$.

\section{Correlational Path from Self-regulation and Self-efficacy}

According to the conceptual framework of the current study, self-regulation and selfefficacy were assumed to be correlated. The adjusted model provides evidence that these two variables are correlated $(r=.69, p<.01)$. Students who tended to utilize metacognitive strategies, regulate their effort, and manage their time and study environment were more likely to believe in their capabilities and that they have control over their actions.

\section{Discussion}

This finding is congruent with previous studies. For instance, the model suggested by Yusuf (2011) provided evidence that self-regulation and self-efficacy are correlated among 
undergraduate students. In addition, studies that used a prediction design supported this finding because prediction indicates relationships between the predictors and the outcome variables. However, the literature contradicted results regarding the prediction role of these variables. Some studies suggested that self-efficacy predicts self-regulatory strategies, but others indicated that self-regulation affected students' beliefs in their learning capacity. To illustrate, Alafghani and Purwandari (2019) demonstrated that self-efficacy and self-regulation are associated—students who believed in their capabilities and were highly motivated opted to regulate their learning processes. Arik (2019) argued that efficacious students tend to engage in controlling their behavior and manage learning performance. $\mathrm{Ng}$ (2012) concluded that self-efficacy and control beliefs predict students' abilities to conduct regulatory strategies.

On the other hand, several studies suggested that self-regulation is a significant predictor of self-efficacy. According to Saeid and Eslaminejad (2017) self-directed learners who take responsibility, utilize metacognitive strategies, accept learning, have positive self-concepts, and are independent were more likely to have high levels of self-efficacy. Among these factors, Independency was the best predictor of self-efficacy. Self-efficacy and control of beliefs were significantly associated with a tendency to conduct deep strategies, regulate learning performance and effort, and present interest and enjoyment.

Furthermore, an experimental study (Lavasani et al., 2011) supported the findings of the current study regarding the correlation between self-regulation and self-efficacy. The researchers conducted a self-regulation strategies program to promote self-efficacy and academic motivation. The program included instructions that taught students how to set goals, monitor progress, assess behaviors, create a well-established environment, and make information meaningful. The findings of the study indicated that self-regulatory strategies training for the experimental group 
improved self-efficacy, academic motivation, and academic performance when compared with the control group. Yuka (2017) indicated that implementing self-regulation strategies can enhance students' self-efficacy. Wang (2017) conducted a self-reflective program to improve self-efficacy, self-regulation, and academic motivation. The results indicated students developed beliefs in their capabilities, tended to utilize self-regulatory skills, and were academically motivated. These findings suggest that students who already believe in their learning competence are more likely to regulate their thoughts and behavior. While students trained to utilize regulatory strategies can develop a belief in their ability to perform well and control their behaviors and environment. Interestingly, a correlational study found that self-efficacy predicted self-regulation; while experimental studies determined that learning self-regulatory strategies improved self-efficacy. Perhaps, the contradicting results between these studies may be attributed to the differences in methodology. To better understand this, future research may conduct experimental studies that implement self-efficacy programs to improve self-regulation skills, while other studies may adopt a correlational predictive design to examine whether selfregulation predicts self-efficacy.

Regardless of these contradictory results, the findings of previous studies explain the SCT perspective of the cyclical relationships between personal, behavioral, and environmental factors. Previous achievement leads to satisfaction and confidence in personal competence. Students build self-efficacy through monitoring and evaluating their performance; at the same time when students hold efficacy beliefs, they tend to engage in regulatory strategies.

\section{Predictive Direct Effect from Self-regulation to Students' Academic Motivation}

The third hypothesis of the current study suggests that self-regulation predicts academic motivation. Academic motivation in this study was indicated by seven factors-intrinsic 
motivation to know, intrinsic motivation to accomplish, intrinsic motivation to experience stimulation, external regulation, identified regulation, integrated regulation, amotivation. According to the SEM, self-regulation (metacognitive self-regulation, time and study environment management, and effort-regulation) was a statistically significant predictor $(\beta=.24$; $p<.01$ ) of academic motivation. Hence, university students who utilized metacognitive and selfregulatory strategies, managed time and study environments, and persevered when they encountered difficulties showed high levels of academic motivation.

\section{Discussion}

This finding is consistent with previous research indicating self-regulation predicted university students' academic motivation (Saki \& Nadari, 2018). Previous studies conducted to enhance students' academic motivation via promoting self-regulatory strategies support the role of self-regulation in predicting academic motivation. For instance, an intervention based on goal setting revealed that goal commitment was a significant predictor of intrinsic motivation (Yuka, 2017). A self-regulation strategy program effectively enhanced students' academic motivation (Lavasani et al., 2011). The experimental group — which was taught how to set goals, monitor and evaluate learning behaviors, and establish an effective environment—had high scores in academic motivation compared to the control group. Similarly, self-directed learners were highly motivated toward academic activities through their independent learning skills, adoption of problem-solving techniques, and effective study skills (Saeid \& Eslaminejad, 2017).

This finding contradicts assumptions that academic motivation predicts self-regulation abilities where academically motivated students with advanced beliefs in their potential tended to regulate their learning and performance (Alafghani \& Purwandari, 2019). Other research 
indicated that academic motivation impacts self-regulation (Ariani, 2016; Dresel \& Grassinger, 2013). However, Arik (2019) refuted that claim.

These results may differ from the findings of this study due to cultural differences. The first study examined Indonesian students (Alafghani \& Purwandari, 2019) and the second research was done in Germany (Dresel \& Grassinger, 2013). These contradictory results may also be attributed to differences in statistical techniques used or the way these studies conceptualize self-regulation and academic motivation. For instance, the Dresel and Grassinger (2013) study conducted multiple linear regression and considered students' self-efficacy, subjective value, and achievement goals as indicators of academic motivation. The literature review revealed that self-regulation, self-efficacy, and academic motivation intertwined/ overlapped in terms of defining the concept or identifying its indicators. Therefore, future research could be more specific in defining each variable as a construct instead of considering self-efficacy as one component of academic motivation, or self-regulation constructs. It is vital to differentiate between these variables in future research to better understand how these constructs affect each other.

The reciprocal correlation between these variables suggested by SCT (Bandura, 1991) and the cyclical model of self-regulated learning (Zimmerman, 2008) demonstrates why some studies found self-regulation as the predictor while others found academic motivation as the predictor. This can be explained by understanding that when students observe a model and analyze the performed task, they believe they can also perform the task. Then, they set goals, plan, and select suitable strategies to increase their academic motivation. Once motivated, students engage in higher levels of self-regulatory processes such as self-monitoring, selfevaluation, persistence, and adjustment of maladaptive behavior. This is clearly illustrated in a 
study that stated goal setting, specifically goal commitment, predicted academic, intrinsic motivation (Yuka, 2017); while another study that examined metacognition and effort regulation indicated that self-regulation predicted academic motivation. To understand these cyclical relationships, future research could investigate both direction paths from self-regulation to academic motivation, and from academic motivation to self-regulation.

\section{Predictive Direct Effect from Self-efficacy to Academic Motivation}

The current study hypothesized that self-efficacy, indicated by control of learning beliefs and self-efficacy for learning and performance, would predict academic motivation. There was a statistically significant predicting role of self-efficacy in academic motivation $(\beta=.45 ; p<.01)$.

\section{Discussion}

This result is congruent with Arik's (2019) finding that self-efficacy was a predictor of both academic motivation and self-management. In addition, self-concept which implies selfefficacy was a statistically significant predictor of academic motivation (Saki \& Nadari, 2019). The predicting correlation implies correlated relationships between predictor variables and outcome variables. Hence, this finding is consistent with studies that determined relationships between self-efficacy and academic motivation (Alafghani et al., 2019; Ball \& Edelman, 2018; Hassankhani et al., 2015; Yusuf, 2011).

This finding is also consistent with Ng's (2012) study that investigated the effect of selfefficacy and control of beliefs on students' attitude toward learning. There was evidence that efficacious students who believed in their ability to control valued their learning and showed interest and enjoyment in academic settings.

However, this conclusion is contrary to findings that self-efficacy did not predict students' academic motivation (AL-Baddareen et al., 2014). Rather, self-efficacy was a 
suppressor variable. This result was attributed to the multicollinearity of self-efficacy with mastery goal, performance goal, and metacognition.

Most research investigating self-efficacy and academic motivation among university students adopted a correlational design; very few studies used a prediction design. The current findings contributed to identifying the effect of self-efficacy on academic motivation. It is imperative to note that self-efficacy has different concepts and psychometric properties from academic motivation (Zimmerman, 2000b). Thus, future research could investigate the impacts of self-efficacy on academic motivation and distinguish between these constructs to better understand them.

\section{Direct Path from Self-regulation to Amotivation}

The adjusted model demonstrated a significant path from self-regulation $(\beta=-.32 ; p<$ .01) to amotivation (academic motivation indicator). This indicated that self-regulation explained some variance in amotivation.

\section{Discussion}

It is a logical conclusion that university students who reported high levels of selfregulation abilities showed decreased levels of or lack of motivation or interest. Such findings were consistent with SDT's theory that lack of autonomy and agency to control one's emotions, cognitions, and behaviors reduced motivation to initiate function (Deci \& Ryan, 2020). This finding aligned with Saki and Nadari's (2018) assertions that students who exhibited low levels of self-regulation were amotivated in academic performance. Disability to regulate negative emotions, such as anxiety or anger, produced amotivation or absence of internal desire to participate in learning processes (Valinasab \& Zeinali, 2018).

This finding of the current study was also congruent with the argument that students who 
quit or give up when they encountered difficulties showed a lack of motivation (Vallerand et al., 1992). Autonomy-supportive environments have a negative correlation with amotivation (Duchatelet \& Donche, 2019).

This unexpected path from self-regulation to amotivation is related to the psychometric characteristics of the items used. This indicates that self-regulation explains some proportion of the variance in amotivation, metacognitive self-regulation, time and study environment management, effort regulation, and control of learning beliefs. Therefore, future studies could examine the psychometric analysis of self-regulation scales in the MSLQ questionnaire to explain this finding.

\section{Conclusion}

Students' academic motivation is an essential component for achievement and knowledge attainment in higher education. Intrinsically motivated students will be interested not only in obtaining theoretical knowledge from study materials but also in engaging in occupational practices related to the field of study. The current study sought to examine a hypothesized model, based on SCT and SDT, to determine the influence of self-regulation and self-efficacy in academic motivation. According to SEM analysis, the initial model did not fit the observed data, therefore, an adjusted model was developed based on exploratory analysis and modification indices. The adjusted model with a Chi-square value of $187.547(d f=37, \mathrm{p}=.000)$ adequately fitted the data as acceptable criterion fit indices were met $(\mathrm{GFI}=.918, \mathrm{NFI}=.913, \mathrm{CFI}=.928$, RMSEA $=.108$, and SRMR $=.072$ ). A significant correlation between self-regulation and selfefficacy $(r=.69, p<.01)$ was found. The adjusted model explained $41 \%$ of the variance in academic motivation. Although both exogenous variables were statistically significant predictors 
of academic motivation, self-efficacy was the better predictor $(\beta=.45 ; p<.01)$ compared to selfregulation $(\beta=.24 ; p<.01)$.

\section{Limitations}

1. The findings of the current study were limited due to the utilization of a convenience sampling method which affects generalization.

2. There was a gender imbalance because $80.2 \%$ of the participants were female. Other psychological factors that may affect academic motivation that were not included in this study, where self-regulation and self-efficacy explained $43 \%$ of the variance in academic motivation.

3. When interpreting the findings of the current study it is important to consider the impacts of self-report questionnaires and the use of a Likert scale.

4. The examination of the hypothesized model and the obtained results were attributed to the sample of this study; thus, it was possible to get different results in different regions and different years of university study.

\section{Recommendations}

\section{Recommendations for Future Research}

1. Researchers should investigate the impacts of different psychological variables, e.g., students' attitude toward higher education, attribution, competencies in academic motivation.

2. Researchers should examine social factors-e.g., the learning environment, teaching methods, curriculum structures, and students' interrelationships with teachers and peers - that may affect the levels of academic motivation.

3. Previous studies showed a lack of prediction methods when studying academic motivation. Although the current study fills in this gap, further studies are needed particularly for examining the effect of self-efficacy on academic motivation. 
4. Researchers should replicate the current study while conducting the randomized sample method to better validate the hypothesized model.

5. The current study adopted three subscales of MSLQ to measure self-regulation; further study should include the other subscales of help seeking and peer learning.

6. A mixed-methods research design is recommended to better understand academic motivation and factors influencing this variable. Obtaining results from quantitative and qualitative methods will enrich our understanding of academic motivation.

7. Researchers should examine the hypothesized model among male undergraduate students to support generalizing the findings of the current study.

8. The current study investigated the hypothesized model among different ethnic groups; however, most of the participants were Caucasian or white. Further research is needed to examine the model among a variety of ethnic groups to understand how these variables correlate in different cultural backgrounds.

\section{Recommendation for Educational Practice}

1. The university curriculum committees should consider the role of self-regulation and self-efficacy in students' academic motivation. Curriculum should be designed in a way that allows students to practice self-reflection and that has instructions for explicit metacognitive strategies. For instance, lessons' activities may build to teach students planning, selecting effective strategies, and assessing their performance to enhance their metacognitive abilities. The curriculum committee may include real stories about successful people with inspired language to enhance students' self-efficacy. The objective and content of the curriculum should be wellstated and organized. The activities should vary to cover self-regulation skills such as group discussion, thoughtful reflection, and application of one's worldview. 
2. It would be better if university and college faculty articulate the objectives and activities of the course in a way that enhances students' academic motivation. For instance, developing a course syllabus that is clear and timely organized with a calendar to identify dates for required reading, papers, tests, and projects will help students to improve planning, and to monitor their progress during the course. Teaching strategies, such as delivery methods and learning activities, should include scaffolding of metacognitive skills and self-control which in turn will help students to imitate their instructors' behavior. Instructors may require students to participate in teaching and presenting some aspects of the materials. This should improve their autonomy and self-regulation through taking responsibilities, leading discussions, and controlling learning tools and times during class. When students gain successful experience of teaching, their self-efficacy and control beliefs will improve.

3. University and college faculty should create an autonomy-supportive environment through offering constructive feedback, acknowledging students' perspectives and feelings which give students insight into their strengths and promote their confidence in their capabilities. Providing choices and allowing students to get involved in decision-making will enhance students' sense of autonomy and self-regulation. Instructors should encourage using metacognitive strategies and regulating resources (time and environment) and effort that will help students to develop such skills and behavior.

4. Universities and colleges should construct the campus environment including events, workshops, and activities in a way that improves the students' sense of self-efficacy and ability to regulate their learning performance. Students should be encouraged to engage in various clubs where they have a sense of relatedness; this will increase their motivation and efficacy. Providing students with opportunities to be involved in voluntary service and enroll in service- 
learning experiences will address campus responsibility to the community and improve career development among students. Through such practical activities, students' self-efficacy will improve as well as their abilities to regulate themselves which in turn will enhance academic motivation. 
APPENDIX A

IRB APPROVAL 
July 6, 2020

\section{Andrews University}

Fatimah Alijuaid

Tel. 313-290-7:262

Email:alijuaid@andrews.edu

RE: APPLICATION FOR APPROVAL OF RESEARCH INVOLVING HUMAN SUBJECTS

IRB Protocol \#:20-067Application Type: Original Dept.: Graduate Psychology and Counseling Review Category: Exempt Action Taken: Approved Advisor: Elvin Gabriel

Title: Self-regulation and self-efficacy as predictors of academic motivation among university students.

Your IRB application for approval of research involving human subjects entitled: "Selfregulation and self-efficacy as predictors of academic motivation among university students" IRB protocol \# 20-067 has been evaluated and determined Exempt from IRB review under regulation CF R 46.104 (3)(i)(A): Research involving benign behavioral interventions in conjunction with the collection of information from an adult subject through written responses (including data entry) and information collection and the information obtained is recorded by the investigator in such a manner that the identity of the human subjects cannot readily be ascertained, directly or through identifiers linked to the subject. You may now proceed with your research.

Please note that any future changes made to the study design and/or informed consent form require prior approval from the IRB before such changes can be implemented. Incase you need to make changes please use the attached report form.

While there appears to be no more than minimum risks with your study, should an incidence occur that results in a research-related adverse reaction and/or physical injury, this must be reported immediately in writing to the IRB. Any research-related physical injury must also be reported immediately to the University Physician, Dr. Katherine, by calling (269) 473-2222.

We ask that you reference the protocol number in any future correspondence regarding this study for easy retrieval of information.

Best wishes in your research.

Sincerely,

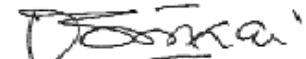

Mordekai Ongo, PhD.

Research Integrity and Compliance Officer

Institutional Review Board - 8488 E Campus Circle Dr Room 234 - Berrien Springs, M I 49104-0355 Tel: (269) 471-6361 E-mail: inb@andrews.edu 
APPENDIX B

\section{INFORMED CONSENT}




\section{INFORMED CONSENT}

You are being invited to participate in a research study titled self-regulation and selfefficacy as predictors of academic motivation among university students. This study is being done by Fatimah Aljuaid from the Andrews University. You were selected to participate in this study because of your current enrollment at university education. The purpose of this research study is investigating whether self-efficacy and self-regulation will predict academic motivation. If you agree to take part in this study, you will be asked to complete an online survey. This survey will ask about your self-regulatory strategies, self-efficacy, and academic motivation; and it will take you approximately 20-25 minutes to complete. You may not directly benefit from this research; however, we hope that your participation in the study may lead to better understanding of variables that predict academic motivation. We believe there are no known risks associated with this research study; however, as with any online related activity the risk of a breach of confidentiality is always possible. To the best of our ability your answers in this study will remain confidential. We will minimize any risks by storing the data file on a password protected computer. None of the information gathered will identify you by name. Your participation in this study is completely voluntary and you can withdraw at any time. You are free to skip any question that you choose. If you have questions about this project or if you have a researchrelated problem, you may contact the researcher's advisor Elvin Gabriel (269-471-6223). Or the

researcher Fatimah Aljuaid, (313 290 7262). If you have any questions concerning your rights as a research subject, you may contact the Andrews University IRB Office at (269) 471-6361 or 
irb@andrews.edu By clicking "I agree" below you are indicating that you are at least 18 years old, have read and understood this consent form and agree to participate in this research study. Please print a copy of this page for your records. 
APPENDIX C

DEMOGRAPHIC QUESTIONNAIRE \& MSLQ \& AMC 


\section{DEMOGRAPHIC INFORMATION}

Please respond to each of the following demographic items listed below.

Age:

Gender:

○ Female

○ Male

Race/Ethnicity:

- Hispanic or Latino

- American Indian or Alaska Native

- Asian

- Black or African American

- Native Hawaiian or Other Pacific Islander

- Caucasian or White

- Multiracial

o Other

- Prefer not to say

Employment Status:

○ Full-time employment

- Part-time employment

○ Unemployed 


\section{Self-regulation Scale}

The following questions ask about your learning strategies and study skills in your academic study. Remember there are no right or wrong answers, just answer as accurately as possible. Use the scale below to answer the questions. If you think the statement is very true of you, circle 7 ; if a statement is not at all true of you, circle 1. If the statement is more or less true of you, find the number between 1 and 7 that best describes you.

Not at all

Very true

true of me of me

MQ1. During class time I often miss important points because I'm thinking of other things.

MQ2. When reading for this course, I make up questions to help focus my reading.

MQ3. When I become confused about something I'm reading for this class, I go back and try to figure it out.

MQ4. If course materials are difficult to understand, I change the way I read the material.

MQ5. Before I study new course material thoroughly, I often skim it to see how it is organized.

MQ6. I ask myself questions to make sure I understand the material I have been studying in this class.

MQ7. I try to change the way I study in order to fit the course requirements and instructor's teaching style

MQ8. I often find that I have been reading for class but don't know what it was all about.

MQ9. I try to think through a topic and decide what I am supposed to learn from it rather than just reading it over when studying.

MQ10. When studying for this course I try to determine which concepts I don't understand well.

MQ 11. When I study for this class, I set goals for myself in order to direct my activities in each study period.

MQ 12. If I get confused taking notes in class, I make sure I sort it out afterwards.

$\begin{array}{lllllll}1 & 2 & 3 & 4 & 5 & 6 & 7\end{array}$

$\begin{array}{lllllll}1 & 2 & 3 & 4 & 5 & 6 & 7\end{array}$

$\begin{array}{lllllll}1 & 2 & 3 & 4 & 5 & 6 & 7\end{array}$

$\begin{array}{lllllll}1 & 2 & 3 & 4 & 5 & 6 & 7\end{array}$

$\begin{array}{lllllll}1 & 2 & 3 & 4 & 5 & 6 & 7\end{array}$

$\begin{array}{lllllll}1 & 2 & 3 & 4 & 5 & 6 & 7\end{array}$

$\begin{array}{lllllll}1 & 2 & 3 & 4 & 5 & 6 & 7\end{array}$

$\begin{array}{lllllll}1 & 2 & 3 & 4 & 5 & 6 & 7\end{array}$

$\begin{array}{lllllll}1 & 2 & 3 & 4 & 5 & 6 & 7\end{array}$

$\begin{array}{lllllll}1 & 2 & 3 & 4 & 5 & 6 & 7\end{array}$

$\begin{array}{lllllll}1 & 2 & 3 & 4 & 5 & 6 & 7\end{array}$

$\begin{array}{lllllll}1 & 2 & 3 & 4 & 5 & 6 & 7\end{array}$




\begin{tabular}{|c|c|c|c|c|c|c|c|}
\hline $\begin{array}{l}\text { TQ1. I usually study in place where I can concentrate on my } \\
\text { course work. }\end{array}$ & 1 & 2 & 3 & 4 & 5 & 6 & 7 \\
\hline TQ2. I make good use of my study time for this course. & 1 & 2 & 3 & 4 & 5 & 6 & 7 \\
\hline TQ3. I found it hard to stick to study schedule. & 1 & 2 & 3 & 4 & 5 & 6 & 7 \\
\hline TQ4. I have a regular place set side for studying. & 1 & 2 & 3 & 4 & 5 & 6 & 7 \\
\hline $\begin{array}{l}\text { TQ5. I make sure I keep up with the weekly reading and } \\
\text { assignments for this course. }\end{array}$ & 1 & 2 & 3 & 4 & 5 & 6 & 7 \\
\hline TQ6. I attend class regularly. & 1 & 2 & 3 & 4 & 5 & 6 & 7 \\
\hline $\begin{array}{l}\text { TQ7. I often find that I don't spend very much time on this } \\
\text { course because of other activities }\end{array}$ & 1 & 2 & 3 & 4 & 5 & 6 & 7 \\
\hline $\begin{array}{l}\text { TQ8. I rarely find time to review my notes or readings before } \\
\text { an exam. }\end{array}$ & 1 & 2 & 3 & 4 & 5 & 6 & 7 \\
\hline $\begin{array}{l}\text { FQ1. I often feel so lazy or bored when I study for this class } \\
\text { that I quit before I finish what I planned to do. }\end{array}$ & 1 & 2 & 3 & 4 & 5 & 6 & 7 \\
\hline $\begin{array}{l}\text { FQ2. I work hard to do well in this class even if I don't like } \\
\text { what we are doing. }\end{array}$ & 1 & 2 & 3 & 4 & 5 & 6 & 7 \\
\hline $\begin{array}{l}\text { FQ3. When course work is difficult, I give up or only study } \\
\text { the easy parts. }\end{array}$ & 1 & 2 & 3 & 4 & 5 & 6 & 7 \\
\hline $\begin{array}{l}\text { FQ4. Even when course materials are dull and uninteresting, } \\
\text { I manage to keep working until I finish. }\end{array}$ & 1 & 2 & 3 & 4 & 5 & 6 & 7 \\
\hline
\end{tabular}

\section{self-efficacy scale}

The following questions ask about your learning strategies and study skills in your academic study. Remember there are no right or wrong answers, just answer as accurately as possible. Use the scale below to answer the questions. If you think the statement is very true of you, circle 7; if a statement is not at all true of you, circle 1. If the statement is more or less true of you, find the number between 1 and 7 that best describes you.

Not at all true of me

CQ1. If I study in appropriate ways, then I will be able to learn the material in this course.

CQ2. It is my own fault if I don't learn the material in this course.

$\begin{array}{lllllll}1 & 2 & 3 & 4 & 5 & 6 & 7 \\ 1 & 2 & 3 & 4 & 5 & 6 & 7\end{array}$




\begin{tabular}{|c|c|c|c|c|c|c|c|}
\hline $\begin{array}{l}\text { CQ3. If I try hard enough, then I will understand the course } \\
\text { material. } \\
\text { CQ4. If I don't understand the course material, it is because I } \\
\text { didn't try hard enough. }\end{array}$ & 1 & 2 & 3 & 4 & 5 & 6 & 7 \\
\hline LQ1. I believe I will receive an excellent grade in this class. & 1 & 2 & 3 & 4 & 5 & 6 & 7 \\
\hline $\begin{array}{l}\text { LQ2. I'm certain I can understand the most difficult material } \\
\text { presented in the readings for this course. }\end{array}$ & 1 & 2 & 3 & 4 & 5 & 6 & 7 \\
\hline $\begin{array}{l}\text { LQ3. I'm confident I can understand the basic concepts } \\
\text { taught in this course. }\end{array}$ & 1 & 2 & 3 & 4 & 5 & 6 & 7 \\
\hline $\begin{array}{l}\text { LQ4. I'm confident I can understand the most complex } \\
\text { material presented by the instructor in this course. }\end{array}$ & 1 & 2 & 3 & 4 & 5 & 6 & 7 \\
\hline $\begin{array}{l}\text { LQ5. I'm confident I can do an excellent job on the } \\
\text { assignments and tests in this course. }\end{array}$ & 1 & 2 & 3 & 4 & 5 & 6 & 7 \\
\hline LQ6. I expect to do well in this class. & 1 & 2 & 3 & 4 & 5 & 6 & 7 \\
\hline $\begin{array}{l}\text { LQ7. I'm certain I can master the skills being taught in this } \\
\text { class. }\end{array}$ & 1 & 2 & 3 & 4 & 5 & 6 & 7 \\
\hline $\begin{array}{l}\text { LQ8. Considering the difficulty of this course, the teacher, } \\
\text { and my skills, I think I will do well in this class. }\end{array}$ & 1 & 2 & 3 & 4 & 5 & 6 & 7 \\
\hline
\end{tabular}




\section{Academic motivation}

The following questions ask about your learning strategies and study skills in your academic study. Remember there are no right or wrong answers, just answer as accurately as possible. Use the scale below to answer the questions. If you think the statement is Corresponds exactly, circle 7 ; if a statement Does not correspond at all, circle 1. If the statement is more or less Corresponds, find the number between 1 and 7 that best describes you.

\begin{tabular}{|c|c|c|c|c|c|c|}
\hline $\begin{array}{c}\text { Does not } \\
\text { correspond at } \\
\text { all }\end{array}$ & & $\begin{array}{c}\text { Corresponds at a } \\
\text { little }\end{array}$ & $\begin{array}{l}\text { Corresponds } \\
\text { moderately }\end{array}$ & & Corresponds a lot & Corresponds exactly \\
\hline 1 & 2 & 3 & 4 & 5 & 6 & 7 \\
\hline
\end{tabular}

\section{WHY DO YOU GO TO COLLEGE?}

\begin{tabular}{|c|c|c|c|c|c|c|c|}
\hline $\begin{array}{l}\text { 18. Because with only a high-school degree I would } \\
\text { not find a high-paying job later on. }\end{array}$ & 1 & 2 & 3 & 4 & 5 & 6 & 7 \\
\hline $\begin{array}{l}\text { 19. Because I experience pleasure and satisfaction while } \\
\text { learning new things. }\end{array}$ & 1 & 2 & 3 & 4 & 5 & 6 & 7 \\
\hline $\begin{array}{l}\text { 20. Because I think that a college education will help } \\
\text { me better prepare for the career I have chosen. }\end{array}$ & 1 & 2 & 3 & 4 & 5 & 6 & 7 \\
\hline $\begin{array}{l}\text { 21. For the intense feelings I experience when I am } \\
\text { communicating my own ideas to others. }\end{array}$ & 1 & 2 & 3 & 4 & 5 & 6 & 7 \\
\hline $\begin{array}{l}\text { 22. Honestly, I don't know; I really feel that I am } \\
\text { wasting my time in school. }\end{array}$ & 1 & 2 & 3 & 4 & 5 & 6 & 7 \\
\hline $\begin{array}{l}\text { 23. For the pleasure I experience while surpassing } \\
\text { myself in my studies. }\end{array}$ & 1 & 2 & 3 & 4 & 5 & 6 & 7 \\
\hline $\begin{array}{l}\text { 24. To prove to myself that I am capable of completing } \\
\text { my college degree. }\end{array}$ & 1 & 2 & 3 & 4 & 5 & 6 & 7 \\
\hline 25. In order to obtain a more prestigious job later on. & 1 & 2 & 3 & 4 & 5 & 6 & 7 \\
\hline $\begin{array}{l}\text { 26. For the pleasure I experience when I discover new } \\
\text { things never seen before. }\end{array}$ & 1 & 2 & 3 & 4 & 5 & 6 & 7 \\
\hline $\begin{array}{l}\text { 27. Because eventually it will enable me to enter the job } \\
\text { market in a field that I like. }\end{array}$ & 1 & 2 & 3 & 4 & 5 & 6 & 7 \\
\hline $\begin{array}{l}\text { 28. For the pleasure that I experience when I read } \\
\text { interesting authors. }\end{array}$ & 1 & 2 & 3 & 4 & 5 & 6 & 7 \\
\hline $\begin{array}{l}\text { 29. I once had good reasons for going to college; } \\
\text { however, now I wonder whether I should continue. }\end{array}$ & 1 & 2 & 3 & 4 & 5 & 6 & 7 \\
\hline $\begin{array}{l}\text { 30. For the pleasure that I experience while I am } \\
\text { surpassing myself in one of my personal } \\
\text { accomplishments. }\end{array}$ & 1 & 2 & 3 & 4 & 5 & 6 & 7 \\
\hline $\begin{array}{l}\text { 31. Because of the fact that when I succeed in college I } \\
\text { feel important. }\end{array}$ & 1 & 2 & 3 & 4 & 5 & 6 & 7 \\
\hline 32. Because I want to have "the good life" later on. & 1 & 2 & 3 & 4 & 5 & 6 & 7 \\
\hline
\end{tabular}




\begin{tabular}{|c|c|c|c|c|c|c|c|}
\hline $\begin{array}{l}\text { 33. For the pleasure that I experience in broadening my } \\
\text { knowledge about subjects which appeal to me. }\end{array}$ & 1 & 2 & 3 & 4 & 5 & 6 & 7 \\
\hline $\begin{array}{l}\text { 34. For the pleasure that I experience when I feel } \\
\text { completely absorbed by what certain authors have } \\
\text { written. }\end{array}$ & 1 & 2 & 3 & 4 & 5 & 6 & 7 \\
\hline $\begin{array}{l}\text { 35. I can't see why I go to college and frankly, I couldn't } \\
\text { care less. }\end{array}$ & 1 & 2 & 3 & 4 & 5 & 6 & 7 \\
\hline $\begin{array}{l}\text { 36. For the satisfaction I feel when I am in the process } \\
\text { of accomplishing difficult academic activities. }\end{array}$ & 1 & 2 & 3 & 4 & 5 & 6 & 7 \\
\hline 37. To show myself that I am an intelligent person. & 1 & 2 & 3 & 4 & 5 & 6 & 7 \\
\hline $\begin{array}{l}\text { 38. Because my studies allow me to continue to learn } \\
\text { about many things that interest me. }\end{array}$ & 1 & 2 & 3 & 4 & 5 & 6 & 7 \\
\hline $\begin{array}{l}\text { 39. Because I believe that a few additional years of } \\
\text { education will improve my competence as a worker. }\end{array}$ & 1 & 2 & 3 & 4 & 5 & 6 & 7 \\
\hline $\begin{array}{l}\text { 40. For the "high" feeling that I experience while } \\
\text { reading about various interesting subjects. }\end{array}$ & 1 & 2 & 3 & 4 & 5 & 6 & 7 \\
\hline $\begin{array}{l}\text { 41. I don't know; I can't understand what I am doing in } \\
\text { school. }\end{array}$ & 1 & 2 & 3 & 4 & 5 & 6 & 7 \\
\hline $\begin{array}{l}\text { 42. Because college allows me to experience a personal } \\
\text { satisfaction in my quest for excellence in my } \\
\text { studies. }\end{array}$ & 1 & 2 & 3 & 4 & 5 & 6 & 7 \\
\hline $\begin{array}{l}\text { 43. Because I want to show myself that I can succeed in } \\
\text { my studies. }\end{array}$ & 1 & 2 & 3 & 4 & 5 & 6 & 7 \\
\hline $\begin{array}{l}\text { 44. Because this will help me make a better choice } \\
\text { regarding my career orientation. }\end{array}$ & 1 & 2 & 3 & 4 & 5 & 6 & 7 \\
\hline 45. In order to have a better salary later on. & 1 & 2 & 3 & 4 & 5 & 6 & 7 \\
\hline
\end{tabular}


APPENDIX D

STRUCTURAL EQUATION MODELING ANALYSIS TABLES 


\section{The Initial Model}

\section{Variable counts (Group number 1)}

Number of variables in your model: 28

Number of observed variables: 12

Number of unobserved variables: 16

Number of exogenous variables: 15

Number of endogenous variables: 13

Parameter Summary (Group number 1)

\begin{tabular}{|r|rrrrrr|}
\hline & Weights & Covariances & Variance & Means & Intercepts & Tota \\
& & & & & & 1 \\
\hline Fixed & 16 & 0 & 1 & 0 & 0 & 17 \\
Labeled & 0 & 0 & 0 & 0 & 0 & 0 \\
Unlabeled & 11 & 13 & 14 & 0 & 0 & 38 \\
Total & 27 & 13 & 15 & 0 & 0 & 55 \\
\hline
\end{tabular}

Sample Moments (Group number 1)

Sample Covariances (Group number 1)

\begin{tabular}{|l|rrrrrrrrrrrr|}
\hline & AM & In & In & InM & ExM & ExM & Ex & SE & SE & SM & SR & SR \\
& OT & MC & MS & K & N & D & ME & C & LP & R & TE & EF \\
\hline AM & 2.78 & & & & & & & & & & & \\
OT & 7 & & & & & & & & & & & \\
InM & -.494 & 1.7 & & & & & & & & & & \\
C & & 44 & & & & & & & & & & \\
InM & .258 & 1.1 & 1.9 & & & & & & & & \\
S & & 29 & 18 & & & & & & & & \\
InM & -.734 & 1.2 & .91 & 1.54 & & & & & & & \\
K & & 02 & 8 & 2 & & & & & & & \\
ExM & -.509 & 1.1 & .61 & .900 & 1.76 & & & & & & \\
N & & 14 & 7 & & 2 & & & & & & \\
ExM & -.972 & .71 & .31 & .803 & .776 & 1.24 & & & & \\
D & & 6 & 1 & & & 8 & & & & & \\
& & & & & & & & & & & \\
\end{tabular}




\begin{tabular}{|l|rrrrrrrrrrrr|r|} 
ExM & -.567 & .38 & - & .488 & .744 & .768 & 1.40 & & & & & \\
& & 5 & .01 & & & & 6 & & & & & \\
SEC & & & 6 & & & & & & & & \\
& .330 & .36 & .26 & .174 & .214 & .153 & .199 & 1.0 & & & & \\
& & 3 & 9 & & & & & 68 & & & & \\
SEL & -.618 & .69 & .38 & .721 & .597 & .616 & .437 & .39 & 1.1 & & & \\
P & & 3 & 8 & & & & & 7 & 45 & & & \\
SMR & & .198 & .56 & .51 & .507 & .335 & .295 & .126 & .23 & .51 & .78 & & \\
& & 7 & 3 & & & & & 1 & 8 & 4 & & \\
SRT & -.795 & .36 & .13 & .488 & .342 & .516 & .355 & .02 & .58 & .43 & 1.0 & \\
E & & 6 & 4 & & & & & 4 & 7 & 9 & 19 & \\
SRE & -.940 & .42 & .14 & .487 & .401 & .414 & .252 & - & .66 & .43 & .78 & 1.3 \\
F & & 7 & 6 & & & & & .04 & 1 & 1 & 6 & 21 \\
& & & & & & & & 2 & & & & \\
\hline
\end{tabular}

Eigenvalues

7.311 3.359 1.697 1.407.899.760.518. 427.399.366.329.274

Determinant of sample covariance matrix $=.116$

Sample Correlations (Group number 1)

\begin{tabular}{|l|rrrrrrrrrrrr|}
\hline & AM & In & In & InM & ExM & ExM & Ex & SE & SE & SM & SR & SR \\
& OT & MC & MS & K & N & D & ME & C & LP & R & TE & EF \\
\hline AM & 1.00 & & & & & & & & & & & \\
OT & 0 & & & & & & & & & & & \\
InM & -.224 & 1.0 & & & & & & & & & & \\
C & & 00 & & & & & & & & & & \\
InM & .111 & .61 & 1.0 & & & & & & & & \\
S & & 7 & 00 & & & & & & & & \\
InM & -.354 & .73 & .53 & 1.00 & & & & & & & \\
K & & 3 & 4 & 0 & & & & & & & \\
ExM & -.230 & .63 & .33 & .546 & 1.00 & & & & & & \\
N & & 5 & 5 & & 0 & & & & & & \\
ExM & -.521 & .48 & .20 & .579 & .523 & 1.00 & & & & \\
D & & 6 & 1 & & & 0 & & & & & \\
& & & & & & & & & & \\
\end{tabular}




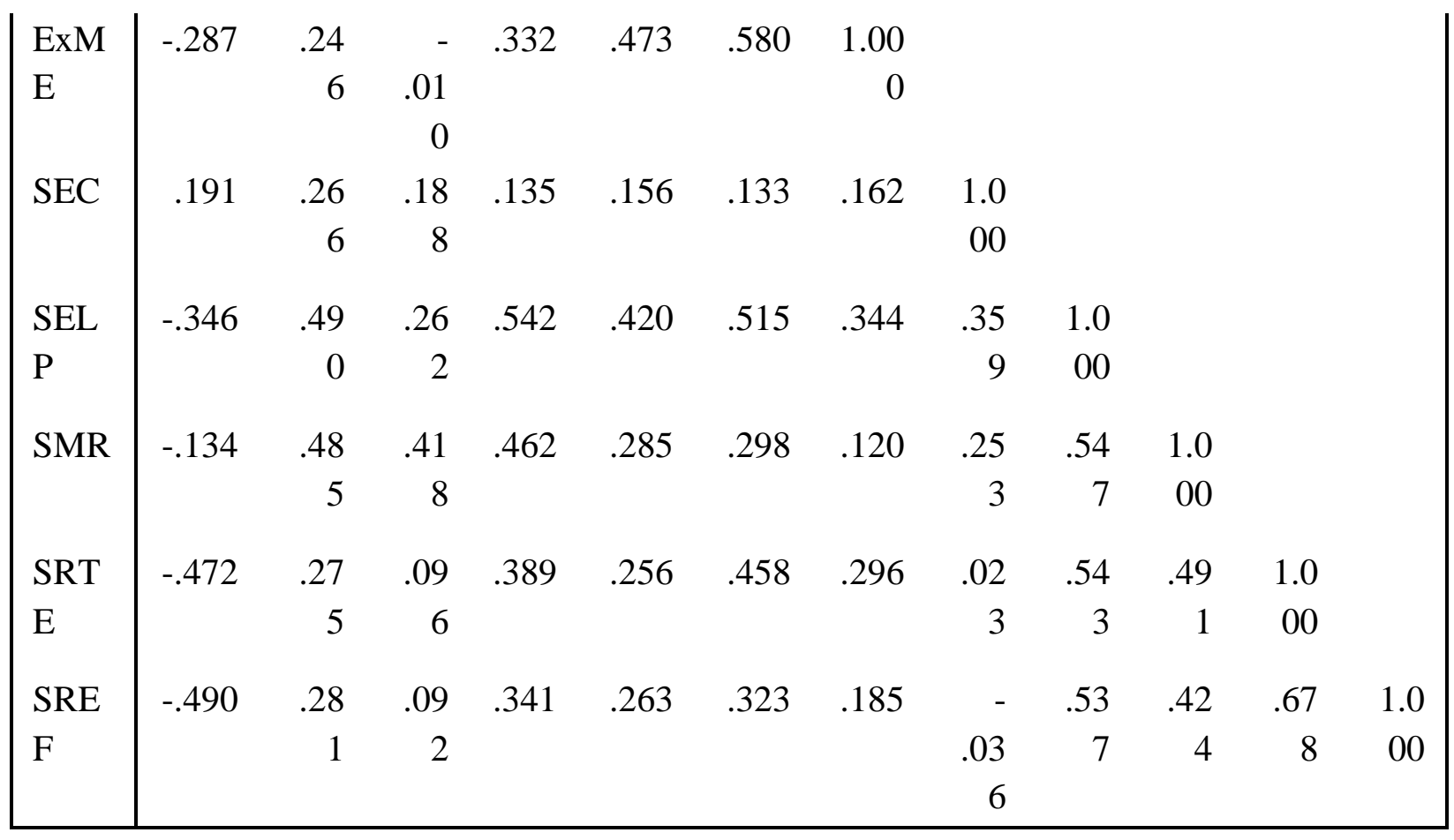

Eigenvalues

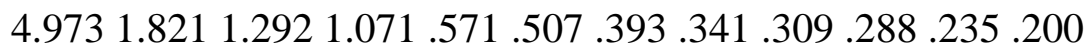

Models

Default model (Default model)

Notes for Model (Default model)

Computation of degrees of freedom (Default model)

Number of distinct sample moments: $\quad 78$

Number of distinct parameters to be estimated: 38

Degrees of freedom $(78-38): \quad 40$

Result (Default model)

Minimum was achieved

Chi-square $=271.569$

Degrees of freedom $=40$

Probability level $=.000$

Group number 1 (Group number 1 - Default model)

Estimates (Group number 1 - Default model)

Scalar Estimates (Group number 1 - Default model)

Maximum Likelihood Estimates

Regression Weights: (Group number 1 - Default model) 


\begin{tabular}{|c|c|c|c|c|c|c|}
\hline & & & Estimate & S.E. & C.R. & P $\quad$ Label \\
\hline AcadMotiv & $<--$ & SE & .173 & .037 & 4.646 & $* * *$ \\
\hline AcadMotiv & & SR & .129 & .039 & 3.298 & $* * *$ \\
\hline SREF & & SR & 1.000 & & & \\
\hline SRTE & $<-$ & SR & .833 & .064 & 13.062 & $* * *$ \\
\hline SMR & $\begin{array}{l}<- \\
-\end{array}$ & SR & .679 & .059 & 11.590 & $* * *$ \\
\hline SELP & $\begin{array}{l}<- \\
-\end{array}$ & SE & 1.000 & & & \\
\hline SEC & $\begin{array}{l}<- \\
-\end{array}$ & SE & .337 & .048 & 7.009 & $* * *$ \\
\hline ExME & $\begin{array}{l}<- \\
-\end{array}$ & AcadMotiv & 1.000 & & & \\
\hline ExMD & $\begin{array}{l}<- \\
-\end{array}$ & AcadMotiv & 1.665 & .211 & 7.894 & $* * *$ \\
\hline ExMN & $\begin{array}{l}<- \\
-\end{array}$ & AcadMotiv & 1.829 & .252 & 7.261 & $* * *$ \\
\hline InMK & $\begin{array}{l}<- \\
-\end{array}$ & AcadMotiv & 2.578 & .383 & 6.727 & $* * *$ \\
\hline InMS & $\begin{array}{l}<- \\
-\end{array}$ & AcadMotiv & 1.826 & .334 & 5.472 & $* * *$ \\
\hline InMC & $\begin{array}{l}<- \\
-\end{array}$ & AcadMotiv & 2.404 & .364 & 6.613 & $* * *$ \\
\hline AMOT & & AcadMotiv & -1.501 & .273 & -5.502 & $* * *$ \\
\hline
\end{tabular}

Standardized Regression Weights: (Group number 1 - Default model) 


\begin{tabular}{|c|c|c|c|}
\hline & & & Estimate \\
\hline AcadMotiv & $<-$ & $\mathrm{SE}$ & .425 \\
\hline AcadMotiv & & SR & .280 \\
\hline SREF & & SR & .823 \\
\hline SRTE & $\begin{array}{l}<- \\
-\end{array}$ & SR & .781 \\
\hline SMR & $\begin{array}{l}<- \\
-\end{array}$ & SR & .717 \\
\hline SELP & $<-$ & SE & 1.000 \\
\hline SEC & $<-$ & SE & .350 \\
\hline ExME & $<-$ & AcadMotiv & .370 \\
\hline ExMD & $\begin{array}{l}<- \\
-\end{array}$ & AcadMotiv & .653 \\
\hline ExMN & $\begin{array}{l}<- \\
-\end{array}$ & AcadMotiv & .599 \\
\hline InMK & $<-$ & AcadMotiv & .906 \\
\hline InMS & $<-$ & AcadMotiv & .584 \\
\hline InMC & $<-$ & AcadMotiv & .794 \\
\hline AMOT & & AcadMotiv & -.393 \\
\hline
\end{tabular}

Covariances: (Group number 1 - Default model)

\begin{tabular}{|c|c|c|c|c|c|}
\hline & Estimate & S.E. & C.R. & & Label \\
\hline SR $\langle-->\quad S E$ & .700 & .074 & 9.461 & **** & \\
\hline
\end{tabular}




\begin{tabular}{|c|c|c|c|c|c|c|}
\hline e6 & $\langle--\rangle$ & e7 & .441 & .058 & 7.583 & $* * *$ \\
\hline $\mathrm{e} 10$ & $\langle--\rangle$ & e12 & .703 & .097 & 7.236 & $* * *$ \\
\hline e6 & $\langle-->$ & e8 & .416 & .063 & 6.597 & $* * *$ \\
\hline e7 & $\langle--\rangle$ & e12 & -.480 & .078 & -6.195 & $* * *$ \\
\hline e10 & $\langle--\rangle$ & e11 & .230 & .056 & 4.139 & $* * *$ \\
\hline e8 & $\langle-->$ & e11 & .298 & .051 & 5.886 & $* * *$ \\
\hline e7 & $\langle--\rangle$ & e8 & .199 & .046 & 4.312 & $* * *$ \\
\hline e6 & $\langle--\rangle$ & e10 & -.320 & .062 & -5.164 & $* * *$ \\
\hline e1 & $\langle-->$ & $\mathrm{e} 3$ & -.141 & .040 & -3.554 & $* * *$ \\
\hline e7 & $\langle-->$ & e10 & -.242 & .051 & -4.724 & $* * *$ \\
\hline e3 & $\langle--\rangle$ & e5 & .126 & .037 & 3.371 & $* * *$ \\
\hline e6 & $\langle--\rangle$ & e12 & -.250 & .087 & -2.882 & .004 \\
\hline
\end{tabular}

Correlations: (Group number 1 - Default model)

\begin{tabular}{|lll|r|}
\hline & & & Estimate \\
\hline SR & $<-->$ & SE & .692 \\
e6 & $<->$ & e7 & .476 \\
e10 & $<->$ & e12 & .413 \\
e6 & <-> & e8 & .355
\end{tabular}




\begin{tabular}{lll|r}
$\mathrm{e} 7$ & $\langle-->$ & $\mathrm{e} 12$ & -.370 \\
$\mathrm{e} 10$ & $\langle-->$ & $\mathrm{e} 11$ & .258 \\
$\mathrm{e} 8$ & $\langle-->$ & $\mathrm{e} 11$ & .347 \\
$\mathrm{e} 7$ & $\langle-->$ & $\mathrm{e} 8$ & .221 \\
$\mathrm{e} 6$ & $\langle-->$ & $\mathrm{e} 10$ & -.263 \\
$\mathrm{e} 1$ & $\langle-->$ & $\mathrm{e}$ & -.345 \\
$\mathrm{e} 7$ & $\langle-->$ & $\mathrm{e} 10$ & -.258 \\
$\mathrm{e} 3$ & $\langle-->$ & $\mathrm{e} 5$ & .209 \\
$\mathrm{e} 6$ & $\langle-->$ & $\mathrm{e} 12$ & -.148 \\
\hline
\end{tabular}

Variances: (Group number 1 - Default model)

\begin{tabular}{|c|c|c|c|c|}
\hline & Estimate & S.E. & C.R. & P Label \\
\hline $\begin{array}{l}\mathrm{SR} \\
\end{array}$ & .895 & .110 & 8.126 & $* * *$ \\
\hline SE & 1.145 & .087 & $\begin{array}{r}13.19 \\
1\end{array}$ & $* * *$ \\
\hline e13 & .110 & .033 & 3.325 & $* * *$ \\
\hline e4 & .000 & & & \\
\hline e1 & .426 & .065 & 6.573 & $* * *$ \\
\hline $\mathrm{e} 2$ & .397 & .044 & 8.961 & $* * *$ \\
\hline e3 & .390 & .044 & 8.957 & $* * *$ \\
\hline e5 & .931 & .071 & $\begin{array}{r}13.19 \\
1\end{array}$ & $* * *$ \\
\hline e6 & 1.205 & .093 & $\begin{array}{r}12.98 \\
9\end{array}$ & $* * *$ \\
\hline e7 & .712 & .060 & $\begin{array}{r}11.92 \\
7\end{array}$ & $* * *$ \\
\hline
\end{tabular}




\begin{tabular}{|l|rrrr|} 
e8 & 1.140 & .092 & 12.45 & $* * *$ \\
& & & 5 & \\
e10 & .276 & .052 & 5.261 & $* * *$ \\
& & & & \\
e11 & 1.230 & .101 & 12.11 & $* * *$ \\
& & & 7 & \\
e12 & .645 & .065 & 9.983 & $* * *$ \\
& & & & \\
& 2.358 & .183 & 12.85 & $* * *$ \\
& & & 2 & \\
\hline
\end{tabular}

Squared Multiple Correlations: (Group number 1 - Default model)

\begin{tabular}{|c|c|}
\hline & Estimate \\
\hline AcadMotiv & .424 \\
\hline AMOT & .154 \\
\hline InMC & .631 \\
\hline InMS & .341 \\
\hline InMK & .821 \\
\hline ExMN & .359 \\
\hline ExMD & .426 \\
\hline ExME & .137 \\
\hline SEC & .123 \\
\hline
\end{tabular}




$\mid$\begin{tabular}{l|l} 
SELP & 1.000 \\
SMR & .514 \\
SRTE & .610 \\
SREF & .678 \\
\hline
\end{tabular}

Matrices (Group number 1 - Default model)

Implied Covariances (Group number 1 - Default model)

\begin{tabular}{|l|rrrrrrrrrrrr|}
\hline & AM & In & In & InM & ExM & ExM & Ex & SE & SE & SM & SR & SR \\
& OT & MC & MS & K & N & D & ME & C & LP & R & TE & EF \\
\hline AM & 2.78 & & & & & & & & & & & \\
OT & 7 & & & & & & & & & & & \\
InM & -.688 & 1.7 & & & & & & & & & & \\
C & & 47 & & & & & & & & & & \\
InM & .181 & 1.0 & 1.8 & & & & & & & & \\
S & & 67 & 65 & & & & & & & & \\
InM & -.738 & 1.1 & .89 & 1.54 & & & & & & & \\
K & & 82 & 7 & 2 & & & & & & & \\
ExM & -.523 & 1.1 & .63 & .899 & 1.77 & & & & & & \\
N & & 36 & 6 & & 8 & & & & & & \\
ExM & -.957 & .76 & .33 & .818 & .780 & 1.24 & & & & & \\
D & & 3 & 8 & & & 1 & & & & & \\
ExM & -.536 & .45 & .02 & .491 & .765 & .758 & 1.39 & & & & & \\
E & & 8 & 9 & & & & 5 & & & & \\
SEC & -.146 & .23 & .17 & .251 & .178 & .162 & .098 & 1.0 & & & \\
& & 4 & 8 & & & & & 61 & & & \\
SEL & -.434 & .69 & .52 & .745 & .529 & .481 & .289 & .38 & 1.1 & & \\
P & & 5 & 8 & & & & & 6 & 45 & & \\
& & & & & & & & & & \\
\end{tabular}




\begin{tabular}{|l|rrrrrrrrrrrr|} 
SMR & -.242 & .38 & .29 & .415 & .294 & .268 & .161 & .28 & .47 & .80 & & \\
& & 7 & 4 & & & & & 6 & 5 & 2 & & \\
SRT & -.297 & .47 & .36 & .509 & .361 & .329 & .198 & .19 & .58 & .50 & 1.0 & \\
E & & 5 & 1 & & & & & 7 & 4 & 6 & 19 & \\
SRE & -.356 & .57 & .43 & .611 & .434 & .395 & .237 & .23 & .70 & .46 & .74 & 1.3 \\
F & & 0 & 3 & & & & & 6 & 0 & 7 & 6 & 21 \\
\hline
\end{tabular}

\begin{tabular}{|c|c|c|c|c|c|c|c|c|c|c|c|c|}
\hline & $\begin{array}{l}\mathrm{AM} \\
\mathrm{OT}\end{array}$ & $\begin{array}{r}\text { In } \\
\text { MC }\end{array}$ & $\begin{array}{r}\text { In } \\
\text { MS }\end{array}$ & $\begin{array}{r}\text { InM } \\
\mathrm{K}\end{array}$ & $\begin{array}{r}\text { ExM } \\
\mathrm{N}\end{array}$ & $\begin{array}{r}\text { ExM } \\
D\end{array}$ & $\begin{array}{r}\text { Ex } \\
M E\end{array}$ & $\begin{array}{r}\text { SE } \\
C\end{array}$ & $\begin{array}{l}\text { SE } \\
\text { LP }\end{array}$ & $\begin{array}{r}\mathrm{SM} \\
\mathrm{R}\end{array}$ & $\begin{array}{l}\text { SR } \\
\text { TE }\end{array}$ & $\begin{array}{l}\mathrm{SR} \\
\mathrm{EF}\end{array}$ \\
\hline $\mathrm{AM}$ & 1.00 & & & & & & & & & & & \\
\hline OT & 0 & & & & & & & & & & & \\
\hline $\begin{array}{l}\text { InM } \\
\mathrm{C}\end{array}$ & -.312 & $\begin{array}{r}1.0 \\
00\end{array}$ & & & & & & & & & & \\
\hline $\begin{array}{l}\text { InM } \\
S\end{array}$ & .079 & $\begin{array}{r}.59 \\
1\end{array}$ & $\begin{array}{r}1.0 \\
00\end{array}$ & & & & & & & & & \\
\hline $\begin{array}{l}\text { InM } \\
\mathrm{K}\end{array}$ & -.356 & $\begin{array}{r}.72 \\
0\end{array}$ & $\begin{array}{r}.52 \\
9\end{array}$ & $\begin{array}{r}1.00 \\
0\end{array}$ & & & & & & & & \\
\hline $\begin{array}{l}\text { ExM } \\
\mathrm{N}\end{array}$ & -.235 & $\begin{array}{r}.64 \\
5\end{array}$ & $\begin{array}{r}.35 \\
0\end{array}$ & .543 & $\begin{array}{r}1.00 \\
0\end{array}$ & & & & & & & \\
\hline $\begin{array}{l}\text { ExM } \\
\text { D }\end{array}$ & -.514 & $\begin{array}{r}.51 \\
8\end{array}$ & $\begin{array}{r}.22 \\
2\end{array}$ & .591 & .525 & $\begin{array}{r}1.00 \\
0\end{array}$ & & & & & & \\
\hline $\begin{array}{l}\text { ExM } \\
\text { E }\end{array}$ & -.272 & $\begin{array}{r}.29 \\
4\end{array}$ & $\begin{array}{r}.01 \\
8\end{array}$ & .335 & .485 & .576 & $\begin{array}{r}1.00 \\
0\end{array}$ & & & & & \\
\hline SEC & -.085 & $\begin{array}{r}.17 \\
2\end{array}$ & $\begin{array}{r}.12 \\
7\end{array}$ & 196 & .130 & .141 & .080 & $\begin{array}{r}1.0 \\
00\end{array}$ & & & & \\
\hline $\begin{array}{l}\text { SEL } \\
\text { P }\end{array}$ & -.243 & $\begin{array}{r}.49 \\
1\end{array}$ & $\begin{array}{r}.36 \\
1\end{array}$ & .561 & .370 & .404 & .229 & $\begin{array}{r}.35 \\
0\end{array}$ & $\begin{array}{r}1.0 \\
00\end{array}$ & & & \\
\hline SMR & -.162 & $\begin{array}{r}.32 \\
7\end{array}$ & $\begin{array}{r}.24 \\
0\end{array}$ & .373 & .246 & .269 & .152 & $\begin{array}{r}.31 \\
0\end{array}$ & $\begin{array}{r}.49 \\
6\end{array}$ & $\begin{array}{r}1.0 \\
00\end{array}$ & & \\
\hline $\begin{array}{l}\text { SRT } \\
\text { E }\end{array}$ & -.176 & $\begin{array}{r}.35 \\
6\end{array}$ & $\begin{array}{r}.26 \\
2\end{array}$ & .406 & .268 & .293 & .166 & $\begin{array}{r}.18 \\
9\end{array}$ & $\begin{array}{r}.54 \\
0\end{array}$ & $\begin{array}{r}.56 \\
0\end{array}$ & $\begin{array}{r}1.0 \\
00\end{array}$ & \\
\hline
\end{tabular}




\begin{tabular}{|l|rrrrrrrrrrrr|} 
SRE & -.185 & .37 & .27 & .428 & .283 & .308 & .175 & .20 & .56 & .45 & .64 & 1.0 \\
$\mathrm{~F}$ & & 5 & 6 & & & & & 0 & 9 & 4 & 3 & 00 \\
\hline
\end{tabular}

Covariances: (Group number 1 - Default model)

\begin{tabular}{|c|c|c|c|c|}
\hline & & & M.I. & Par Change \\
\hline $\mathrm{e} 12$ & $\langle--\rangle$ & SE & 8.394 & .168 \\
\hline e12 & $\langle-->$ & SR & 28.917 & -.297 \\
\hline e12 & $\langle--\rangle$ & e13 & 4.314 & .054 \\
\hline e11 & $\langle-->$ & e12 & 6.559 & .134 \\
\hline e5 & $\langle-->$ & SE & 9.991 & .131 \\
\hline e5 & $\langle-\rangle$ & SR & 23.987 & -.193 \\
\hline e5 & $\langle-->$ & e12 & 36.449 & .407 \\
\hline e5 & $\langle-\rangle$ & e11 & 14.696 & .146 \\
\hline e5 & $\langle-->$ & e6 & 4.288 & .095 \\
\hline e4 & $\langle-->$ & e5 & 8.223 & .104 \\
\hline e3 & $\langle-->$ & e13 & 9.807 & .043 \\
\hline e3 & $\langle-->$ & e12 & 4.858 & .109 \\
\hline e3 & $\langle-->$ & e11 & 8.418 & .081 \\
\hline e3 & $\langle-->$ & $\mathrm{e} 10$ & 7.237 & .098 \\
\hline e2 & $\langle-->$ & $\mathrm{e} 12$ & 5.765 & -.119 \\
\hline e2 & $\langle-->$ & e11 & 7.392 & -.076 \\
\hline $\mathrm{e} 2$ & $\langle-->$ & e7 & 6.624 & .068 \\
\hline e2 & $\langle-->$ & e3 & 4.158 & -.050 \\
\hline e1 & $\langle-->$ & e13 & 4.678 & -.035 \\
\hline e1 & $\langle-->$ & $\mathrm{e} 12$ & 32.330 & -.331 \\
\hline e1 & $\langle-->$ & e7 & 9.640 & -.097 \\
\hline & $\langle-->$ & $\mathrm{e} 5$ & 16.233 & -.168 \\
\hline
\end{tabular}

Variances: (Group number 1 - Default model)

\begin{tabular}{|l|lr|}
\hline & M.I. & $\begin{array}{r}\text { Par } \\
\text { Change }\end{array}$ \\
\hline
\end{tabular}

Regression Weights: (Group number 1 - Default model)

M.I. Par Change 


\begin{tabular}{|c|c|c|c|c|}
\hline AMOT & $<-$ & SR & 17.515 & -.335 \\
\hline AMOT & $<-$ & SEC & 34.545 & .405 \\
\hline AMOT & $\begin{array}{l}<- \\
-\end{array}$ & SRTE & 19.576 & -.311 \\
\hline AMOT & $<-$ & SREF & 38.313 & -.383 \\
\hline InMC & $<-$ & AMOT & 7.890 & .068 \\
\hline InMC & $<-$ & SEC & 17.713 & .164 \\
\hline InMC & $\begin{array}{l}<- \\
-\end{array}$ & SMR & 4.345 & .093 \\
\hline InMC & $\begin{array}{l}<- \\
-\end{array}$ & SRTE & 4.240 & -.082 \\
\hline InMK & $\begin{array}{l}<- \\
-\end{array}$ & SEC & 4.219 & -.079 \\
\hline ExME & $\begin{array}{l}<- \\
-\end{array}$ & SEC & 4.004 & .094 \\
\hline SEC & $<-$ & SR & 11.005 & -.190 \\
\hline SEC & $<-$ & AMOT & 31.003 & .170 \\
\hline SEC & $<--$ & SRTE & 9.336 & -.154 \\
\hline SEC & $\begin{array}{l}<- \\
-\end{array}$ & SREF & 19.245 & -.194 \\
\hline SELP & $\begin{array}{l}<- \\
-\end{array}$ & ExMD & 5.710 & .085 \\
\hline SELP & $\begin{array}{l}<- \\
-\end{array}$ & ExME & 5.928 & .081 \\
\hline SELP & $\begin{array}{l}<- \\
-\end{array}$ & SEC & 8.140 & .109 \\
\hline SMR & $\begin{array}{l}<- \\
-\end{array}$ & AcadMotiv & 7.474 & .248 \\
\hline SMR & $\begin{array}{l}<- \\
-\end{array}$ & AMOT & 9.514 & .069 \\
\hline
\end{tabular}




\begin{tabular}{|c|c|c|c|c|}
\hline SMR & $<--$ & InMC & 17.262 & .118 \\
\hline SMR & $<--$ & InMS & 37.330 & . 167 \\
\hline SMR & $<--$ & InMK & 6.507 & .077 \\
\hline SMR & $<-$ & ExME & 7.428 & -.086 \\
\hline SRTE & $<-$ & AMOT & 16.798 & -.092 \\
\hline SRTE & $\begin{array}{l}<- \\
-\end{array}$ & InMC & 5.052 & -.064 \\
\hline SRTE & $\begin{array}{l}<- \\
-\end{array}$ & InMS & 11.433 & -.093 \\
\hline SRTE & $\begin{array}{l}<- \\
-\end{array}$ & ExMD & 13.482 & .123 \\
\hline SRTE & $<-$ & ExME & 11.242 & .106 \\
\hline SREF & $\begin{array}{l}<- \\
-\end{array}$ & AMOT & 15.142 & -.102 \\
\hline SREF & $<-$ & InMS & 6.120 & -.080 \\
\hline SREF & $\begin{array}{l}<- \\
-\end{array}$ & InMK & 4.273 & -.073 \\
\hline SREF & $<--$ & ExMD & 5.212 & -.090 \\
\hline SREF & $\begin{array}{l}<- \\
-\end{array}$ & SEC & 17.314 & -.178 \\
\hline
\end{tabular}

Minimization History (Default model)

\begin{tabular}{|c|c|c|c|c|c|c|c|c|}
\hline $\begin{array}{r}\text { Iteratio } \\
\mathrm{n}\end{array}$ & & $\begin{array}{r}\text { Negative } \\
\text { eigenvalu } \\
\text { es }\end{array}$ & $\begin{array}{r}\text { Conditio } \\
\mathrm{n} \#\end{array}$ & $\begin{array}{r}\text { Smallest } \\
\text { eigenvalu } \\
\mathrm{e}\end{array}$ & $\begin{array}{r}\text { Diamete } \\
\mathrm{r}\end{array}$ & $\mathrm{F}$ & $\begin{array}{r}\text { NTrie } \\
\mathrm{s}\end{array}$ & Ratio \\
\hline 0 & $\mathrm{e}$ & 11 & & -1.356 & $\begin{array}{r}9999.00 \\
0\end{array}$ & $\begin{array}{r}2159.78 \\
6\end{array}$ & 0 & $\begin{array}{r}9999.00 \\
0\end{array}$ \\
\hline 1 & $\mathrm{e}$ & 9 & & -.235 & 1.398 & $\begin{array}{r}1254.72 \\
4\end{array}$ & 20 & .576 \\
\hline
\end{tabular}




\begin{tabular}{|c|c|c|c|c|c|c|c|c|}
\hline 2 & $\mathrm{e}$ & 4 & & -.144 & .466 & 983.459 & 6 & .822 \\
\hline 3 & $\mathrm{e}$ & 2 & & -.046 & .676 & 670.963 & 5 & .861 \\
\hline 4 & $\begin{array}{l}\mathrm{e} \\
*\end{array}$ & 0 & 137.905 & & .939 & 437.045 & 5 & .679 \\
\hline 5 & $\mathrm{e}$ & 0 & 148.976 & & .924 & 385.952 & 1 & .483 \\
\hline 6 & $\mathrm{e}$ & 0 & 172.539 & & .520 & 293.088 & 1 & 1.165 \\
\hline 7 & $\mathrm{e}$ & 0 & 450.906 & & .432 & 277.893 & 1 & 1.213 \\
\hline 8 & $\mathrm{e}$ & 0 & $\begin{array}{r}1289.44 \\
0\end{array}$ & & .501 & 273.535 & 1 & 1.146 \\
\hline 9 & $\mathrm{e}$ & 0 & $\begin{array}{r}3201.17 \\
7\end{array}$ & & .305 & 271.933 & 1 & 1.194 \\
\hline 10 & $\mathrm{e}$ & 0 & $\begin{array}{r}5302.71 \\
1\end{array}$ & & .256 & 271.606 & 1 & 1.114 \\
\hline 11 & $\mathrm{e}$ & 0 & $\begin{array}{r}7150.58 \\
8\end{array}$ & & .076 & 271.570 & 1 & 1.068 \\
\hline 12 & $\mathrm{e}$ & 0 & $\begin{array}{r}7356.15 \\
3\end{array}$ & & .015 & 271.569 & 1 & 1.012 \\
\hline 13 & $\mathrm{e}$ & 0 & $\begin{array}{r}7273.42 \\
9\end{array}$ & & .000 & 271.569 & 1 & 1.000 \\
\hline
\end{tabular}

Model Fit Summary

CMIN

\begin{tabular}{|c|c|c|c|c|c|}
\hline Model & $\begin{array}{r}\mathrm{NPA} \\
\mathrm{R}\end{array}$ & CMIN & DF & $\mathrm{P}$ & CMIN/DF \\
\hline Default model & 38 & 271.569 & 40 & .000 & 6.789 \\
\hline Saturated model & 78 & .000 & 0 & & \\
\hline
\end{tabular}




\begin{tabular}{|c|c|c|c|c|}
\hline Independence model & 12 & 2157.8 & 22 & .000 \\
\hline \multicolumn{5}{|l|}{ RMR, GFI } \\
\hline Model & RMR & GFI & $\begin{array}{l}\mathrm{AGF}_{\mathrm{I}} \\
\end{array}$ & PGFI \\
\hline Default model & .138 & .875 & .757 & .449 \\
\hline Saturated model & .000 & 1.000 & & \\
\hline Independence model & .522 & .375 & .261 & .317 \\
\hline
\end{tabular}

Baseline Comparisons

\begin{tabular}{|l|rrrrr|}
\hline Model & $\begin{array}{r}\text { NFI } \\
\text { Delta1 }\end{array}$ & $\begin{array}{r}\text { RFI } \\
\text { rho1 }\end{array}$ & $\begin{array}{r}\text { IFI } \\
\text { Delta2 }\end{array}$ & $\begin{array}{r}\text { TLI } \\
\text { rho2 }\end{array}$ & CFI \\
\hline Default model & .874 & .792 & .891 & .817 & .889 \\
Saturated model & 1.000 & & 1.000 & & 1.000 \\
& & & & & \\
Independence model & .000 & .000 & .000 & .000 & .000 \\
\hline
\end{tabular}

Parsimony-Adjusted Measures

\begin{tabular}{|l|rrr|}
\hline Model & $\begin{array}{r}\text { PRATI } \\
\text { O }\end{array}$ & PNFI & PCFI \\
\hline Default model & .606 & .530 & .539 \\
Saturated model & .000 & .000 & .000 \\
Independence model & 1.000 & .000 & .000 \\
\hline
\end{tabular}

\begin{tabular}{|l|rrr|}
\hline Model & NCP & LO 90 & HI 90 \\
\hline Default model & 231.569 & 183.086 & 287.546 \\
Saturated model & .000 & .000 & .000 \\
Independence model & 2091.802 & 1943.787 & 2247.170 \\
\hline
\end{tabular}

FMIN

\begin{tabular}{|l|rrrr|}
\hline Model & FMIN & F0 & LO 90 & HI 90 \\
\hline Default model & .780 & .665 & .526 & .826 \\
Saturated model & .000 & .000 & .000 & .000 \\
Independence model & 6.201 & 6.011 & 5.586 & 6.457 \\
\hline
\end{tabular}

RMSEA

\begin{tabular}{|l|rrrr|}
\hline Model & RMSEA & LO 90 & HI 90 & PCLOSE \\
\hline Default model & .129 & .115 & .144 & .000
\end{tabular}




\begin{tabular}{|c|c|c|c|c|}
\hline Independence model & .302 & .291 & 13 & 00 \\
\hline \multicolumn{5}{|l|}{ AIC } \\
\hline Model & AIC & $\mathrm{BCC}$ & $\mathrm{BIC}$ & CAIC \\
\hline Default model & 347.569 & 350.518 & 494.062 & 532.062 \\
\hline Saturated model & 156.000 & 162.054 & 456.696 & 534.696 \\
\hline Independence model & 2181.802 & 2182.734 & 2228.063 & 2240.063 \\
\hline
\end{tabular}

ECVI

\begin{tabular}{|l|rrrr|}
\hline Model & ECVI & LO 90 & HI 90 & MECVI \\
\hline Default model & .999 & .859 & 1.160 & 1.007 \\
Saturated model & .448 & .448 & .448 & .466 \\
Independence model & 6.270 & 5.844 & 6.716 & 6.272 \\
\hline
\end{tabular}

HOELTER

\begin{tabular}{|l|rr|}
\hline Model & HOELTER & HOELTE \\
& .05 & $\mathrm{R}$ \\
& & .01 \\
\hline Default model & 72 & 82 \\
Independence model & 14 & 16 \\
\hline
\end{tabular}

Execution time summary

Minimization: $\quad .003$

Miscellaneous: .329

Bootstrap: $\quad .000$

Total: $\quad .332$

\section{Execution time summary}

Parameter Summary (Group number 1)

\section{Adjusted Model}

\begin{tabular}{|r|rrrrrr|}
\hline & Weights & Covariances & Variance & Means & Intercepts & Tota \\
& & & $\mathrm{s}$ & & & 1 \\
\hline Fixed & 16 & 0 & 1 & 0 & 0 & 17 \\
Labeled & 0 & 0 & 0 & 0 & 0 & 0 \\
Unlabeled & 13 & 14 & 14 & 0 & 0 & 41 \\
Total & 29 & 14 & 15 & 0 & 0 & 58 \\
\hline
\end{tabular}


Sample Moments (Group number 1)

Sample Covariances (Group number 1)

\begin{tabular}{|l|rrrrrrrrrrrr|}
\hline & AM & In & In & InM & ExM & ExM & Ex & SE & SE & SM & SR & SR \\
& OT & MC & MS & K & N & D & ME & C & LP & R & TE & EF \\
\hline AM & 2.78 & & & & & & & & & & & \\
OT & 7 & & & & & & & & & & & \\
InM & -.494 & 1.7 & & & & & & & & & & \\
C & & 44 & & & & & & & & & & \\
InM & .258 & 1.1 & 1.9 & & & & & & & & & \\
S & & 29 & 18 & & & & & & & & & \\
InM & -.734 & 1.2 & .91 & 1.54 & & & & & & & \\
K & & 02 & 8 & 2 & & & & & & & \\
ExM & -.509 & 1.1 & .61 & .900 & 1.76 & & & & & & \\
N & & 14 & 7 & & 2 & & & & & & \\
ExM & -.972 & .71 & .31 & .803 & .776 & 1.24 & & & & & \\
D & & 6 & 1 & & & 8 & & & & & \\
ExM & -.567 & .38 & - & .488 & .744 & .768 & 1.40 & & & & \\
E & & 5 & .01 & & & & 6 & & & & \\
& & & 6 & & & & & & & & & \\
SEC & .330 & .36 & .26 & .174 & .214 & .153 & .199 & 1.0 & & & & \\
& & 3 & 9 & & & & & 68 & & & & \\
SEL & -.618 & .69 & .38 & .721 & .597 & .616 & .437 & .39 & 1.1 & & & \\
P & & 3 & 8 & & & & & 7 & 45 & & \\
SMR & -.198 & .56 & .51 & .507 & .335 & .295 & .126 & .23 & .51 & .78 & & \\
SRT & & 7 & 3 & & & & & 1 & 8 & 4 & & \\
E & -.795 & .36 & .13 & .488 & .342 & .516 & .355 & .02 & .58 & .43 & 1.0 & \\
SRE & -.940 & .42 & .14 & .487 & .401 & .414 & .252 & - & .66 & .43 & .78 & 1.3 \\
F & & 7 & 6 & & & & & .04 & 1 & 1 & 6 & 21 \\
& & & & & & & & 2 & & & \\
\hline
\end{tabular}

Eigenvalues

7.311 3.359 1.697 1.407.899.760.518.427.399.366.329.274

Determinant of sample covariance matrix $=.116$

Sample Correlations (Group number 1)

\begin{tabular}{|r|rrrrrrrrrrrr|}
\hline & AM & In & In & InM & ExM & ExM & Ex & SE & SE & SM & SR & SR \\
& OT & MC & MS & K & N & D & ME & C & LP & R & TE & EF \\
\hline
\end{tabular}




\begin{tabular}{|c|c|c|c|c|c|c|c|c|c|c|c|c|}
\hline AM & 1.00 & & & & & & & & & & & \\
\hline OT & 0 & & & & & & & & & & & \\
\hline InM & -.224 & 1.0 & & & & & & & & & & \\
\hline $\mathrm{C}$ & & 00 & & & & & & & & & & \\
\hline InM & .111 & .61 & 1.0 & & & & & & & & & \\
\hline$S$ & & 7 & 00 & & & & & & & & & \\
\hline InM & -.354 & .73 & .53 & 1.00 & & & & & & & & \\
\hline K & & 3 & 4 & 0 & & & & & & & & \\
\hline ExM & -.230 & .63 & .33 & .546 & 1.00 & & & & & & & \\
\hline $\mathrm{N}$ & & 5 & 5 & & 0 & & & & & & & \\
\hline ExM & -.521 & .48 & .20 & .579 & .523 & 1.00 & & & & & & \\
\hline D & & 6 & 1 & & & 0 & & & & & & \\
\hline ExM & -.287 & .24 & - & .332 & .473 & .580 & 1.00 & & & & & \\
\hline E & & 6 & $\begin{array}{r}.01 \\
0\end{array}$ & & & & 0 & & & & & \\
\hline SEC & .191 & $\begin{array}{r}.26 \\
6\end{array}$ & $\begin{array}{r}.18 \\
8\end{array}$ & .135 & .156 & .133 & .162 & $\begin{array}{r}1.0 \\
00\end{array}$ & & & & \\
\hline $\begin{array}{l}\text { SEL } \\
\mathrm{P}\end{array}$ & -.346 & $\begin{array}{r}.49 \\
0\end{array}$ & $\begin{array}{r}.26 \\
2\end{array}$ & .542 & .420 & .515 & .344 & $\begin{array}{r}.35 \\
9\end{array}$ & $\begin{array}{r}1.0 \\
00\end{array}$ & & & \\
\hline SMR & -.134 & $\begin{array}{r}.48 \\
5\end{array}$ & $\begin{array}{r}.41 \\
8\end{array}$ & .462 & .285 & .298 & .120 & $\begin{array}{r}.25 \\
3\end{array}$ & $\begin{array}{r}.54 \\
7\end{array}$ & $\begin{array}{r}1.0 \\
00\end{array}$ & & \\
\hline SRT & -.472 & .27 & .09 & .389 & .256 & .458 & .296 & .02 & .54 & .49 & 1.0 & \\
\hline $\mathrm{E}$ & & 5 & 6 & & & & & 3 & 3 & 1 & 00 & \\
\hline SRE & -.490 & .28 & .09 & .341 & .263 & .323 & .185 & - & .53 & .42 & .67 & 1.0 \\
\hline $\mathrm{F}$ & & 1 & 2 & & & & & $\begin{array}{r}.03 \\
6\end{array}$ & 7 & 4 & 8 & 00 \\
\hline
\end{tabular}

Eigenvalues

4.9731 .8211 .2921 .071 .571 .507 .393 .341 .309 .288 .235 .200

Models

Default model (Default model)

Notes for Model (Default model)

Computation of degrees of freedom (Default model)

Number of distinct sample moments: 78

Number of distinct parameters to be estimated: 41

Degrees of freedom $(78-41): \quad 37$

Result (Default model) 
Minimum was achieved

Chi-square $=187.547$

Degrees of freedom $=37$

Probability level $=.000$

Group number 1 (Group number 1 - Default model)

Estimates (Group number 1 - Default model)

Scalar Estimates (Group number 1 - Default model)

Maximum Likelihood Estimates

Regression Weights: (Group number 1 - Default model)

\begin{tabular}{|c|c|c|c|c|c|c|}
\hline & & & Estimate & S.E. & C.R. & $\begin{array}{ll} & \text { Label }\end{array}$ \\
\hline AcadMotiv & $\begin{array}{l}<-- \\
-\end{array}$ & SE & .184 & .038 & 4.827 & $* * *$ \\
\hline AcadMotiv & $\begin{array}{l}<-- \\
-\end{array}$ & SR & .106 & .036 & 2.950 & .003 \\
\hline SREF & $\begin{array}{l}<-- \\
-\end{array}$ & SR & 1.000 & & & \\
\hline SRTE & $\begin{array}{l}<-- \\
-\end{array}$ & SR & .811 & .057 & 14.151 & $* * *$ \\
\hline SMR & $\begin{array}{l}<-- \\
-\end{array}$ & SR & .608 & .055 & 11.012 & $* * *$ \\
\hline SELP & $\begin{array}{l}<-- \\
-\end{array}$ & SE & 1.000 & & & \\
\hline SEC & $\begin{array}{l}<-- \\
-\end{array}$ & SE & .553 & .068 & 8.129 & $* * *$ \\
\hline ExME & $\begin{array}{l}<-- \\
-\end{array}$ & AcadMotiv & 1.000 & & & \\
\hline ExMD & $\begin{array}{l}<-- \\
-\end{array}$ & AcadMotiv & 1.665 & .211 & 7.877 & $* * *$ \\
\hline ExMN & $\begin{array}{l}<-- \\
-\end{array}$ & AcadMotiv & 1.835 & .253 & 7.252 & $* * *$ \\
\hline InMK & $\begin{array}{l}<-- \\
-\end{array}$ & AcadMotiv & 2.594 & .387 & 6.700 & $* * *$ \\
\hline InMS & $\begin{array}{l}<-- \\
-\end{array}$ & AcadMotiv & 1.821 & .334 & 5.447 & $* * *$ \\
\hline InMC & $\begin{array}{l}<-- \\
-\end{array}$ & AcadMotiv & 2.420 & .366 & 6.603 & $* * *$ \\
\hline
\end{tabular}




\begin{tabular}{|lll|llll|} 
AMOT & $<--$ & AcadMotiv & -.760 & .237 & -3.206 & .001 \\
& - & & & & & \\
AMOT & $<--$ & SR & -.547 & .098 & -5.576 & $* * *$ \\
& - & & & & & \\
SEC & $<--$ & SR & -.387 & .085 & -4.546 & $* * *$ \\
& - & & & & & \\
\hline
\end{tabular}

Standardized Regression Weights: (Group number 1 - Default model)

\begin{tabular}{|c|c|c|c|}
\hline & & & Estimate \\
\hline AcadMotiv & $\begin{array}{l}<- \\
-\end{array}$ & SE & .452 \\
\hline AcadMotiv & $<-$ & SR & .236 \\
\hline SREF & $\begin{array}{l}<- \\
-\end{array}$ & SR & .847 \\
\hline SRTE & $<-$ & SR & .783 \\
\hline SMR & $\begin{array}{l}<- \\
-\end{array}$ & SR & .670 \\
\hline SELP & $<-$ & SE & 1.000 \\
\hline SEC & $<-$ & SE & .590 \\
\hline ExME & $<-$ & AcadMotiv & .368 \\
\hline ExMD & $\begin{array}{l}<- \\
-\end{array}$ & AcadMotiv & .651 \\
\hline ExMN & $\begin{array}{l}<- \\
-\end{array}$ & AcadMotiv & .598 \\
\hline InMK & $<-$ & AcadMotiv & .909 \\
\hline InMS & $<-$ & AcadMotiv & .578 \\
\hline InMC & - & AcadMotiv & .797 \\
\hline AMOT & & AcadMotiv & -.202 \\
\hline
\end{tabular}




\begin{tabular}{|lll|l|} 
AMOT & $<--$ & SR & -.325 \\
& - & & \\
SEC & $<--$ & SR & -.376 \\
& - & & \\
\hline
\end{tabular}

Covariances: (Group number 1 - Default model)

\begin{tabular}{|c|c|c|c|c|c|c|}
\hline & & & Estimate & S.E. & C.R. & P Label \\
\hline SR & $\langle--\rangle$ & $\mathrm{SE}$ & .714 & .075 & 9.577 & $* * *$ \\
\hline e6 & $\langle--\rangle$ & e7 & .444 & .058 & 7.617 & $* * *$ \\
\hline e10 & $\langle--\rangle$ & $\mathrm{e} 12$ & .609 & .088 & 6.920 & $* * *$ \\
\hline e6 & $\langle-->$ & e8 & .420 & .063 & 6.655 & $* * *$ \\
\hline e7 & $\langle-->$ & $\mathrm{e} 12$ & -.459 & .071 & -6.501 & $* * *$ \\
\hline e10 & $\langle-->$ & e11 & .253 & .056 & 4.538 & $* * *$ \\
\hline e8 & $\langle-->$ & $\mathrm{e} 11$ & .296 & .050 & 5.876 & $* * *$ \\
\hline e7 & $\langle-->$ & e8 & .203 & .047 & 4.347 & $* * *$ \\
\hline e6 & $\langle-->$ & $\mathrm{e} 10$ & -.319 & .062 & -5.165 & $* * *$ \\
\hline e1 & $\langle-->$ & e3 & -.144 & .038 & -3.799 & $* * *$ \\
\hline e7 & $\langle--\rangle$ & e10 & -.238 & .051 & -4.649 & $* * *$ \\
\hline e6 & $\langle-->$ & e12 & -.272 & .079 & -3.431 & $* * *$ \\
\hline e5 & $\langle-->$ & e12 & .280 & .066 & 4.260 & $* * *$ \\
\hline e3 & $\langle--\rangle$ & e5 & .126 & .038 & 3.353 & $* * *$ \\
\hline
\end{tabular}

Correlations: (Group number 1 - Default model)

\begin{tabular}{|lll|r|}
\hline & & & Estimate \\
\hline SR & $<->$ & SE & .685 \\
e6 & $<-->$ & e7 & .477 \\
e10 $<-->$ & e12 & .376
\end{tabular}




\begin{tabular}{|c|c|c|c|}
\hline e6 & $\langle--\rangle$ & e8 & .357 \\
\hline e7 & $\langle--\rangle$ & e12 & -.375 \\
\hline e10 & $\langle--\rangle$ & e11 & .283 \\
\hline e8 & $\langle--\rangle$ & e11 & .347 \\
\hline e7 & $\langle-->$ & e8 & .224 \\
\hline e6 & $\langle--\rangle$ & e10 & -.260 \\
\hline $\mathrm{e} 1$ & $\langle-->$ & e3 & -.358 \\
\hline e7 & $\langle-->$ & e10 & -.251 \\
\hline e6 & $\langle-->$ & e12 & -.171 \\
\hline e5 & $<-->$ & e12 & .214 \\
\hline e3 & $\langle--\rangle$ & $\mathrm{e} 5$ & .212 \\
\hline
\end{tabular}

Variances: (Group number 1 - Default model)

\begin{tabular}{|c|c|c|c|c|}
\hline & Estimate & S.E. & C.R. & P Label \\
\hline SR & .948 & .109 & 8.688 & $* * *$ \\
\hline SE & 1.145 & .087 & $\begin{array}{r}13.19 \\
1\end{array}$ & $* * *$ \\
\hline e13 & .112 & .034 & 3.319 & $* * *$ \\
\hline e4 & .000 & & & \\
\hline e1 & .373 & .059 & 6.315 & $* * *$ \\
\hline e2 & .395 & .042 & 9.397 & $* * *$ \\
\hline e3 & .431 & .043 & 9.905 & $* * *$ \\
\hline e5 & .819 & .065 & $\begin{array}{r}12.66 \\
7\end{array}$ & $* * *$ \\
\hline e6 & 1.207 & .093 & $\begin{array}{r}13.00 \\
9\end{array}$ & $* * *$ \\
\hline e7 & .716 & .060 & $\begin{array}{r}11.95 \\
1\end{array}$ & $* * *$ \\
\hline e8 & 1.144 & .092 & $\begin{array}{r}12.43 \\
6\end{array}$ & $* * *$ \\
\hline e9 & .267 & .054 & 4.967 & $* * *$ \\
\hline
\end{tabular}




\begin{tabular}{|l|rrrl|}
$\mathrm{e} 10$ & 1.251 & .102 & 12.20 & $* * *$ \\
$\mathrm{e} 11$ & & & 5 & \\
$\mathrm{e} 12$ & .636 & .065 & 9.860 & $* * *$ \\
& & & & \\
& 2.093 & .160 & 13.05 & $* * *$ \\
& & & 1 & \\
\hline
\end{tabular}

Squared Multiple Correlations: (Group number 1 - Default model)

\begin{tabular}{|l|r|}
\hline AcadMotiv & Estimate \\
AMOT & .407 \\
InMC & .636 \\
InMS & .334 \\
InMK & .827 \\
ExMN & .358 \\
ExMD & .423 \\
ExME & .136 \\
SEC & .185 \\
SELP & 1.000 \\
SMTE & .449 \\
& .613 \\
& \\
SREF & .718 \\
\hline
\end{tabular}

Matrices (Group number 1 - Default model)

Implied Covariances (Group number 1 - Default model)

\begin{tabular}{|l|rrrrrrrrrrrr|}
\hline & AM & In & In & InM & ExM & ExM & Ex & SE & SE & SM & SR & SR \\
& OT & MC & MS & K & N & D & ME & C & LP & R & TE & EF \\
\hline AM & 2.67 & & & & & & & & & & & \\
OT & 8 & & & & & & & & & & &
\end{tabular}




\begin{tabular}{|c|c|c|c|c|c|c|c|c|c|c|c|c|}
\hline $\begin{array}{l}\text { InM } \\
\text { C }\end{array}$ & -.654 & $\begin{array}{r}1.7 \\
45\end{array}$ & & & & & & & & & & \\
\hline InM & . 1177 & 1.0 & 1.8 & & & & & & & & & \\
\hline$S$ & & 87 & 79 & & & & & & & & & \\
\hline InM & -.702 & 1.1 & .89 & 1.54 & & & & & & & & \\
\hline K & & 89 & 5 & 2 & & & & & & & & \\
\hline ExM & -.496 & 1.1 & .63 & .902 & 1.78 & & & & & & & \\
\hline $\mathrm{N}$ & & 37 & 3 & & 2 & & & & & & & \\
\hline ExM & -.910 & .76 & .33 & .819 & .782 & 1.24 & & & & & & \\
\hline D & & 3 & 7 & & & 2 & & & & & & \\
\hline ExM & -.543 & .45 & .02 & .492 & .768 & .759 & 1.39 & & & & & \\
\hline $\mathrm{E}$ & & 8 & 6 & & & & 7 & & & & & \\
\hline SEC & .213 & $\begin{array}{r}.16 \\
6\end{array}$ & $\begin{array}{r}.12 \\
5\end{array}$ & .178 & .126 & .114 & .069 & $\begin{array}{r}1.0 \\
06\end{array}$ & & & & \\
\hline SEL & -.608 & .69 & .52 & .742 & .525 & .476 & .286 & .35 & 1.1 & & & \\
\hline$P$ & & 2 & 1 & & & & & 7 & 45 & & & \\
\hline SMR & -.422 & .34 & .25 & .365 & .258 & .235 & .141 & .14 & .43 & .78 & & \\
\hline & & 1 & 6 & & & & & 3 & 5 & 2 & & \\
\hline SRT & -.563 & .45 & .34 & .487 & .345 & .313 & .188 & .02 & .58 & .46 & 1.0 & \\
\hline $\mathrm{E}$ & & 5 & 2 & & & & & 3 & 0 & 8 & 19 & \\
\hline SRE & -.694 & .56 & .42 & .601 & .425 & .385 & .231 & .02 & .71 & .43 & .76 & 1.3 \\
\hline $\mathrm{F}$ & & 0 & 2 & & & & & 8 & 4 & 3 & 9 & 21 \\
\hline
\end{tabular}

\begin{tabular}{|l|rrrrrrrrrrrr|}
\hline & AM & In & In & InM & ExM & ExM & Ex & SE & SE & SM & SR & SR \\
& OT & MC & MS & K & N & D & ME & C & LP & R & TE & EF \\
\hline AM & 1.00 & & & & & & & & & & & \\
OT & 0 & & & & & & & & & & & \\
InM & -.303 & 1.0 & & & & & & & & & & \\
C & & 00 & & & & & & & & & & \\
InM & .052 & .60 & 1.0 & & & & & & & & \\
S & & 0 & 00 & & & & & & & & \\
InM & -.345 & .72 & .52 & 1.00 & & & & & & & \\
K & & 5 & 6 & 0 & & & & & & & \\
ExM & -.227 & .64 & .34 & .544 & 1.00 & & & & & & \\
N & & 5 & 6 & & 0 & & & & & & & \\
ExM & -.499 & .51 & .22 & .591 & .525 & 1.00 & & & & & \\
D & & 9 & 1 & & & 0 & & & & &
\end{tabular}




\begin{tabular}{|l|rrrrrrrrrrr|r|} 
ExM & -.281 & .29 & .01 & .335 & .486 & .577 & 1.00 & & & & & \\
E & & 4 & 6 & & & & 0 & & & & & \\
SEC & .130 & .12 & .09 & .143 & .094 & .102 & .058 & 1.0 & & & & \\
& & 5 & 1 & & & & & 00 & & & & \\
SEL & -.347 & .48 & .35 & .558 & .367 & .399 & .226 & .33 & 1.0 & & & \\
P & & 9 & 5 & & & & & 2 & 00 & & & \\
SMR & -.292 & .29 & .21 & .333 & .219 & .238 & .135 & .16 & .45 & 1.0 & & \\
& & 2 & 2 & & & & & 1 & 9 & 00 & & \\
SRT & -.341 & .34 & .24 & .389 & .256 & .278 & .157 & .02 & .53 & .52 & 1.0 & \\
E & & 1 & 7 & & & & & 2 & 6 & 4 & 00 & \\
SRE & -.369 & .36 & .26 & .421 & .277 & .301 & .170 & .02 & .58 & .42 & .66 & 1.0 \\
F & & 9 & 8 & & & & & 4 & 1 & 6 & 3 & 00 \\
\hline
\end{tabular}

Covariances: (Group number 1 - Default model)

\begin{tabular}{|c|c|c|c|c|}
\hline & & & M.I. & Par Change \\
\hline $\mathrm{e} 12$ & $\langle--\rangle$ & $\mathrm{SE}$ & 4.519 & .114 \\
\hline e5 & $\langle--\rangle$ & e11 & 5.639 & .083 \\
\hline e5 & $\langle-->$ & e9 & 4.373 & -.073 \\
\hline e5 & $\langle-->$ & e6 & 4.886 & .094 \\
\hline e4 & $\langle--\rangle$ & e12 & 4.464 & .095 \\
\hline e4 & $\langle--\rangle$ & e10 & 4.031 & -.073 \\
\hline e4 & $\langle--\rangle$ & e7 & 5.433 & .062 \\
\hline e3 & $\langle--\rangle$ & SE & 8.760 & .091 \\
\hline e3 & $\langle-->$ & SR & 4.388 & -.061 \\
\hline e3 & $\langle--\rangle$ & e13 & 10.742 & .047 \\
\hline e3 & $<-->$ & e12 & 17.105 & .193 \\
\hline e3 & $\langle--\rangle$ & e11 & 11.847 & .098 \\
\hline e2 & $\langle-->$ & e11 & 4.561 & -.059 \\
\hline e2 & $<-->$ & e7 & 8.169 & .076 \\
\hline e1 & $\langle--\rangle$ & e13 & 5.292 & -.036 \\
\hline e1 & $\langle--\rangle$ & e12 & 7.227 & -.138 \\
\hline e1 & $\langle--\rangle$ & e7 & 5.055 & -.068 \\
\hline
\end{tabular}

Variances: (Group number 1 - Default model)

\begin{tabular}{|l|lr|}
\hline & M.I. & $\begin{array}{r}\text { Par } \\
\text { Change }\end{array}$ \\
\hline
\end{tabular}


Regression Weights: (Group number 1 - Default model)

\begin{tabular}{|c|c|c|c|c|}
\hline & & & M.I. & Par Change \\
\hline AMOT & $\begin{array}{l}<-- \\
-\end{array}$ & SMR & 11.452 & .250 \\
\hline InMC & $<--$ & AMOT & 4.940 & .054 \\
\hline InMC & $<--$ & SEC & 12.260 & .139 \\
\hline InMC & $<--$ & SMR & 6.578 & .115 \\
\hline InMK & $<-$ & SEC & 7.954 & -.112 \\
\hline ExMD & $\begin{array}{l}<- \\
-\end{array}$ & SE & 4.740 & .078 \\
\hline ExMD & $\begin{array}{l}<-- \\
-\end{array}$ & SELP & 4.740 & .078 \\
\hline ExMD & $\begin{array}{l}<- \\
-\end{array}$ & SRTE & 8.224 & .109 \\
\hline ExME & $\begin{array}{l}<- \\
-\end{array}$ & SEC & 5.820 & .117 \\
\hline SMR & $\begin{array}{l}<-- \\
-\end{array}$ & SE & 4.403 & .075 \\
\hline SMR & $\begin{array}{l}<- \\
-\end{array}$ & AcadMotiv & 11.675 & .320 \\
\hline SMR & $\begin{array}{l}<- \\
-\end{array}$ & AMOT & 22.398 & .111 \\
\hline SMR & $\begin{array}{l}<- \\
-\end{array}$ & InMC & 23.468 & .141 \\
\hline SMR & $\begin{array}{l}<- \\
-\end{array}$ & InMS & 41.163 & .180 \\
\hline SMR & $\begin{array}{l}<-- \\
-\end{array}$ & InMK & 9.120 & .094 \\
\hline SMR & $\begin{array}{l}<- \\
-\end{array}$ & ExME & 4.760 & -.071 \\
\hline SMR & $\begin{array}{l}<- \\
-\end{array}$ & SEC & 4.808 & .084 \\
\hline
\end{tabular}




\begin{tabular}{|c|c|c|c|c|}
\hline |SMR & $<--$ & SELP & 4.403 & .075 \\
\hline SRTE & $<--$ & AMOT & 10.039 & -.072 \\
\hline & - & & & \\
\hline SRTE & $<--$ & InMS & 7.936 & -.076 \\
\hline SRTE & $<-$ & ExMD & 14.282 & .125 \\
\hline SRTE & $\begin{array}{l}<- \\
-\end{array}$ & ExME & 11.951 & .108 \\
\hline SREF & $\begin{array}{l}<- \\
-\end{array}$ & AcadMotiv & 4.892 & -.227 \\
\hline SREF & $\begin{array}{l}<-- \\
-\end{array}$ & InMS & 4.195 & -.063 \\
\hline SREF & $\begin{array}{l}<- \\
-\end{array}$ & InMK & 4.888 & -.075 \\
\hline SREF & $\begin{array}{l}<- \\
-\end{array}$ & ExMD & 6.294 & -.095 \\
\hline
\end{tabular}

Minimization History (Default model)

\begin{tabular}{|c|c|c|c|c|c|c|c|c|}
\hline $\begin{array}{r}\text { Iteratio } \\
\mathrm{n}\end{array}$ & & $\begin{array}{r}\text { Negative } \\
\text { eigenvalu } \\
\text { es }\end{array}$ & $\begin{array}{r}\text { Conditio } \\
\mathrm{n} \#\end{array}$ & $\begin{array}{r}\text { Smallest } \\
\text { eigenvalu } \\
\mathrm{e}\end{array}$ & $\begin{array}{r}\text { Diamete } \\
r\end{array}$ & $\mathrm{~F}$ & $\begin{array}{r}\text { NTrie } \\
\mathrm{s}\end{array}$ & Ratio \\
\hline 0 & $\mathrm{e}$ & 11 & & -1.381 & $\begin{array}{r}9999.00 \\
0\end{array}$ & $\begin{array}{r}2183.62 \\
9\end{array}$ & 0 & $\begin{array}{r}9999.00 \\
0\end{array}$ \\
\hline 1 & e & 9 & & -.241 & 1.487 & $\begin{array}{r}1202.60 \\
7\end{array}$ & 20 & .551 \\
\hline 2 & e & 5 & & -.186 & .483 & 918.121 & 6 & .804 \\
\hline 3 & $\mathrm{e}$ & 2 & & -.062 & .651 & 599.947 & 5 & .903 \\
\hline 4 & $\begin{array}{l}\mathrm{e} \\
*\end{array}$ & 1 & & -.015 & .985 & 389.181 & 5 & .555 \\
\hline 5 & $\mathrm{e}$ & 0 & 81.969 & & .602 & 263.207 & 6 & 1.062 \\
\hline 6 & e & 0 & 132.311 & & .548 & 212.322 & 1 & 1.224 \\
\hline 7 & e & 0 & 346.490 & & .570 & 197.252 & 1 & 1.103 \\
\hline
\end{tabular}




\begin{tabular}{|c|c|c|c|c|c|c|c|}
\hline 8 & $\mathrm{e}$ & 0 & 957.532 & .410 & 190.193 & 1 & 1.196 \\
\hline 9 & e & 0 & $\begin{array}{r}2296.59 \\
9\end{array}$ & .446 & 188.252 & 1 & 1.079 \\
\hline 10 & $\mathrm{e}$ & 0 & $\begin{array}{r}4715.00 \\
5\end{array}$ & .210 & 187.619 & 1 & 1.132 \\
\hline 11 & e & 0 & $\begin{array}{r}6507.70 \\
5\end{array}$ & .138 & 187.549 & 1 & 1.072 \\
\hline 12 & $\mathrm{e}$ & 0 & $\begin{array}{r}7111.82 \\
2\end{array}$ & .020 & 187.547 & 1 & 1.019 \\
\hline 13 & $\mathrm{e}$ & 0 & $\begin{array}{r}6908.36 \\
9\end{array}$ & .001 & 187.547 & 1 & 1.001 \\
\hline 14 & $\mathrm{e}$ & 0 & $\begin{array}{r}6911.45 \\
9\end{array}$ & .000 & 187.547 & 1 & 1.000 \\
\hline
\end{tabular}

Model Fit Summary

CMIN

\begin{tabular}{|l|rrrrr|}
\hline Model & NPA & CMIN & DF & P & CMIN/DF \\
& $\mathrm{R}$ & & & & \\
\hline Default model & 41 & 187.547 & 37 & .000 & 5.069 \\
Saturated model & 78 & .000 & 0 & & \\
Independence model & 12 & 2157.802 & 66 & .000 & 32.694 \\
\hline
\end{tabular}

RMR, GFI

\begin{tabular}{|l|rrrr|}
\hline Model & RMR & GFI & $\begin{array}{r}\text { AGF } \\
\text { I }\end{array}$ & PGFI \\
\hline Default model & .102 & .918 & .828 & .436 \\
Saturated model & .000 & 1.000 & & \\
& & & & \\
Independence model & .522 & .375 & .261 & .317 \\
\hline
\end{tabular}

Baseline Comparisons

\begin{tabular}{|l|rrrrr|}
\hline Model & $\begin{array}{r}\text { NFI } \\
\text { Delta1 }\end{array}$ & $\begin{array}{r}\text { RFI } \\
\text { rho1 }\end{array}$ & $\begin{array}{r}\text { IFI } \\
\text { Delta2 }\end{array}$ & $\begin{array}{r}\text { TLI } \\
\text { rho2 }\end{array}$ & CFI \\
\hline Default model & .913 & .845 & .929 & .872 & .928 \\
Saturated model & 1.000 & & 1.000 & & 1.000 \\
& & & & & \\
Independence model & .000 & .000 & .000 & .000 & .000 \\
\hline
\end{tabular}

Parsimony-Adjusted Measures 


\begin{tabular}{|l|rrr|}
\hline Model & PRATI & PNFI & PCFI \\
& $\mathrm{O}$ & & \\
\hline Default model & .561 & .512 & .520 \\
Saturated model & .000 & .000 & .000 \\
Independence model & 1.000 & .000 & .000 \\
\hline
\end{tabular}

\begin{tabular}{|l|rrr|}
\hline Model & NCP & LO 90 & HI 90 \\
\hline Default model & 150.547 & 111.479 & 197.144 \\
Saturated model & .000 & .000 & .000 \\
Independence model & 2091.802 & 1943.787 & 2247.170 \\
\hline
\end{tabular}

\section{FMIN}

\begin{tabular}{|l|rrrr|}
\hline Model & FMIN & F0 & LO 90 & HI 90 \\
\hline Default model & .539 & .433 & .320 & .567 \\
Saturated model & .000 & .000 & .000 & .000 \\
Independence model & 6.201 & 6.011 & 5.586 & 6.457 \\
\hline
\end{tabular}

RMSEA

\begin{tabular}{|l|rrrr|}
\hline Model & RMSEA & LO 90 & HI 90 & PCLOSE \\
\hline Default model & .108 & .093 & .124 & .000 \\
Independence model & .302 & .291 & .313 & .000 \\
\hline
\end{tabular}

\begin{tabular}{|l|rrrr|}
\hline Model & AIC & BCC & BIC & CAIC \\
\hline Default model & 269.547 & 272.729 & 427.605 & 468.605 \\
Saturated model & 156.000 & 162.054 & 456.696 & 534.696 \\
Independence model & 2181.802 & 2182.734 & 2228.063 & 2240.063 \\
\hline
\end{tabular}

\section{ECVI}

\begin{tabular}{|l|rrrr|}
\hline Model & ECVI & LO 90 & HI 90 & MECVI \\
\hline Default model & .775 & .662 & .908 & .784 \\
Saturated model & .448 & .448 & .448 & .466 \\
Independence model & 6.270 & 5.844 & 6.716 & 6.272 \\
\hline
\end{tabular}

HOELTER 


\begin{tabular}{|l|rr|}
\hline Model & HOELTER & HOELTE \\
& .05 & $\mathrm{R}$ \\
& & .01 \\
\hline Default model & 97 & 112 \\
Independence model & 14 & 16 \\
\hline
\end{tabular}

Execution time summary

Minimization: $\quad .003$

Miscellaneous: $\quad .360$

Bootstrap: $\quad .000$

Total: $\quad .363$ 


\section{References}

Adams, J. S. (1965). Inequity in social exchange. In Advances in experimental social psychology, Academic Press, 2, 267-299.

Akyol, B. (2016). Teacher self-efficacy perceptions, learning oriented motivation, lifelong learning tendencies of candidate teachers: A modeling study. Eurasian Journal of Educational Research, 65, 19-34. https://doi:10.14689/ejer.2016.65.02

Alafgani, M., \& Purwandari, E. (2019). Self-efficacy, academic motivation, self-regulated learning and academic achievement. Jurnal Psikologi Pendidikan Dan Konseling [Journal of Education and Counseling Psycology], 5(2), 104-111. https://doi.org/10.26858/jppk.v5i2.10930

AL-Baddareen, G., Ghaith, S., \& Akour, M. (2014). Self-efficacy, achievement goals, and metacognition as predictors of academic motivation, Procedia-Social and Behavioral Sciences, 191, 2068-2073.

Alderfer, C. (1972). Existence, relatedness and growth: Human needs in organizational settings. New York: Free Press.

Allport, G. W. (1961). Pattern and growth in personality. Holt, Reinhart \& Winston.

Ames, C., \& Archer, J. (1988). Achievement goals in the classroom: Students' learning strategies and motivation processes. Journal of Educational Psychology, 80(3), 260267. https://doi.org/10.1037/0022-0663.80.3.260

Ariani, D. W. (2016). Why Do I Study? The mediating effect of motivation and self-regulation on student performance. Business, Management and Education, 14(2), 153-178. https://doi.org/10.3846/bme.2016.329 
Arik, S. (2019). The relations among university students' academic self-efficacy, academic motivation, and self-control and self-management levels. International Journal of Education and Literacy Studies, 7(4), 23-34. https://doi.org/10.7575/aiac.ijels.v.7n.4p.23

Arkavazi, S., \& Nosratinia, M. (2018). Self-regulation and locus of control predicting EFL learners' willingness to communicate. Theory and Practice in Language Studies, 8(8), $1094-1103$.

Aquinas, T. (1975). Summa contra gentiles (A. C. Pegis, Trans.). University of Notre Dame Press. (Original works published 1259-1265)

Ball, S., \& Edelman, C. (2018). Self-efficacy, motivation, and perceived importance of English as an L2 among Japanese university students. The Language Teacher, 42(4), 13-18. http://jalt- publications.org/tlt

Bandura, A. (1986). Social foundations of thought and action: A social cognitive theory. Prentice Hall.

Bandura, A. (1989). Social cognitive theory. In R. Vasta (Ed.), Annals of child development. Vol .6. Six theories of child development (pp. 1-60). JAI Press.

Bandura, A. (1991). Social Cognitive theory of self-regulation. Organizational Behavior and Human Decision Processes, 50(2), 248-287.

Bandura, A. (1994). Self-efficacy. In V. S. Ramachaudran (Ed.), Encyclopedia of human behavior (Vol. 4, p. 71-81). Academic Press. (Reprinted in H. Friedman [Ed.], Encyclopedia of mental health. Academic Press, 1998).

Bandura, A. (1997). Self-efficacy: The exercise of control. Freeman. 
Bandura, A., \& Cervone, D. (1986). Differential engagement of self-reactive influences in cognitive motivation. Organizational Behavior and Human Decision Processes, 38(1), $92-113$.

Baron, S. W. (2003). Self-control, social consequences, and criminal behavior: street youth and the general theory of crime. Journal of Research in Crime and Delinquency, 40(4), 403425.

Ben-Eliyahu, A. (2011). The regulatory capacities of motivational constructs: An examination of academic motivation and self-regulation toward academic success in favorite and least favorite classes (Doctoral dissertation, Duke University).

Busse, V., \& Walter, C. (2017). A longitudinal study of motivational foreign language learning motivation in higher education: Changes and their causes. Wiley on Behalf of the National Federation of Modern Language Teachers Associations, 97(2), 435-456. https://doi.org/10.1111/j.1540-4781.2013.12004.x

Cerino, E. S. (2014). Relationships between academic motivation, self-efficacy, and academic procrastination. Psi Chi Journal of Psychological Research, 19(4), 156-163. https://doi.org/10.24839/2164-8204.jn19.4.156

Cetin, B. (2015). Academic Motivation and Self-Regulated Learning in Predicting Academic Achievement in College. Journal of International Education Research, 11(2), 95-106. https://doi.org/10.19030/jier.v11i2.9190

Cooley, C. H. (1902). Human nature and the social order. New York: Scribner.

Deci, E. L., \& Ryan, R. M. (1985). Intrinsic motivation and self-determination in human behavior. Plenum. 
Deci, E. L., \& Ryan, R. M. (2000). The "what" and "why” of goal pursuits: Human needs and the self-determination of behavior. Psychological Inquiry, 11, 227-268.

Deci, E. L., \& Ryan, R. M. (2008). Self-determination theory: A macrotheory of human motivation, development, and health. Canadian Psychology/Psychologie Canadienne, 49(3), 186-193.

Deci, E. L., Vallerand, R. J., Pelletier, L. G., \& Ryan, R. M. (1991). Motivation and education: The self-determination perspective. Educational Psychologist, 26(3-4), 325-346.

Descartes, R. (2008). Meditations on first philosophy (M. Moriarty, Trans.). Oxford University Press.

Dresel, M., \& Grassinger, R. (2013). Changes in achievement motivation among university freshmen. Journal of Education and Training Studies, 1(2), 159-173. https://doi.org/10.11114/jets.v1i2.147

Duchatelet, D., \& Donche, V. (2019). Fostering self-efficacy and self-regulation in higher education: A matter of autonomy support or academic motivation? Higher Education Research \& Development, 38(4), 733-747. http://dx.doi.org.ezproxy.andrews.edu/10.1080/07294360.2019.1581143

Eccles, J. S. (2005). Subjective task value and the Eccles et al. model of achievement-related choices. In A. J. Elliot \& C. S. Dweck (Eds.), Handbook of competence and motivation, (pp. 105-121). Guilford Publications.

Eisenberg, D., Gollust, S. E., Golberstein, E., \& Hefner, J. L. (2007). Prevalence and correlates of depression, anxiety, and suicidality among university students. American Journal of Orthopsychiatry, 77(4), 534-542. 
Faye, C., \& Sharpe, D. (2008). Academic motivation in university: The role of basic psychological needs and identity formation. Canadian Journal of Behavioural Science/Revue canadienne des sciences du comportement, 40(4), 189.

Freud, S. (1961). The ego and the id. In J. Strachey (Ed. and Trans.), The Standard Edition of the Complete Psychological Works of Sigmund Freud (Vol. 19, pp. 3-66, 1923-1925). Hogarth Press. (Original work published 1923.)

Freud, S., \& Jones, E. (Ed.). (1922). International psychoanalytical library: Vol. 4. Beyond the pleasure principle. (C. J. M. Hubback, Trans.). The International Psycho-Analytical Press. https://doi.org/10.1037/11189-000

García, T., \& McKeachie, W. (2005). The making of the Motivated Strategies for Learning Questionnaire. Educational Psychologist, 40(2), 117-128.

Ghonsooly, B., \& Ghanizadeh, A. (2011). Self-efficacy and self-regulation and their relationship: A study of Iranian EFL teachers. The Language Learning Journal, 41 (1), 68-84. https://www.tandfonline.com/doi/abs/10.1080/09571736.2011.625096

Girelli, L., Alivernini, F., Lucidi, F., Cozzolino, M., Savarese, G., Sibilio, M., \& Salvatore, S. (2018, November). Autonomy supportive contexts, autonomous motivation, and selfefficacy predict academic adjustment of first-year university students. In Frontiers in Education (Vol. 3, p. 95). Frontiers.

Gollwitzer, P. M., \& Oettingen, G. (2001). Motivation: History of the concept. In N. J. Smelser \& P. B. Baltes (Eds.). International Encyclopedia of the Social \& Behavioral Sciences (pp. 10109-10112). Pergamon. https://doi.org/10.1016/b0-08-043076-7/00134-0

Hair, J. F., Black, W. C., Babin, B. J., \& Anderson, R. E. (2010). Multivariate data analysis (7th ed.). Pearson. 
Hassankhani, H., Aghdam, A. M., Rahmani, A., \& Mohammadpoorfard, Z. (2015). The relationship between learning motivation and self-efficacy among nursing students. Research and Development in Medical Education, 4(1), 97-101.

Heckhausen, J., \& Heckhausen, H. (Eds.). (2008). Motivation and action (2nd ed.). Cambridge University Press. https://doi.org/10.1017/CBO9780511499821

Heider, F. (1958). The psychology of interpersonal relations. John Wiley \& Sons Inc. https://doi.org/10.1037/10628-000

Herzberg, F. (1959). The motivation to work. Wiley.

Hussar, B., Zhang, J., Hein, S., Wang, K., Roberts, A., Cui, J., Smith, M., Bullock Mann, F., Barmer, A., \& Dilig, R. (2020). The Condition of Education 2020 (NCES 2020-144). U.S. Department of Education. Washington, DC: National Center for Education Statistics. https://nces.ed.gov/pubsearch/pubsinfo.asp?pubid=2020144.

James, W. (1890). The consciousness of self. In The Principles of psychology (Vol. 1, p. 291401). Harvard University Press.

Jeno, L. M., \& Diseth, Å. (2014) A self-determination theory perspective on autonomy support, autonomous self-regulation, and perceived school performance. Reflecting Education, $9(1), 1-20$.

Keith, Timothy Z. (2019). Multiple regression and beyond. Routledge.

Klapp, A. (2016). The importance of self-regulation and negative emotions for predicting educational outcomes-Evidence from 13-year-olds in Swedish compulsory and upper secondary school. Learning and Individual Differences, 52, 29-38. 
Koludrović, M., \& Ercegovac, I. R. (2015). Academic motivation in the context of selfdetermination theory in initial teacher education. Croatian Journal of Education, 17(1), 25-36.

Komarraju, M., \& Nadler, D. (2013). Self-efficacy and academic achievement: why do implicit beliefs, goals, and effort regulation matter? Learning and Individual Differences, 25, 6772.

Kormos, J., \& Csizer, K. (2014). The interaction of motivation, self-regulatory strategies, and autonomous learning behavior in different learner groups. TESOL Quarterly, 48(2), 275299.

Kruglanski, A. W., \& Higgins, E. T. (2007). Social psychology: Handbook of basic principles. Guilford Press.

Lavasani, M. G., Mirhosseini, F. S., Hejazi, E., \& Davoodi, M. (2011). The effect of selfregulation learning strategies training on academic motivation and self-efficacy. Procedia-Social and Behavioral Sciences, 29, 627-632. https://doi.org/10.1016/j.sbspro.2011.11.285

Lawler, E. E., and Porter, L. W. Antecedent attitudes of effective managerial performance. Organizational Behavior and Human Performance, 2(2), 122-142.

Lewin, K. (1936). A dynamic theory of personality: Selected papers. The Journal of Nervous and Mental Disease, 84(5), 612-613.

Malkoç, A., \& Mutlu, A. K. (2018). Academic self-efficacy and academic procrastination: Exploring the mediating role of academic motivation in Turkish University Students, Universal Journal of Educational Research, 6(10), 2087-2093. https://doi:10.13189/ujer.2018.061005 
Mantasiah, R., \& Yusri, Y. (2018). Pay It Forward Model in foreign language learning to increase student's self-efficacy and academic motivation. 2nd International Conference on Statistics, Mathematics, Teaching, and Research. https://doi:10.1088/17426596/1028/1/012178

Maslow, A. H. (1943). A theory of human motivation. Psychological Review, 50(4), 370-96.

McClelland, D. (1987). Human motivation. Cambridge University Press.

Meyers, L. W., Gamst, G., \& Guarino, A. J. (2016). Applied multivariate research: Design and interpretation ( $3^{\text {rd }}$ ed.). Sage Publications.

Miller J., \& Dollard N. (1941). Social learning and imitation. Yale University Press.

Miller, J. W. (2010). Academic motivation to self-regulatory associations: Controlling the effect of test anxiety. College Student Journal, 44(2), 433-436.

Mirhosseini, F. S., Lavasani, M. G., \& Hejazi, E. (2018). The effectiveness of self-regulation learning skills on motivational and academic variables among students. World Family Medicine Journal/Middle East Journal of Family Medicine, 16(5), 68-75. https://doi.org/10.5742/mewfm.2018.93385

$\mathrm{Ng}, \mathrm{C}$. (2012). The role of self-efficacy, control beliefs and achievement goals on learning among distance learners. International Perspectives of Distance Learning in Higher Education, 233-252.

Niemiec, C. P., \& Ryan, R. M. (2009). Autonomy, competence, and relatedness in the classroom: Applying self-determination theory to educational practice. Theory and Research in Education, 7(2), 133-144. 
Ning, H. K., \& Downing, K. (2010). The reciprocal relationship between motivation and selfregulation: A longitudinal study on academic performance. Learning and Individual Differences, 20(6), 682-686. https://doi.org/10.1016/j.lindif.2010.09.010

Nuttin, J. R. (1964). The future time perspective in human motivation and learning. Acta Psychologica, 23, 60-82. https://doi.org/10.1016/0001-6918(64)90075-7

Panadero, E. (2017). A review of self-regulated learning: Six models and four directions for research. Frontiers in Psychology, 8(422) 1-28.

Pavlov, I. P. (1927). Conditioned Reflexes: An Investigation of the Physiological Activity of the Cerebral Cortex (G. V. Anrep, Ed., Trans.). Oxford University Press.

Piaget J. (1952). The origins of intelligence in children. New York International University Press.

Pintrich, P. R. (2000). The role of goal orientation in self-regulated learning. In Handbook of self-regulation, p. 451-502. Academic Press.

Pintrich, P. R., \& Schunk, D. H. (1996). Motivation in education: Theory, research, and applications. Prentice Hall.

Pintrich, P. R., Smith, D. A. F., Garcia, T., \& McKeachie, W. J. (1993). Reliability and predictive validity of the Motivated Strategies for Learning Questionnaire (MSLQ). Educational and Psychological Measurement, 53(3), 801-813. https://doi.org/10.1177/0013164493053003024

Post, Y., Boyer, W., \& Brett, L. A. (2006). Historical examination of self-regulation: Helping children now and in the future. Early Childhood Education Journal, 34, 5-14. https://doi.org/10.1007/s10643-006-0107-x 
Prat-Sala, M., \& Redford, P. (2010), The interplay between motivation, self-efficacy, and approaches to studying. British Journal of Educational Psychology, 80, 283-305. https://doi:10.1348/000709909X480563

Remes, P., \& Sihvola, J. (Eds.). (2008). Ancient philosophy of the self. Springer.

Rensh, M. A., Leontev, M. G., Chernyshev, V. P., Mezentseva, L. V., \& Kovalevskaia, N. V. (2020). Motivation and self-regulation research: historical background, methodological considerations, and future prospects. Psychology and Education, 57(1), 70-74.

Rizkallah, E. G., \& Seitz, V. (2017). Understanding student motivation: A key to retention in higher education. Scientific Annals of Economics and Business, 64(1), 45-57. https://doi.org/10.1515/saeb-2017-0004

Rogers, C. R. (1951). Client-centered therapy: Its current practice, implications, and theory. Houghton Mifflin.

Rotter, J. B. (1966). Generalized expectancies for internal versus external control of reinforcement. Psychological Monographs: General and Applied, 80(1), 1-28. https://doi.org/10.1037/h0092976

Rowell, L., \& Hong, E. (2013). Academic motivation: Concepts, strategies, and counseling approaches. Professional School Counseling, 16(3), 158-171. https://doi.org/10.5330/psc.n.2013-16.158

Ryan, R. M., \& Deci, E. L. (2000). Intrinsic and extrinsic motivations: Classic definitions and new directions. Contemporary Educational Psychology, 25(1), 54-67. https://doi.org/10.1006/ceps.1999.1020 
Ryan, R. M., \& Deci, E. L. (2002). Overview of self-determination theory: An organismic dialectical perspective. In E. L. Deci \& R. M. Ryan (Eds.). Handbook of selfdetermination research (pp. 3-33). University of Rochester Press.

Ryan, R. M., \& Deci, E. L. (2006). Self-regulation and the problem of human autonomy: Does psychology need choice, self-determination, and will? Journal of Personality, 74(6), 1557-1586.

Ryan, R. M., \& Deci, E. L. (2020). Intrinsic and extrinsic motivation from a self-determination theory perspective: Definitions, theory, practices, and future directions. Contemporary Educational Psychology, 61, 101860. https://doi.org/10.1016/j.cedpsych.2020.101860

Saeid, N., \& Eslaminejad, T. (2017). Relationship between student's self-directed-learning readiness and academic self-efficacy and achievement motivation in students. International Education Studies, 10(1), 225-231.

Saki, K., \& Nadari, M. (2018). The relationship between self-regulated learning, academic selfconcept and the academic achievement motivation of students in the second grade of high school. World Family Medicine, 16(2), 325-335. doi: 10.5742/MEWFM.2018.93277

Schermelleh-Engel, K., Moosbrugger, H., \& Müller, H. (2003), Evaluating the fit of structural equation models: Tests of significance and descriptive goodness-of-fit measures, Methods of Psychological Research Online, 8(2), 23-74.

Schunk, D. H., \& DiBenedetto, M. K. (2020). Motivation and social cognitive theory. Contemporary Educational Psychology, 60, 101832. https://doi.org/10.1016/j.cedpsych.2019.101832

Schunk, D. H., \& Pajares, F. (2002). The development of academic self-efficacy. In A. Wigfield \& J. S. Eccles (Eds.), In The educational psychology series. Development of achievement 
motivation (pp. 15-31). Academic Press. https://doi.org/10.1016/B978-0127500539/50003-6

Schunk, D. H., \& Usher, E. L. (2019). Social cognitive theory and motivation. The Oxford handbook of human motivation, $\left(2^{\text {nd }}\right), 11-26$.

Sidola, S., Saini, S., \& Kang, T. K. (2020). Locus of control as correlate of self-regulation among college students. The Pharma Innovation Journal, 9(1), 116-122.

Skinner, B. F. (1935) Two types of conditioned reflex and a pseudo type. Journal of General Psychology, 12, 66-77. https://doi.org/10.1080/00221309.1935.9920088

Tabernero C., \& Hernández, B. (2011). Self-efficacy and intrinsic motivation guiding environmental behavior. Environment and Behavior, 43(5), 658-675.

Tahmassian, K., \& Moghadam, N. J. (2011). Relationship between self-efficacy and symptoms of anxiety, depression, worry and social avoidance in a normal sample of students. Iranian Journal of Psychiatry and Behavioral Sciences, 5(2), 91-98.

Thorndike, E. L. (1898). Animal intelligence: An experimental study of the associative processes in animals. The Psychological Review: Series of Monograph Supplements, 2(4), 1-109. https://doi.org/10.1037/h0092987

Thorne, F. C. (1946). Directive psychotherapy: IX. Personality integration and self-regulation. Journal of Clinical Psychology, 2(4), 371-383.

Usher, E. L., \& Schunk, D. H. (2018). Social cognitive theoretical perspective of self-regulation. In D. H. Schunk, \& J. A. Greene (Eds.), Educational psychology handbook series. Handbook of self-regulation of learning and performance (pp. 19-35). Routledge/Taylor \& Francis. 
Uzuntiryaki-Kondakci E. \& Capa-Aydin Y. (2013). Predicting critical thinking skills of university students through metacognitive self-regulation skills and chemistry selfefficacy, Kuram Uygulama. Egi., 13(1), 666-670.

Valinasab, S., \& Zeinali, A. (2018). The mediational pathway among academic emotions, selfregulated learning, and academic motivation with academic achievement of high school students. International Journal of Educational and Psychological Research, 3(4), 255261.

Vallerand, R. J., Pelletier, L. G., Blais, M. R., Brière, N. M., Senecal, C., \& Vallieres, E. F. (1992). The Academic Motivation Scale: A measure of intrinsic, extrinsic, and amotivation in education. Educational and Psychological Measurement, 52(4), 10031017. https://doi.org/10.1177/0013164492052004025.

Vandenberg, R. J. (2006), Statistical and methodological myths and urban legends, Organizational Research Methods, 9(2), 194-201.

Vroom, V. H. (1964). Work and motivation. Jossey-Bass.

Vygotsky, L. (1962). Studies in communication, thought and language (E. Hanfmann \& G. Vakar, Eds.). MIT Press. https://doi.org/10.1037/11193-000

Wang, H. H., Chen, H. T., Lin, H. S., \& Hong, Z. R. (2017). The effects of college students' positive thinking, learning motivation and self-regulation through a self-reflection intervention in Taiwan. Higher Education Research and Development, 36(1), 201-216. https://doi.org/10.1080/07294360.2016.1176999

Wang, Q., \& Pomerantz, E. M. (2009). The motivational landscape of early adolescence in the US and China: A longitudinal study. Child Development, 80, 1272-1287. https://doi.org/10.1111/j.1467-8624.2009.01331.x 
Watson, J. B. (1913). Psychology as the behaviorist views it. Psychological Review, 20(2), 158177.

Weinstein, C. E., Palmer, D., \& Schulte, A. C. (1987). Learning and study strategies inventory (LASSI). H \& H Publishing.

Winne, P. H. (1995). Inherent details in self-regulated learning. Educational Psychologist, 30(4), 173-187. https://doi.org/10.1207/s15326985ep3004_2

Yuka, M. (2017). Relationship between goal setting, intrinsic motivation, and self-efficacy in extensive reading, JACET Journal, 61, 41-56.

Yusuf, M. (2011). The impact of self-efficacy, achievement motivation, and self-regulated learning strategies on students' academic achievement. Procedia-Social and Behavioral Sciences. 15, 2623-2626. https://doi.org/10.1016/j.sbspro.2011.04.158

Zimmerman, B. J. (1989). A social cognitive view of self-regulated academic learning. Journal of Educational Psychology, 81(3), 329-339.

Zimmerman, B. J. (1998). Academic studying and the development of personal skill: A selfregulatory perspective. Educational Psychologist. 33(2-3), 73-86. https://doi.org/10.1207/s15326985ep3302\&3_3

Zimmerman, B. J. (2000a). Attaining self-regulation: A social cognitive perspective. In M. Boekaerts, P. R. Pintrich, \& M. Zeidner (Eds.), Handbook of self-regulation, p. 13-40. Academic Press.

Zimmerman, B. J. (2000b). Self-Efficacy: An Essential Motive to Learn. Contemporary Educational Psychology, 25(1), 82-91. https://doi.org/10.1006/ceps.1999.1016 
Zimmerman, B. J. (2008). Investigating self-regulation and motivation: Historical background, methodological developments, and future prospects. American Educational Research Journal, 45(1), 166-183. https://doi.org/10.3102/0002831207312909

Zimmerman, B. J. (2013). From cognitive modeling to self-regulation: A social cognitive career path. Educational Psychologist, 48(3), 135-147.

Zimmerman, B. J., \& Martinez-Pons, M. (1986). Development of a structured interview for assessing students' use of self-regulated learning strategies. American Educational Research Journal, 23, 614-628.

Zimmerman, B. J., Martinez Pons, M. (1988). Construct validation of a strategy model of student self-regulated learning. Journal of Educational Psychology, 80, 284-290.

Zimmerman, B. J., \& Moylan, A. R (2009). Self-regulation. Handbook of metacognition in education. Routledge. https://www.routledgehandbooks.com/ doi/10.4324/9780203876428.ch16

Zimmerman, B. J., Schunk, D. H., \& DiBenedetto, M. K. (2017). The role of self-efficacy and related beliefs in self-regulation of learning and performance. In A. J. Elliot, C. S. Dweck, \& D. S. Yeager (Eds.), Handbook of competence and motivation: Theory and application (pp. 313-333). The Guilford Press. 


\section{CURRICULUM VITA}

Name: $\quad$ Fatimah Aljuaid

Education:

2020 Ph.D., Educational Psychology

Andrews University, Berrien Springs, Michigan

2012 M.A., Educational Psychology

University of Taif, Taif, Saudi Arabia

2007 B.A., "Shari'a", Islamic Law and Islamic Studies

University of Taif, Taif, Saudi Arabia

\section{Professional Development}

2019 An elected member of Phi Kappa Phi honor society in the U.S.

Andrews University, Berrien Springs, Michigan

2018 An elected presenter of Midwestern Psychological association conference, Chicago, Illinois

2016 Certified International Trainer, International Trainer academy, Riyadh, Saudi Arabia

2013 - 2014 Extensive English Course, ESL Services at UT University, Austin, Texas

2011 Certified Trainer of the Development of Thinking Skills

Preparation Course, Ibdaa' Al-Assel Center, Makkah, Saudi Arabia.

2007 Teacher (internship), The $24^{\text {th }}$ Girl's Middle School

Volunteer Experience University of Taif, Taif, Saudi Arabia

2015- Present Elementary Teacher and curriculum designer, Medina Masjid, Berrien Springs, Michigan

2007-2008 Older Adult Teacher, Shagsaan School, Taif, Saudi Arabia.

Awards

2012

Research

2018
The University of Taif's Nominated Candidate 2012

King Abdullah's Competition for Scientific Research, Saudi Arabia.

Aljuaid, F., (2018) Effectiveness of a CORT-based Training Program to Develop Reasoning Skills, University of Taif, Taif, Saudi Arabia. 